\title{
The Necessity of Geminin for Pluripotency and the Neural Lineage
}

\author{
Doctoral Thesis \\ In partial fulfillment of the requirements \\ for the degree 'Doctor of Philosophy (PhD)' \\ in the Molecular Medicine Study Program \\ at the Georg-August University, Göttingen
}

Submitted by

Golnaz Aghazadeh Tabrizi

Born in

Isfahan, Iran

Göttingen, October 2012 
Members of the Thesis Committee:

\section{Supervisor}

Prof. Dr. Michael Kessel

Max Planck Institute for Biophysical Chemistry

Developmental Biology Research Group

Second member of the thesis committee

Prof. Dr. Matthias Dobbelstein

Göttingen University Medical School

Dept. of Molecular Oncology

Third member of the thesis committee

Prof. Dr. Ahmed Mansouri

Max Planck Institute for Biophysical Chemistry

Molecular Cell Differentiation Research Group

Date of Disputation: 


\section{AFFIDAVIT}

Here I declare that my doctoral thesis entitled "The Necessity of Geminin for Pluripotency and the Neural Lineage" was written independently with no other sources and aids than quoted.

Golnaz Aghazadeh Tabrizi, Göttingen, October 2012 
If you eliminate the impossible, whatever remains, however improbable, must be the truth.

Sherlock Holmes 


\section{Table of Contents}

Table of Contents $\quad$ V

$\begin{array}{ll}\text { Abstract } & 1\end{array}$

$\begin{array}{ll}\text { Acknowledgements } & 2\end{array}$

List of Figures $\quad 3$

List of Tables $\quad 5$

List of Abbreviations $\quad 6$

$\begin{array}{ll}\text { 1. Introduction } & 7\end{array}$

1.1 Early mouse development 7

1.1.1 Transcriptional control of the early lineage determination 9

1.2 Embryonic Stem cells: Pluripotency in vitro 11

1.2.1 Transcriptional control of the ESCs 11

1.2.2 Cell cycle of the pluripotent cells 12

1.2.3 Epigenetic regulation of the pluripotent state 13

1.3 Reprogramming: "climbing the mount improbable" 14

1.4 Geminin $\quad 17$

1.4.1 Geminin and CDT1, inhibition of re-replication 17

1.4.2 Geminin in cancer 19

1.5 Geminin as a transcription modulator 20

1.5.1 Geminin in early development 20

1.5.2 Geminin and pluripotent cells 20

1.5.3 Geminin in neurogenesis 21

1.5.4 Geminin and hematopoietic system $\quad 21$

1.5.5 Geminin and interaction partners 22

1.6 Aim of the thesis $\quad 24$

$\begin{array}{ll}2 \text { Results } & 25\end{array}$

2.1 Geminin protein is expressed in embryonic stem cells and is down regulated during

differentiation $\quad 25$

2.2 Geminin protein is expressed in embryonic stem cells and the neuroectodermal progenitors 26

2.3 Geminin is degraded upon G1 entrance in the ESCs 28 
2.4 Conditional inactivation of Geminin locus 31

2.5 Establishment of iGmnn ESCs 33

2.6 Geminin is necessary for the self-renewal of the ESCs 36

2.7 ESCs lose pluripotency markers upon loss of Geminin 37

2.8 Geminin knockout cells exhibit a slightly lengthened G1 phase 41

2.9 Geminin is necessary for commitment to the neural lineage 42

2.10 Geminin regulates Sox 2 expression through chromatin remodeling complexes 45

2.11 Geminin is redundant in mouse embryonic fibroblasts 48

2.12 Geminin is up-regulated during the reprogramming of MEFs to induced pluripotent stem cells (iPSCs) 53

2.13 Geminin is indispensible for reprogramming 55

2.14 Geminin cannot substitute any reprogramming factor 58

3. Discussion $\quad 60$

3.1 Replication and cell cycle regulation by Geminin $\quad 60$

3.1.1 Geminin is degraded during the cell cycle of ESCs 60

3.1.2 Replication and cell cycle regulation in the absence of Geminin 61

3.2 Geminin is required for pluripotency 62

3.2.1 Geminin is down regulated during differentiation 62

3.2.2 Geminin expression is tightly bound to the pluripotent state 63

3.2.3 Geminin expression is necessary for neural lineage commitment 65

3.2.4 Geminin is necessary for the maintenance of reprogramming 66

3.3 Geminin regulates the Sox 2 expression through modulating its epigenetic signature 67

3.4 Geminin is indispensable to toti-pluri-neural lineages 69

$\begin{array}{ll}\text { 4. Materials and Methods } & \mathbf{7 2}\end{array}$

$\begin{array}{ll}4.1 \text { Cell Biology } & 72\end{array}$

4.1.1 Cell lines

$\begin{array}{ll}\text { 4.1.2 Mouse lines } & 72\end{array}$

4.1.3 Isolation of mouse embryonic fibroblasts $\quad 72$

4.1.4 Cell passage and freeze $\quad 73$

4.1.5 Cell revival $\quad 74$

4.1.6 Gelatin coating of culture plates $\quad 74$

$\begin{array}{ll}\text { 4.1.7 Preparation of mitotically inactivated feeder cells } & 74\end{array}$

$\begin{array}{ll}\text { 4.1.8 Embryonic stem cell derivation } & 75\end{array}$ 
4.1.9 ES cells maintenance and passage $\quad 76$

4.1.10 Tamoxifen (4-hydroxyl tamoxifen) treatment of the cells 76

4.1.11 Feeder layer free culture of ESCs 76

4.1.12 Sub-cloning of the ES Cells 76

$\begin{array}{ll}\text { 4.1.13 ES differentiation } & 77\end{array}$

4.1.14 Transfection of plasmid DNA 78

4.1.15 Transfection of siRNA $\quad 79$

$\begin{array}{ll}\text { 4.1.16 Reprogramming } & 79\end{array}$

4.1.17 Visualization of alkaline phosphatase activity 80

4.1.18 Immunofluorescence analysis of cultured cells 80

4.1.19 Synchronization of ESCs 82

4.1.20 Flow cytometric analysis of the cell cycle 82

4.1.21 Terminal deoxynucleotidyl transferase dUTP nick labeling (TUNEL) assay 83

4.1.22 Annexin V staining 83

4.1.23 BrdU staining 84

4.1.24 Quantification and statistical analysis of immunofluorescence staining $\quad 84$

4.2 Protein Biochemistry 85

4.2.1 Protein Extraction $\quad 85$

4.2.2 Western blot analysis $\quad 85$

4.3 Molecular Biology 88

4.3.1 DNA isolation from mouse 88

4.3.2 DNA isolation from cell culture 88

4.3.3 Genotyping PCR 88

4.3.4 DNA electrophoresis 89

4.3.5 RNA extraction $\quad 89$

4.3.6 Reverse transcription of mRNA 89

4.3.7 Semi-quantitative analysis of gene expression 90

4.3.8 Quantitative analysis of gene expression (qPCR) 91

4.3.9 Chromatin immuno-precipitation (ChIP) 92

4.3.10 Quantitative analysis of ChIP 93

$\begin{array}{lr}\text { 5. Bibliography } & 94\end{array}$

$\begin{array}{ll}\text { Curriculum Vitae } & 103\end{array}$ 


\section{Abstract}

Pluripotent mouse embryonic stem cells (ESCs) are in vitro derivatives of the early mouse embryo. They can self-renew infinitely, and have the ability to differentiate into embryonic lineages including the germ line. ESCs have the ability to give rise to all tissues of a mouse if added early in embryogenesis. They possess a specific transcriptional network, an "open" chromatin state and a rapid cell cycle. Our research group is interested to study the link between cell fate determination and cell cycle regulation, using the Geminin protein as an anchor. Geminin plays a central role in controlling the fidelity of DNA replication, and more recently additional functions in the regulation of proteins involved in patterning and differentiation were recognized. It is highly expressed in the early embryo and in pluripotent cells, and its genetic inactivation is lethal after the first few cell divisions.

We have generated ESCs, in which the Geminin gene can be inactivated by the addition of the small molecule tamoxifen. We found that Geminin is essential for self-renewal of pluripotent cells, and that the absence of Geminin causes reduction of pluripotency markers. The loss of Geminin altered the differentiation capacity of the ESCs; they could not give rise to the neural lineage anymore, but instead differentiated into the alternative mesendodermal lineage. Geminin turned out to be redundant in differentiated, somatic cells, but was necessary for their reprogramming to pluripotent cells. We could show that its function is targeted on the Sox2 gene, a key transcription factor of the pluripotency circuit, essential for the maintenance of pluripotency. The Sox2 enhancer requires Geminin for activity, and becomes epigenetically repressed in its absence. In conclusion, we introduce Geminin as a required factor for totipotency, pluripotency and the early neural lineage. 


\section{Acknowledgements}

$\mathcal{I}$ would like to express my most sincere gratitudes to my supervisor Prof. $\mathcal{D} r$. Michael Kessel, first of all for giving me the chance to lead my project in his laboratory, and second for all the time that was spent on teaching me. 1 am grateful for every step that 1 made under his supervision.

1 am grateful to Prof. Dr. Matthias Dobbelstein and Prof. Dr. Afmed Mansouri for accepting to be members of my $\mathcal{P} h \mathcal{D}$ committee, for great help and instructive comments during progress meetings. $\mathcal{I}$ would like to thank to $\mathcal{D}$ r. Eric Meskauskas and $\mathcal{D} r$. Werner $\mathcal{A}$ lbig for providing me the opportunity to study in the "PhD program of molecular medicine" and for their help during my studies.

$\mathcal{I}$ would like to specially thank Petra $\mathcal{R}$ us who provided most friendly environment. My research project would not have proceeded without her 24/7 technical help! I have an "amighan sepasgozaram" to Sharif Mahsur for his technical help in the tissue culture lab and the happy farsi-speaking atmosphere he created. $\mathcal{I}$ would like to express my gratitudes toward $\mathcal{D}$ r. Yvonne Reimann (Uerlings) whose work provided the basic tool for my research. I would like to thank $\mathcal{D}$ r. Kerstin Boese for technical help and collaboration regarding the reprogramming experiments. Dr. Alexander Klimke provided me with the smart suggestions and technical help.

I am very thankful to other actual and former lab members, Mehdi Pirouz, Dr. Naisana Asli and Sabrina Zeddies. In additions $\mathcal{I}$ would like to express gratitude to all the members of the Gruss department for the friendly atmosphere and their help.

$\mathcal{I}$ would like to thank $\mathcal{B} \mathcal{T} \mathcal{L}$-team and especially Daniela Wollradt, Stefanie Thiel and $\mathcal{D} r$. Ulrike Teichmann for all the help they have provided. Blastocyst derivations, production of the chimeric mice and maintenance of the animal colonies were not possible without their service. In addition, 1 would like to thank Sabrina Becker, from the FACS facility of medical faculty, for all the technical help regarding flow cytometry experimients.

$\mathcal{I}$ would like to thank my parents Mitra and $\mathcal{A}$ li and my sister, Nazgol for all the love and support they have provided overseas. I would like to express my sincere gratitudes toward my best friend, Malihe, who helped with the proofreading of the thesis.

Last but not least, $\mathcal{I}$ would like to express my most sincere gratitude to my love and my husband, Abouzar for his help and love. 


\section{List of Figures}

Figure 1. Early embryonic development.

Figure 2. Transcriptional regulation of fate determination during the early mouse development.

Figure 3. Reprogramming of fibroblasts.

Figure 4. Geminin is down-regulated in mouse ESCs upon differentiation.

Figure 5. Geminin is down-regulated in the mesendoderm, but not in the neuroectoderm.

Figure 6. Down-regulation of mAG-hGem in G1 phase of the ESC cell cycle.

Figure 7. Endogenous Geminin is degraded upon G1 entrance in mESCs.

Figure 8. Targeting strategy to generate Geminin conditional knockout allele.

Figure 9. Genetic inactivation of Geminin leads to embryonic lethality.

Figure 10. iGmnn ESCs are pluripotent.

Figure 11. iGmnn ESCs lose Geminin upon tamoxifen treatment.

Figure 12. Geminin is essential for the self-renewal of ESCs.

Figure 13. Geminin is essential for the pluripotent state of ESCs.

Figure 14. Geminin deficient ESCs possess a lengthened cell cycle.

Figure 15. Geminin deficient ESCs give rise to less Sox2 positive neuroectoderm progenitors.

Figure 16. Geminin is necessary for the differentiation of ESCs to the neural lineage.

Figure 17. Chromatin immunoprecipitations on regulatory regions of Sox 2 and Oct4.

Figure 18. Inactivation of Geminin in mouse embryonic fibroblasts.

Figure 19. Loss of Geminin does not cause cell cycle abberations or apoptosis in MEFs. $\mathbf{5 1}$

Figure 20. Concurrent loss of Geminin and cyclin A can be compensated in MEFs.

Figure 21. Mouse embryonic fibroblasts can undergo reprogramming upon overexpression of Oct4, Sox2, Klf4 and C-Myc. 
Figure 22. Geminin is up-regulated in the pluripotent cells.

Figure 23. Geminin is necessary for the reprogramming.

Figure 24. Geminin is necessary for the maintenance of reprogramming.

Figure 25. Geminin deficient cells fail to maintain their proliferation.

Figure 26. Geminin cannot substitude any reprogramming factor.

Figure 27. Geminin regulates Sox2 through regulation of the epigenetic signature of SRR2.

69

Figure 28. Geminin safeguards the toti-pluri-neural fate determination in the embryonic development. 


\section{List of Tables}

Table 1. Cell lines used in this study

Table 2. Mouse lines used in this study

Table 3. Antibodies used for immunofluorescence analysis

Table 4. Buffers and solutions used in western blotting analysis $\quad 86$

$\begin{array}{ll}\text { Table 5. Antibodies used in western blotting analysis } & \mathbf{8 7}\end{array}$

$\begin{array}{lr}\text { Table 6. Genotyping primers } & 89\end{array}$

$\begin{array}{ll}\text { Table 7. RT-PCR primers } & 90\end{array}$

$\begin{array}{ll}\text { Table 8. qPCR primers } & 91\end{array}$

Table 9. Antibodies used in chromatin immuno-precipitations $\quad 92$

Table 10. Primers for the detection of Sox 2 and Oct 4 genomic regions used in ChIP analysis 


\section{List of Abbreviations}

APS Ammonium persulphate

bp Base pairs

BrdU 5-bromo-2'-deoxyuridine

BSA Bovine serum albumin

cDNA Complementary DNA

ChIP Chromatin immunoprecipitation

CMV Cytomegalovirus

Cre Cre recombinase

DAPI 4,6-diamidino-2-phenylindol

DMEM Dulbecco's modified Eagle's

medium

DMSO Dimethylsulfoxide

DNA Deoxyribonucleic acid

dpc Days post coitum

EB Embryoid body

EDTA ethylenediaminetetraacetic acid

EPI Epiblast

ESCs embryonic stem cells FACS Fluorescence-activated cell

sorting

FBS Inactivated fetal calf serum

HRP Horseradish peroxidase

ICM Inner cell mass

IMEM Isocov's modified Eagle's

medium

$\mathrm{Kb} \quad$ Kilo base pairs

LIF Leukemia inhibitory factor

IoxP DNA recognition site for Cre

mAG monomeric Azumi Green

ME Mesendoderm
MEF Mouse embryonic fibroblasts

NE Neuroectoderm

o/n Overnight

PBS Phosphat buffered saline

PcG Polycomb group

PCR Polymerase chain reaction

PE Primitive endoderm

PFA Paraformaldehyd

PI Propidium iodide

RNA Ribonucleic acid

RNase Ribonuclease

Rpm Revolutions per minute

SDS Sodium dodecyl sulfate

siRNA Small interference RNA

TBE Tris-borate buffer

TEMED Tetramethylethylendiamin

TE Trophectoderm

U Units

V Volt

wt Wild type 


\section{Introduction}

\subsection{Early mouse development}

The totipotent zygote undergoes cleavage divisions without increasing the overall size. Next the 8-cell stage morula undergoes an increase in the intracellular adhesion known as compaction. At this stage the cells are polarized, and they are not totipotent anymore. After compaction the embryo undergoes two more rounds of division to form the 32-cell stage. During these divisions surface cells are polarized while apolar cells are inside the morula. These distinct populations of the cells have different developmental fates: cells on the outside of the embryo give rise to the Trophoectoderm (TE) lineage ${ }^{1}$, while inside cells contribute to the inner cell mass $(\mathrm{ICM})^{1,2}$. Starting from this stage, a fluid filled cavity known as the blastocoel begins to form. Within the formation of the blastocoel the mouse embryo is known as the blastocyst (Fig. 1).

ICM segregates into two distinct lineages, the primitive endoderm (PE), and the epiblast (EPI). These cells are morphologically distinct; they have a specific spatial orientation in the blastocyst and they express a distinct set of transcription factors $^{3-5}$. Epiblast gives rise to the primitive streak, and gastrulation takes place. During gastrulation, epiblast differentiates to form a multilayered structure consisting of endoderm, mesoderm, ectoderm. These germ layers contribute to the formation of the entire adult organism. ICM and epiblast cells are known as pluripotent cells, referring to their ability to differentiate into any cell type found in the adult organism. 


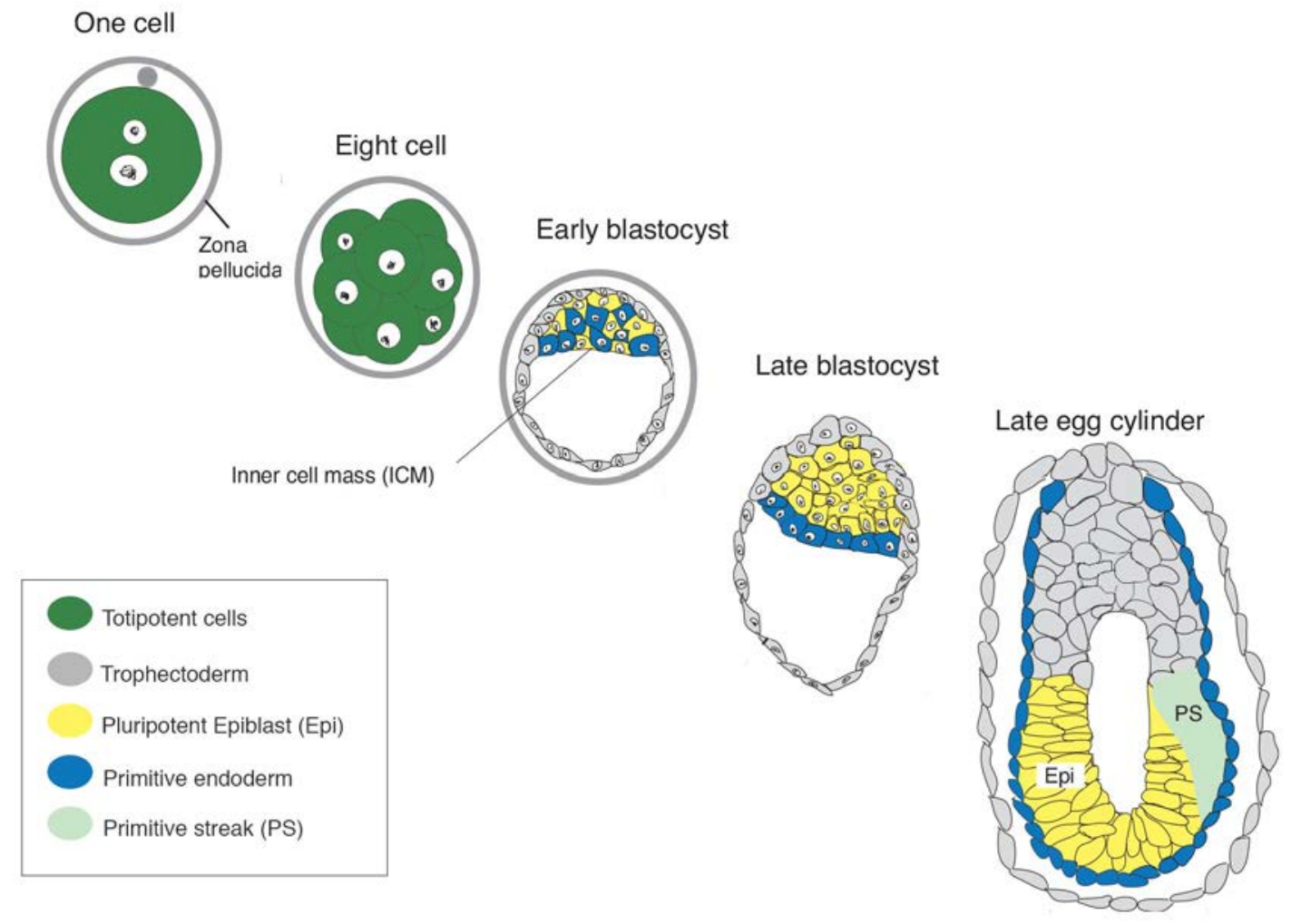

Figure 1. Early embryonic development.

The morphological changes and cell specification events take place from fertilization to gastrulation. The cell types in the embryos are color coded (adapted after $^{6}$ ). 


\subsubsection{Transcriptional control of the early lineage determination}

Although zygote contains a reservoir of transcription factors and an intrinsic regulatory network, during development differences in the cell polarity or exposure to morphogens cause changes in the internal transcription factor subset of the cells leading to their fate determination and specification. Early lineage determinations (specification of TE/ICM, segregation of EPI/PE and fate determination of neuroectoderm (NE)/mesendoderm (ME)) follow such a simple rule $^{7,8}$ (Fig. 2).

\section{TE/ICM specification:}

Trophoectoderm and ICM are the first alternative fates of the developing embryo. Caudal type homeobox $2(\mathrm{Cd} 22)$ transcription factor is expressed in all the cells in the eight-cell stage, but its expression becomes restricted to the outer layer of cells before blastocyst formation. It was shown that $\mathrm{Cdx} 2$ is necessary for the development of the $\mathrm{TE}^{9,10}$ while ICM formation is dependent on the presence of another set of transcription factors known as pluripotency factors. Octamer 4 $(\mathrm{Oct} 4)^{11}$, Nanog $^{12}$, and SRY-box containing gene $2(\mathrm{Sox} 2)^{13}$ play a pivotal role in the establishment of pluripotent ICM.

\section{EPI/PE segregation:}

GATA family transcription factors, especially Gata4 and Gata6, are expressed in the primitive endoderm. It was shown that the primitive endoderm lineage couldn't form properly in the absence of Gata family transcription factors ${ }^{14,15}$ and, Gata6 overexpression in ICM can result in a higher proportion of PE cells ${ }^{16}$. On the other hand, Nanog, the pluripotency promoting protein, contributes to the formation of epiblast ${ }^{17}$. Nanog deficiency causes loss of epiblast ${ }^{18}$. Therefore, it seems proper to say Gata factors and Nanog contribute to the formation of PE and EPI lineages respectively, while inhibiting the formation of the alternate lineage. 


\section{NE/ME fate:}

Like other specification events, it seems that the formation of the mesendoderm and ectoderm from the primitive streak is regulated by two transcription factors belonging to the pluripotency factors. Oct4 and Sox2 are expressed in the pluripotent cells and their co-expression contributes to the maintenance of the pluripotent state ${ }^{19}$. In vitro studies of the mouse pluripotent embryonic stem cells revealed that Oct4 and Sox2 play pivotal role in the early commitment of the neuroectoderm or the mesendoderm lineage, respectively. If expressed alone, these factors can drive a lineage specific differentiation. Sox2 is necessary for the formation of the neuroectoderm, and it can suppress key regulatory genes of the mesendoderm, such as brachyury. On the other hand, Oct4 drives mesodermal specific gene expression and down-regulates neuroectoderm inducing genes ${ }^{20}$.

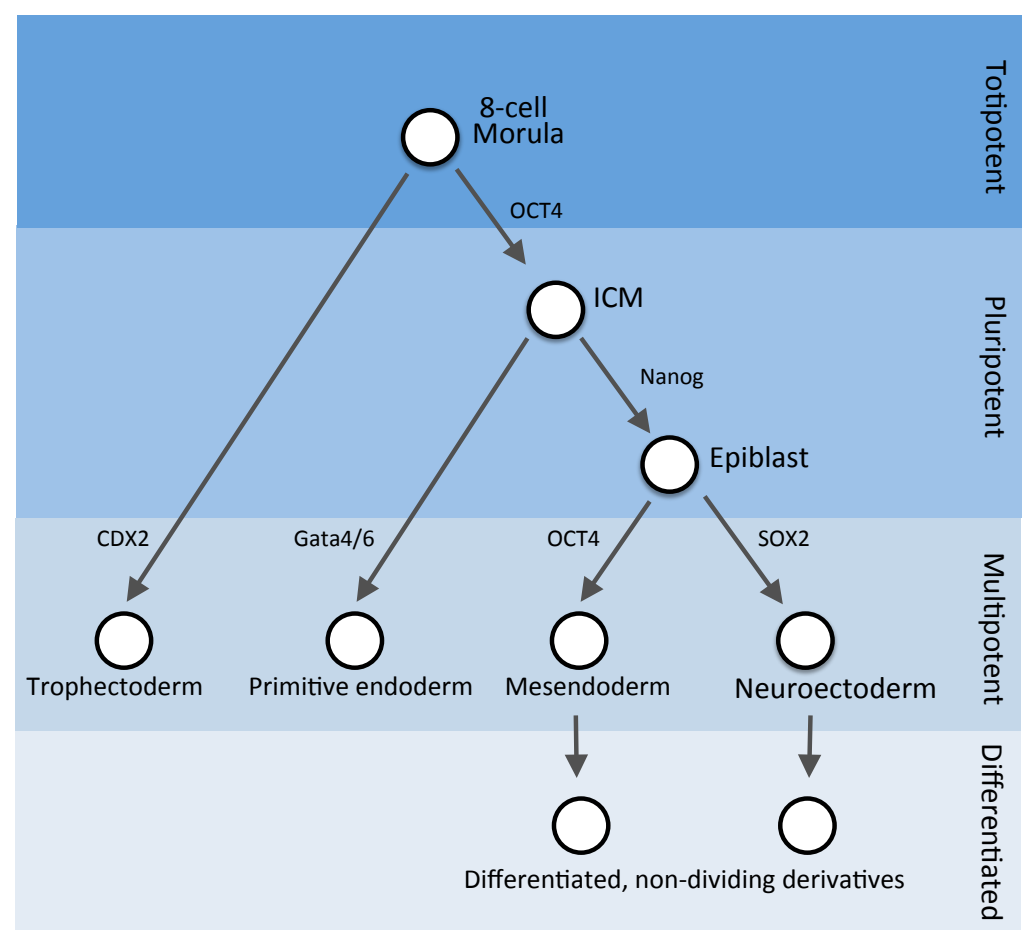

Figure 2. Transcriptional regulation of fate determination during the early mouse development.

Schematic representation of the lineage commitment and its transcription factor regulation (Adapted after ${ }^{8,21}$ ). 


\subsection{Embryonic Stem cells: Pluripotency in vitro}

Mouse embryonic stem cells were the first pluripotent cells derived from the healthy mouse embryos ${ }^{22,23}$. These cells resemble pluripotent cells of the early epiblast in many aspects; they can be maintained in an undifferentiated state, and they have the ability to form all three germ layers of the mouse embryo. In addition to their pluripotentiality, these stem cells can self-renew infinitely. ESCs are traditionally cultured on the feeder layer of inactivated mouse fibroblasts in the presence of fetal bovine serum and leukemia inhibitory factor (LIF). LIF maintains the self-renewal of these cells by activating the signal transducer and activator of transcription 3 (Stat3) pathway ${ }^{24,25}$.

ESCs express alkaline phosphatase and specific surface markers such as SSEA1 and E-cadherin. Furthermore, female blastocyst derived ESC lines possess two active $\mathrm{X}$-chromosomes representing a very primitive developmental state. In mice the method used to test the pluripotency of the ESCs is the ability to form chimeric animals upon injection into the blastocyst. These cells can contribute to all three germ layers: ectoderm, mesoderm and endoderm, in addition to the germ line. ESCs can be differentiated in vitro to any epiblastderived lineage or cell type upon treatment with right signaling factors at the appropriate time. Therefore, these cells provide a strong tool to study differentiation particularly in the early inaccessible stages.

\subsubsection{Transcriptional control of the ESCs}

Mouse embryonic stem cells resemble the early blastocyst in terms of the expression of canonical pluripotency factors, such as Oct4, Sox2 and Nanog. Oct4, the well-studied transcription factor, is exclusively expressed in totipotent, pluripotent and germ cells. This protein is necessary for formation of pluripotent cells in vivo ${ }^{26}$ and in vitro ${ }^{27}$ and for the reprogramming of the somatic cells. Oct4 inactivation in ESCs leads to the exit from self-renewal and differentiation toward the trophectoderm ${ }^{28}$, this finding is notable since it was shown that fate determination of trophoblastic cells takes place before the formation of pluripotent 
cells. Additionally in appropriate conditions, Oct4 can drive the differentiation toward mesendoderm and endoderm ${ }^{8} 29,30$. The interplay between Oct4 and Sox2 is a key regulatory mechanism in the establishment of the pluripotency. These two transcription factors can co-occupy and co-activate other genes in order to maintain the pluripotent state. Sox2 is expressed similar to Oct4 during development however, its inactivation results in a developmental defect in a later stage probably due to high amounts of maternal protein ${ }^{19}$. The third member of the pluripotency network is Nanog. Nanog is necessary for establishment of the pluripotent state and its overexpression can maintain it even in the unfavorable culture conditions $^{31,32}$. These proteins regulate the expression levels of each other and other core pluripotency genes such as Sall4, Hdac2, Sp1, Tcfp2l1, Essrb and Klf4. This regulatory network consists of protein complexes of these pluripotency core factors, which vary in composition and size ${ }^{30,33,34}$. These transcription factor complexes are found in all pluripotent cells, and they collaboratively crosstalk and govern the pluripotent state.

\subsubsection{Cell cycle of the pluripotent cells}

Embryonic stem cells proliferate fast and infinitely and show unusual cell cycle features. Although the duration of the $S$ and $M$ phase are comparable to the somatic cells, these cells possess a shortened G2 and an extremely shortened G1 phase ${ }^{35-37}$. In somatic cells many cell cycle regulators oscillate during the cell cycle and control the length of the gap phases (G1 and G2). In ESCs these proteins oscillate subtly compared to the somatic cells; enabling the cells to have a shorter gap phase and faster cell cycle ${ }^{38}$.

Some studies have shown that upon cell cycle perturbations or depletion of some cell cycle regulators the pluripotency markers are still up-regulated ${ }^{39-41}$ while many more concluded that a fast abbreviated cell cycle is necessary for the pluripotency of the $\mathrm{ESCs}^{38,39,42-46}$. In addition, some pluripotency core factors regulate the cell cycle in the $\mathrm{ESCs}^{47}$. Causing a coordination of the cell cycle and differentiation. The differentiating cells start to lengthen their G1 phase while they 
commit to somatic lineages and express differentiation markers ${ }^{48,49}$. It is still unclear whether differentiation causes the cells to slow down their cycle or the perturbation of the cell cycle leads to longer gap phases and higher transcription of the developmental genes.

\subsubsection{Epigenetic regulation of the pluripotent state}

Chromatin, chromosomal DNA packaged with histones, plays a pivotal role in regulating gene expression and fate determination. Chemical modification of the histones (e.g., acetylation, methylation, de-methylation, and ubiquitination), DNA methylation, action of DNA-binding proteins and chromatin-remodeling enzyme complexes can modify the chromatin structure and affect the gene expression. Embryonic stem cells are known to have a unique "open" chromatin state ${ }^{50}$ which results in global transcriptional hyperactivity ${ }^{51}$. This globally open state is maintained by multiple mechanisms, which are in a tight interaction with pluripotency core genes. In short some pluripotency transcription factors facilitate the interaction of chromatin remodeling factors to the chromatin while some prebound chromatin complexes recruit the transcription factors to their site of action. A well-studied example is the SWI/SNF complex. This complex which is ubiquitously found in cells, contains a cell-specific protein composition ${ }^{52}$. In ESCs the SWI/SNF complex is characterized by the presence of the core subunit Brg1, BAF155, and BAF60. In addition some Oct4-, Nanog-, and Sox2-associated proteins include components of this complex. This complex binds to pluripotency core genes and genes, which are regulated by pluripotency core genes. It was suggested that Brg1 binding to core pluripotency genes such as Sox2, Nanog or Oct4 are "tonically" repressed in order to fine-tune their expression to the desired level ${ }^{53}$.

Although differentiation genes are repressed strongly in the ESCs, it was proposed that ESCs favor a transcriptionally "permissive" state. Differentiation genes are bivalently marked with two regulatory signals, the activating histone 3 lysine 4 tri-methylation ( $\mathrm{H} 3 \mathrm{~K} 4 \mathrm{me} 3)$ and the inactivating histone 3 lysine 27 tri- 
methylation (H3K27me3 $)^{54}$. Presence of H3k27me3 causes the repression of the genes while presence of the activating signal (H3K4me3) facilitates the fast activation of the transcription upon removal of the inactivating mark. Therefore, in these cells the interplay between the differentiation and self renewal is reflected on the chromatin in a global manner (for more $\mathrm{see}^{53}$ ).

Polycomb group proteins are responsible for the inactivation of the gene expression through methylation of the histone 3 lysine 27 . These are two different multi-protein complexes, the polycomb repressive complex 1 (PRC1) and PRC2 ${ }^{55}$. PRC2 consists of four core proteins: EED, Suz12, Ezh2, and RbAp46/48 and catalyzes di- and tri-methylations of the histone k27 while PRC1 is recruited to tri-methylated H3K27 and catalyzed the mono-ubiquitination of the histone 2A. These complexes are responsible for the repression of the poised differentiation genes in ESCs and contribute to the maintenance of embryonic stem cell pluripotency $^{56,57}$ (for more see ${ }^{58}$ ).

\subsection{Reprogramming: "climbing the mount improbable"}

In 1957 Conrad Hal Waddington suggested a simple metaphor to introduce aspects of developmental biology. He considered a developmentally potent cell (like an ESCs) as a ball, which is located on the summit of a hill with uneven slopes and valleys shaped by genes and epigenetic modification of the genes. During development the ball rolls down, and the slopes guide it into certain destination points in different valleys.

This simple model explains many aspects of development and differentiation. If any terminally differentiated cell is considered as a final point in the valleys, two important aspects of differentiation can be interpreted from this model: 1- during differentiation the cells give rise to progenies with lower differentiation potential (showing that the ball always goes down), and 2- the well-coordinated interaction of many factors is necessary to reach each destination (considering the fact that each slope is made by many smaller pieces of rocks (a metaphor for genes) 
oriented in a way to favor rolling down). However, the question is if the terminally differentiated cell can climb the Waddington hill up again.

it was shown that reprogramming to a pluripotent state (Waddington summit) can be achieved by nuclear transplantation, cell fusion or direct reprogramming by expression of the exogenous factors ${ }^{59,60}$. Takahashi and Yamanaka $(2006)^{61}$ demonstrated that the overexpression of merely four transcription factors (Oct4, Sox2, KLF4 and c-Myc) can convert a terminally differentiated fibroblast into a reprogrammed pluripotent cell known as induced pluripotent cell (iPS). These four factors initiate events, leading to cell proliferation and reactivation of endogenous pluripotency genes, which activates an auto-regulatory loop to maintain the pluripotent state. The generated iPSCs resemble ESCs in the pluripotency network expression and the ability to generate chimera and germ line transmission ${ }^{62-64}$. Subsequently it turned out that reprogramming can be achieved through overexpression of alternative combinations of pluripotency transcription factors, chromatin remodeling complexes or substitution of factors with small molecules (for a more detailed discussion see ${ }^{53,65,66}$ ).

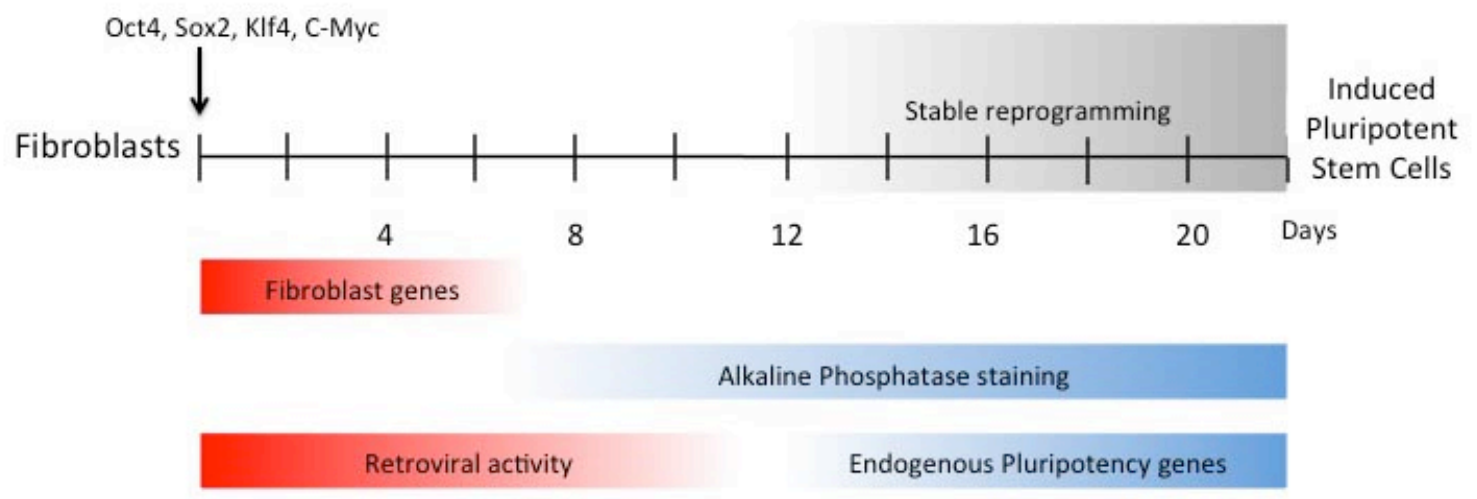

Figure 3. Reprogramming of fibroblasts.

Schematic representation of some important events during the reprogramming (Adapted after ${ }^{67}$ ). 
Although reprogramming looks surprisingly simple, but detailed mechanisms involved in the generation of the iPSCs are still unclear. What is known is that any differentiated cell can be reprogrammed, but the reprogramming efficiency is varied and hard to determine. In a classical reprogramming experiment (mouse embryonic fibroblasts transduced with viral particles coding Oct4, Sox2, Klf4 and c-Myc) the efficiency is calculated as the number of the formed IPSC colonies out of 100 used mouse embryonic fibroblasts. However, the effect of cell proliferation/cell death and the possibility of deriving two colonies out of a single fibroblast has not been considered in these calculations.

Extensive chromatin remodeling events are necessary for the reprogramming of the somatic cells. These remodelings would establish the dynamic, open state of the reprogramming and reactivate the pluripotency genes such as Nanog and Oct4. It was proposed that reactivation of the endogenous factors and reestablishment of the "open" chromatin state is the rate-limiting step defining the efficiency of reprogramming ${ }^{68}$. 


\subsection{Geminin}

Geminin was initially characterized as a bi-functional molecule. A screen for recognition of proteins, which are regulated through a cell cycle dependent degradation, nominated Geminin as a cell cycle regulator, degraded by Anaphase Promoting Complex (APC) at the metaphase to anaphase transition during mitosis ${ }^{69}$. Further investigations showed that Geminin plays a role in the regulation of DNA replication fidelity.

At the same time Geminin was identified in an expression screen for neural inducers in $X$. laevis ${ }^{70}$. It was shown that Geminin overexpression in embryos causes the expansion of neural plate due to the conversion of the ectodermal progenitors into the neural tissue instead of other cell types. In addition reducing Geminin expression results in loss of neural marker expression and formation of non-neural cells. Apparently this neuralizing effect of the Geminin is conserved between vertebrates and invertebrates such as Drosophila ${ }^{71}$.

\subsubsection{Geminin and CDT1, inhibition of re-replication}

In order to maintain the integrity of the genome, each of the two daughter cells need to inherit one identical copy of the maternal genome. Therefore, a strict regulation of DNA duplication guarantees that each part of the DNA is precisely duplicated once and only once during each cell cycle. Origin licensing is one of the main mechanisms to monitor the replication integrity. During the G1 phase of a cell cycle origins of replication associate with pre-replication complexs (pre$\mathrm{RC}$ ). These complexes consist of the chromatin licensing and DNA replication factor 1 (Cdt1), the cell division cycle 6 homolog (Cdc6), the minichromosome maintenance complex (MCMs), and the Origin recognition complex (ORC). Together they "license" a origin of replication. During $S$ phase, the licensed origins are recognized by the replication machinery while the relicensing of the origins is strongly inhibited. Geminin is one of several inhibitors of licensing. It needs to be absent in the $\mathrm{G} 1$ phase before it accumulates through the S/G2/M phases. During the $S$ phase it binds to the released Cdt1, and inhibits its 
rebinding to the origins, thus, preventing the re-launching of the duplicated origin $^{72-74}$. At the end of the $M$ phase it is degraded by the APC/cyclosome $\left(A P C^{C d c 20}\right.$ and $A P C^{C d h 1}$ ) and it would not accumulate until late $G 1$ when the $A P C^{C d h 1}$ is inactivated. The absence of Geminin during the $G 1$ phase allows licensing to take place once more to prepare the genome for the next round of replication. In the late G1 Geminin levels exceed Cdt1 levels; thus, the licensing period ends before replication initiates. This mechanism ensures that every origin can fire only once per cell cycle, so that over-replication is prevented.

However, Geminin is not the only mechanism to prevent re-replication ${ }^{75}$. In addition to Geminin, cyclin dependent kinases (CDKs) regulate the fidelity of DNA replication both directly and indirectly. CDKs down regulate the activity of the pre-RC components. Pre-RC components, ORC, Cdc6, and Cdt1, are recognized and phosphorylated by CDKs in a cell cycle regulated manner. Since all these phosphorylations prevent formation of the pre- $\mathrm{RC}$, the deregulation of CDKs results in re-replication. In mammalian cells Cdk2 targets Cdt1 for destruction via the $\mathrm{SCF}^{\mathrm{Skp} 2}$ E3 ubiquitin ligase and the PCNA-dependent pathway (Cul4-Ddb1 ${ }^{\text {Cdt2 }}$ dependent destruction) during $G 2$ and $S$ phase ${ }^{76}$. This mechanism restricts the availability of Cdt1 during S/G2 phases and contributes to the inhibition of relicensing. Thus, stabilization of Cdt1 can lead to rereplication. Cdk1 is critically necessary to block relicensing during G2 and M phases. It was shown that its inactivation will recruit pre-RC to DNA and activates $A P C^{C d h 1}$ leading to Geminin destruction.

In summary, a network of inhibitory pathways prevents pre-RC assembly. In every cell, these mechanisms cooperate to ensure that DNA is replicated once and only once per cell cycle ${ }^{75}$. 


\subsubsection{Geminin in cancer}

In normal cells Geminin and Cdt1 levels are highly balanced and regulated in order to maintain the genomic integrity. Aberrations of this balance would cause genomic instability and DNA replication defects that predispose a cell to malignant transformations ${ }^{77}$. Geminin expression is frequently deregulated in tumor cells ${ }^{78}$. In addition many reports indicate that Geminin is a useful marker for prognosis prediction in colorectal cancer ${ }^{79}$, pancreatic cancer ${ }^{80}$, advanced intestinal-type gastric carcinoma ${ }^{81}$, salivary gland carcinoma ${ }^{82}$, oral squamous cell carcinoma ${ }^{83}$, penile carcinoma ${ }^{84}$, aggressive breast cancer ${ }^{85,86}$ and lung adenocarcinoma ${ }^{87}$.

Furthermore, overexpression of Geminin in mammary epithelial cells causes the formation of aggressive tumors in immuno-deficient mice ${ }^{86}$. The initiation of DNA replication in some cancer cells is solely regulated by the Geminin, whereas, non-cancer cells have additional regulatory mechanisms ${ }^{88}$. Knockdown of Geminin in some cancer lines causes DNA re-replication and DNA damage, leading to apoptosis, but not in the cells derived from normal tissues. Additionally, normal levels of Geminin are necessary for the action of Topoisomerase type II alpha (Topolla) which acts in the termination of replication. Both depletion and overexpression of Geminin alters the action of Topolla causing genomic instability and replication defects ${ }^{89}$.

In conclusion, Geminin expression is associated with some malignant transformations. Some transformed cells are susceptible to the loss of Geminin and undergo apoptosis in its absence. The possibility of killing some cancer cells by inhibition of Geminin activity, nominates Geminin as a worthy therapeutic target ${ }^{88,89}$. 


\subsection{Geminin as a transcription modulator}

Geminin has an at first sight unrelated function as a transcription or chromatin modulator. It is expressed in proliferating cells and may act in regulation of the transition from proliferation to differentiation. Accordingly, it was shown that Geminin is necessary for early development and maintenance of some differentiating lineages. Embryonic development shows a strong dose dependency to Geminin, suggesting the existence of several interaction partners, which can sense the different amounts of Geminin by competing for it.

\subsubsection{Geminin in early development}

Genetic ablation of Geminin in mouse results in pre-implantation mortality ${ }^{90,91}$. Formation of the ICM is dependent on the Geminin in the early mouse embryo. Lack of Geminin induces endo-reduplication at the 8-cell stage leading to a developmental arrest. Remaining cells of the Geminin deficient embryo exhibit abnormal morphology and impaired cell-cell adhesion. These cells contain nuclei with abnormal shape and size, and they express trophoblastic markers. Therefore, Geminin deficient embryos lack the ability to form inner ICM. However, it is not clear whether Geminin inhibits the endo-reduplication or it regulates the balance between transcription factors necessary for formation of ICM and throphoblast (Oct4 and Cdx2) leading to a change in the cell fate.

\subsubsection{Geminin and pluripotent cells}

Geminin is highly expressed in the pluripotent cells ${ }^{35,38,92}$, and degraded in a cell cycle regulated manner ${ }^{38}$. In a recent study, Geminin was depleted in mouse ESCs and it resulted in a loss of stem cell identity and trophoblastic differentiation ${ }^{92}$. The same lab reports that Geminin, antagonizing SWI/SNF chromatin remodeling complex action, is necessary for the maintenance of pluripotency gene expression. However, it was extensively reported that ESC specific SWI/SNF complex is necessary for the maintenance of the pluripotent state and moderates the expression of the pluripotency genes ${ }^{93-96}$. 


\subsubsection{Geminin in neurogenesis}

Geminin was initially found as a neuralizing factor ${ }^{70}$. Partial interference with Geminin activity in Xenopus embryos resulted in a neural to epidermal cell fate change ${ }^{97}$. In addition, Geminin is necessary to spatially restrict mesoderm, endoderm and non-neural ectoderm to their proper locations in the Xenopus embryo $^{98}$. It is necessary for neural fate determination of the ESCs, through establishment of a hyper-acetylated and open chromatin at neural genes ${ }^{99}$. Geminin plays a role in neural fate acquisition through inhibition of the pro-neural basic helix-loop-helix (bHLH)-Brg1 interactions ${ }^{97}$. Thus, Geminin is necessary to prevent premature differentiation and maintenance of the neural progenitors. It promotes a bivalent chromatin state at genes encoding neurogenesis transcription factors ${ }^{100}$.

Geminin is highly expressed in Sox $2^{+}$neural progenitors of the central nervous system (CNS), and becomes down-regulated upon differentiation and cell specification ${ }^{101}$. However, the role of Geminin in the development of the CNS is highly debated. Genetic inactivation of the Geminin in developing CNS was shown to increase the early born and decrease the late born neurons, without having an effect on the gliogenesis ${ }^{101}$. However, other studies do not report any changes in the progression of the neurogenesis ${ }^{102,103 .}$

In summary, Geminin is necessary for formation of the neural lineage, however, it is not necessary for further maturation of the cells. Its mechanism of action is not well understood, but it seems that Geminin interacts with chromatin remodeling complexes to form the neural lineage.

\subsubsection{Geminin and hematopoietic system}

Hematopoiesis system provides a well-studied system to evaluate the connection between cell differentiation and proliferation in the adult system. The blood cells are derived from the hematopoietic stem cells (HSCs), which are multipotent stem cells that give rise to all the blood cell types including myeloid (monocytes, 
macrophages, neutrophils, basophils, eosinophils, erythrocytes, megakaryocytes and dendritic cells) and lymphoid lineages (T-cells, B-cells and NK-cells). Defects in the well-regulated differentiation and cell divisions of the cells can cause leukemia, myelo-proliferative disorders or marrow failure, but the factors and pathways, regulating this pattern, are not completely understood.

Geminin knockout in the hematopoietic stem cells severely perturbed the hematopoietic pattern ${ }^{104}$. Stem and progenitor cell number are intact but erythrocyte production was abolished leading to severe anemia. On the other hand megakaryocyte production was enormously enhanced. In vitro cultured $\mathrm{Gmnn}^{-/-}$megakaryocyte-erythrocyte precursors formed more megakaryocyte colonies while their ability to form erythroid colonies was lost. Additionally, their DNA content was normal. It was suggested that Geminin plays a role in fate determination of megakaryocyte-erythrocyte precursors by a replicationindependent manner ${ }^{103}$. Geminin can induce quiescence in HSCs through abrogation of their activity ${ }^{105}$; therefore, its stability in HSCs is highly regulated ${ }^{105}$ 106.

\subsubsection{Geminin and interaction partners}

An increasing number of Geminin interaction partners was recently identified. In addition to CDT1, many new interactors with different functions support the role of Geminin as a transcription modulator. Among its interacting partners are basic transcription machinery, chromatin modulating factors (SWI/SNF complex and polycomb group proteins) and known homeodomain transcription factors (Hox and Six3).

\section{Interaction with basic transcription machinery:}

In order to start transcription the basic transcription machinery needs to be assembled near the promoter regions. Either TATA-box binding protein (Tbp) or TBP-like factor 1 (Tbpl1) is necessary to form this pre-initiation complex. The transcription starts with the recruitment of RNA polymerase II. During a screen for 
Geminin interactors a novel protein was identified which binds also to Tbp and Tbpl1. This protein, Tipt (TATA-binding protein-like factor-interacting protein), was shown to activate transcription both from TATA-box-containing and from TATA-less promoters ${ }^{107}$.

\section{Interaction with the chromatin remodeling factors:}

In certain developmental contexts Geminin interacts with members of the polycomb group proteins. The clustered Hox genes, encoding the homeodomain proteins of the hox family, are expressed in a well-regulated, spatiotemporal collinear manner along the anterior-posterior axis of the early embryo. It was shown that Geminin could bind to Hox genes in order to prevent their interaction with the DNA. In the same context Geminin interacted with the PcG protein, Scmh1 to regulate the transcription of the Hox genes during axial patterning ${ }^{108}$. Geminin activity in restraining the commitment of the mesoderm, endoderm, and non-neural ectoderm depends upon the intact polycomb repressor functions ${ }^{98}$. In addition Geminin can regulate the transition from neural precursors to neurons through its binding to the Brg1. During early induction of the neuroectoderm in chicken embryos, Geminin interacts with Brm, another core subunit of the SWI/SNF complex ${ }^{109}$.

In summary, the functional diversity of Geminin interaction partners suggests a significant role for Geminin in coordination of cell cycle pace with the fate determination. 


\subsection{Aim of the thesis}

This study has tried to shed light on the regulatory role of the Geminin in the embryonic stem cells by application of an inducible Geminin knockout ESC line (iGmnn ESC). The role of Geminin in self-renewal of the ESCs, their pluripotency and lineage commitment was of interest. Geminin's effect was explored at a molecular level in order to gain an insight into its mechanism of action. In addition Geminin deficient somatic cells and their ability to reprogram into the pluripotent cells was investigated. In short, this study aimed to characterize the necessity of Geminin for pluripotency, neural induction and reprogramming of the somatic cells. 


\section{Results}

\subsection{Geminin protein is expressed in embryonic stem cells and is down regulated during differentiation}

At first, the Geminin levels in the wild type MPI-II mouse embryonic stem cells (MPI-II ESCs) and their differentiated progenies were investigated. ESCs were differentiated as embryoid bodies (EBs), and after 5 days they were plated on the adhesive plates for further differentiation and analysis (Fig. 4A). Whole cell lysate protein analysis showed that undifferentiated ESCs expressed Geminin strongly but Geminin protein levels decreased upon EB differentiation (Fig. 4B). Data showed a down-regulation of the Oct4 mRNA, however, the levels of Geminin mRNA did not decrease (Fig. 4C). Further mRNA level quantification by quantitative RT-PCR (data not shown) revealed no significant difference in the amount of Geminin mRNA. In short, Geminin was expressed strongly in ESCs and its protein levels were decreased upon differentiation.

A

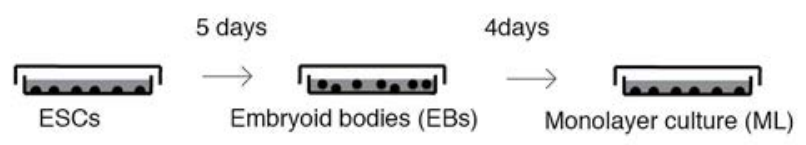

B

C
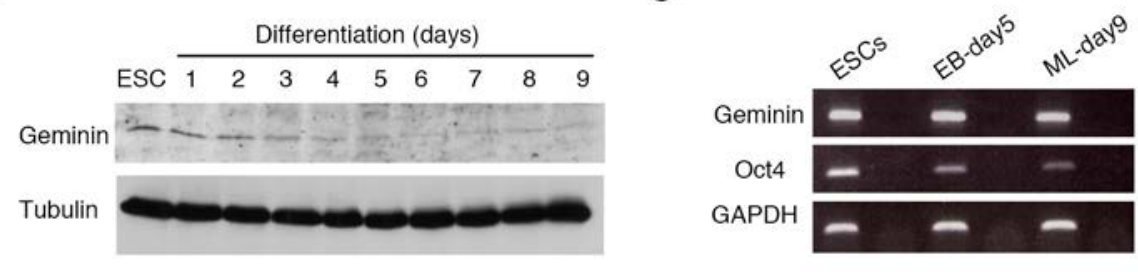

Figure 4. Geminin is down-regulated in mouse ESCs upon differentiation.

A) MPI-II ESCs were differentiated for 5 days as EBs followed by re-plating in adhesive culture plates for 4 more days to form the differentiated monolayer cultures. B) Whole cell lysates were harvested and analyzed by western blot. The amount of the loaded protein was controlled by atubulin amounts. C) ESCs, 5 days old EBs, and 9 days old Monolayer cultures (ML) were analyzed for Geminin and Oct4 mRNA by semi-quantitative RT-PCR. The amount of loaded mRNA was controlled by Gapdh amounts. Data represented in this figure was prepared in collaboration with Judith Schilling during her bachelor thesis project. 


\subsection{Geminin protein is expressed in embryonic stem cells and the neuroectodermal progenitors}

In order to investigate the expression pattern of Geminin in different embryonic lineages such as ectoderm, mesoderm or endoderm, ESCs were differentiated to specific lineages (Fig. 5A). ESCs were plated in low density for 48 hours in the absence of LIF and serum in N2B27 medium and afterward they were differentiated for 36 more hours particularly toward mesendoderm (ME) or neuroectoderm (NE) by treatment with a Wnt agonist named chirion or Retinoic acid (RA). Expression patterns of Sox1, a neural specific transcription factor, and Brachyury, a mesendoderm specific transcription factor, serve as a control for the efficiency of differentiation. As shown in the Fig. 5B the majority of the cells differentiated toward ectoderm or mesendoderm. Further immunofluorescence analysis showed that pluripotency transcription factors Oct4 and Sox2 were present in the ES cells however, upon differentiation their presence was restricted only to a specific lineage; neuroectodermal progenitors expressed Sox2, while mesendodermal progenitors expressed Oct4 as reported previously ${ }^{8}$. In order to investigate Geminin protein levels, whole cell lysates from the ESCs, NE and ME were analyzed by western blot (Fig. 5C). Nanog and Klf4 were used as specific markers for pluripotent cells. These two transcription factors were only observed in pluripotent undifferentiated ESCs and their absence in the mesendoderm and neuroectoderm confirms the absence of the pluripotent cells.

Oct4 was higher in ESCs and ME and its levels decreased in the NE. Sox2 was high in ESCs; it was present in the NE and decreased strongly in the ME. Sox1 and Brachyury were found in a lineage-specific manner depicting a high differentiation specificity of the cultures. Immunoblot staining of Geminin revealed that it was present in ESCs and neuroectoderm progenitors, and was down regulated in mesendodermal progenitors (Fig. 5C). 
A

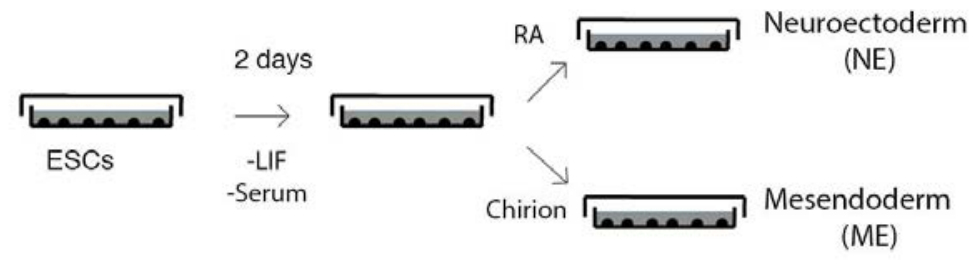

B
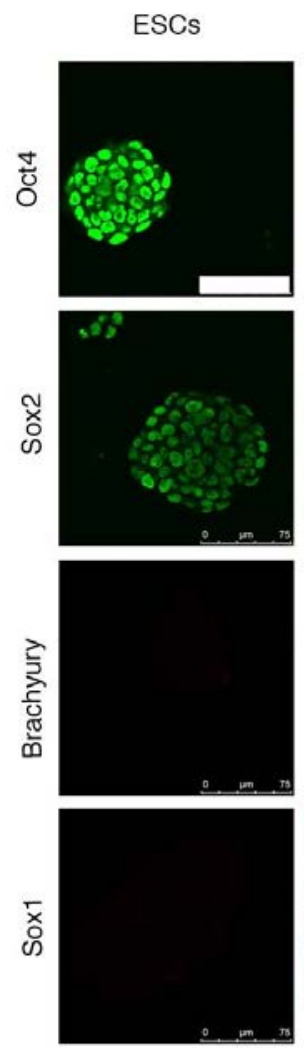

NE
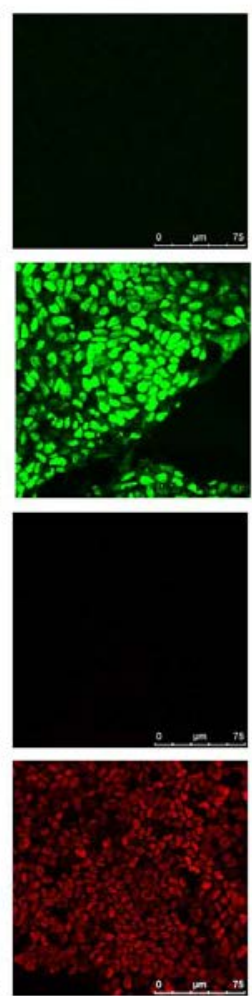

ME
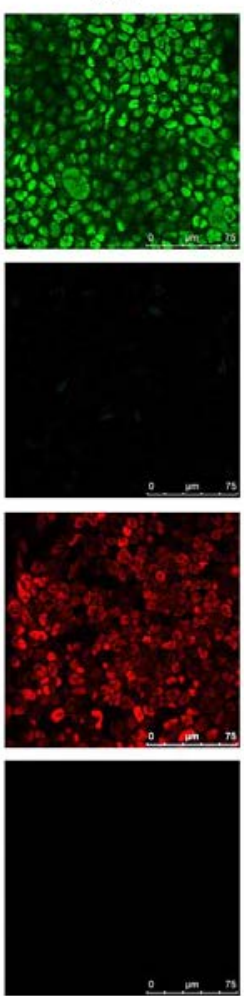

C

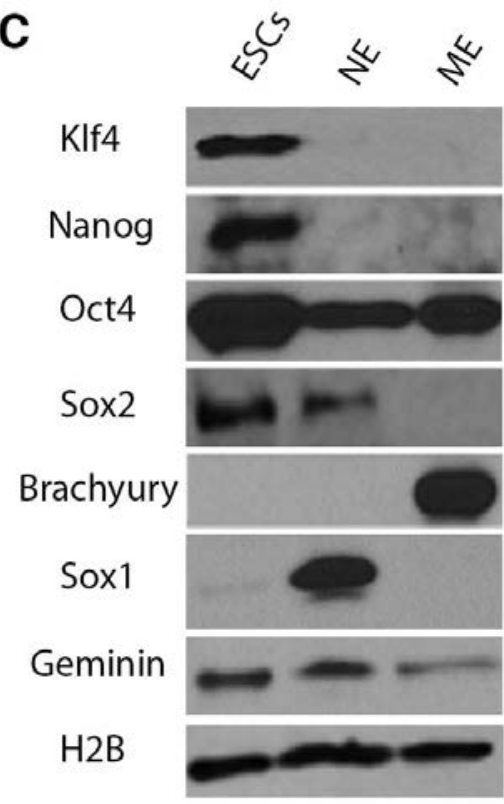

Figure 5. Geminin is down-regulated in the mesendoderm, but not in the neuroectoderm.

A) MPI-II ESCs were differentiated on gelatin-coated plates in the absence of serum for 48 hours and then exposed to RA or Chirion, in order to differentiate the ES cells to neuroectoderm (NE) and mesendoderm (ME), respectively. B) Undifferentiated ESCs, NE and ME were analyzed with immunofluorescence staining of pluripotency markers (Sox2 and Oct4), lineage specific markers (Sox1 and Brachyury). C) Western blot analysis of pluripotency markers (Klf4, Nanog, Sox2 and Oct4), lineage specific markers (Sox1 and Brachyury) and Geminin. Histone 2B levels were shown for control. 


\subsection{Geminin is degraded upon G1 entrance in the ESCs}

Geminin is recognized by the degradation machinery of the somatic cells upon entry into G1. However, it was not clear if Geminin is degraded in a cell cycleregulated manner in the pluripotent cells or not; therefore, it was interesting to study the dynamics of Geminin protein during the cell cycle of the ESCs. In order to visualize the cell cycle transitions in somatic cells, two sensor proteins were designed and applied. These sensor proteins included fluorescence proteins tagged with destruction sites of the proteins, which were degraded in some phases and present in the rest of the cell cycle ${ }^{110}$. One of these sensors known as $m A G-h G e m(1 / 110)$ coded a chimeric protein composed of $m A G$ (monomeric version of Azumi Green) and the 110 amino acids N-terminus of human Geminin containing its destruction box (Fig. 6A). It was transiently overexpressed in order to visualize Geminin degradation in wild type ESCs.

mAG-hGem fusion protein does not interfere with the cell cycle progression of the transfected cells however, it is recognized by destruction machinery of the cell causing elimination of the fluorescence signal. Therefore, it can be applied to visualize the phases in which the endogenous Geminin escapes degradation. Total population of the cells was harvested and stained with propidium iodide in order to visualize their DNA content. Flow cytometric analysis of these cells revealed that more than $35 \%$ of the cells expressed Azumi Green, meaning that at least $35 \%$ of the population received the transfected mAG-hGem coding plasmid. Comparison of the whole population and Azumi Green positive fraction illustrated a change in the shape of the cell cycle distribution depicting a loss of the $\mathrm{G} 1$ phase, which resulted in a significant enrichment toward S/G2/M phase in the Azumi Green expressing fraction (Fig. 6B). 


\section{A}

mAG-hGem reporter

Geminin destruction box Azumi Green

B

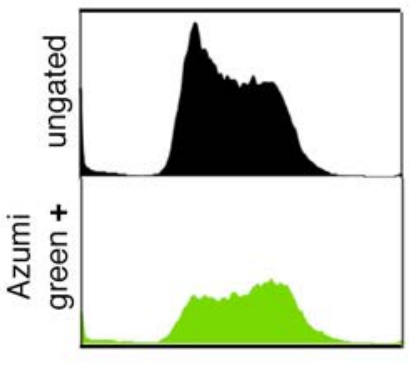

G1 G2/M

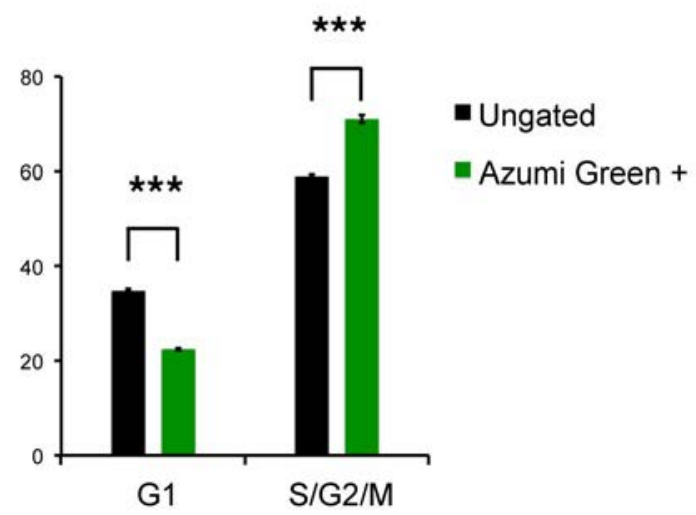

G1 S/G2/M

Figure 6. Down-regulation of mAG-hGem in G1 phase of the ESC cell cycle.

A) A fusion of human Geminin degradation site and a green fluorescent protein is used to visualize the cell cycle. B) ESCs were transfected with mAG-hGem were analyzed by flow cytometry in order to measure the red (DNA content) and green fluorescence content of the cells. Analysis showed that more than $35 \%$ of the cells were positive for green signal. The samples were gated for green fluorescence positivity and the DNA content of the positive population was compared against the DNA content of the whole population. DNA content distribution of one sample was shown on the left panel and the quantification of 3 independent experiments are demonstrated on the righ panel.

However, mAG-hGem visualization did not exclude the possibility of in vivo inhibition of the Geminin degradation during cell cycle of the pluripotent cells. To exclude this possibility, the endogenous Geminin protein level in a synchronized ESC population was investigated. ESCs were synchronized in the M phase and after release into fresh medium cells were collected at different time points for further analysis (Fig. 7A). Flow cytometeric analysis of the PI stained cells revealed an efficient synchronization. Cells were arrested in the $M$ phase and the $80 \%$ of the cells entered the G1 phase after 90 min (Fig. 7B).

Whole cell lysate protein analysis revealed a decrease in the Geminin protein upon entry into G1 phase observed at the $90 \mathrm{~min}$ to $120 \mathrm{~min}$ after the release (Fig. 7C). This observation clearly indicated that degradation machinery of 
pluripotent cells recognizes and degrades endogenous Geminin upon entrance into the G1 phase in pluripotent ESCs.

A

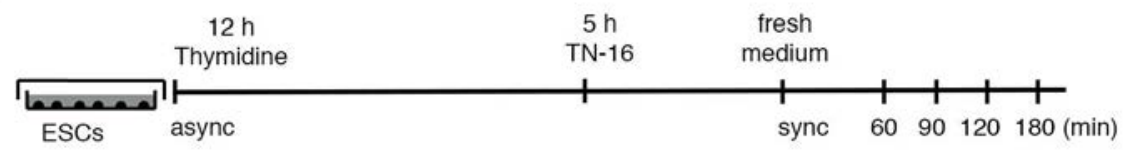

B

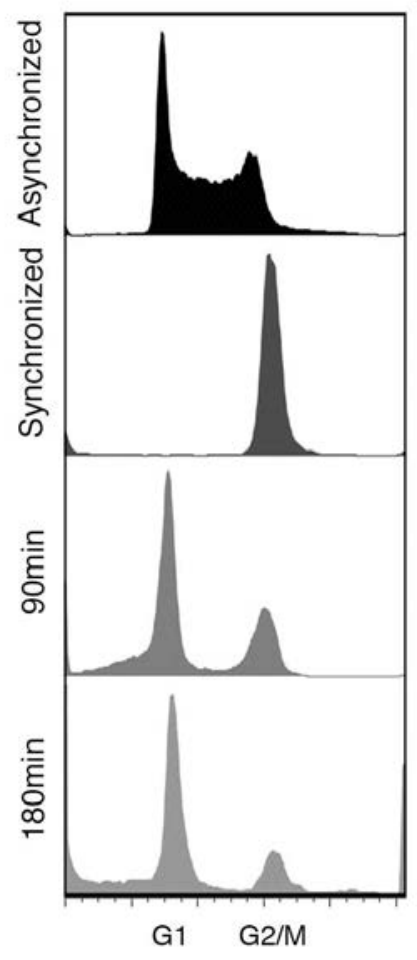

C

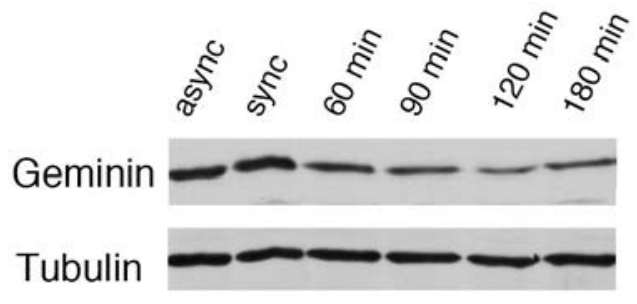

Figure 7. Endogenous Geminin is degraded upon $\mathrm{G} 1$ entrance in mESCs.

A) ESCs were cultured in feeder free cultures in ES-CM+2i medium, synchronized with 14 hours thymidine and 6 hours TN-16 treatment to accumulate in M phase. The cells were then released into the fresh medium and at the indicated time points after release the cells were harvested, trypsinized, fixed and stained with propidium iodide. Untreated asynchronous ESCs were used as control. B) The cell cycle distributions of cells were determined by flow cytometry. C) At the same time points whole cell lysates were collected for western blot analysis of Geminin controlled by levels of tubulin protein (async: asynchronized, sync: synchronized= $0 \mathrm{~min})$. 


\subsection{Conditional inactivation of Geminin locus}

As discussed previously, Geminin null embryos die at the 8-cell stage. To study the Geminin in pluripotent ESCs a conditional knockout strategy was applied. A conditional Geminin knockout mouse line was previously established, in which Gmnn exon 2 and 3 where flanked by loxP sites ${ }^{102}$. This floxed allele is designed and depicted as " Gmnn fl ". Upon Cre expression in the same cell, the Gmnn ${ }^{\text {fl }}$ was excised to generate a Gmnn', unable to produce a functional potein (Fig. 8).

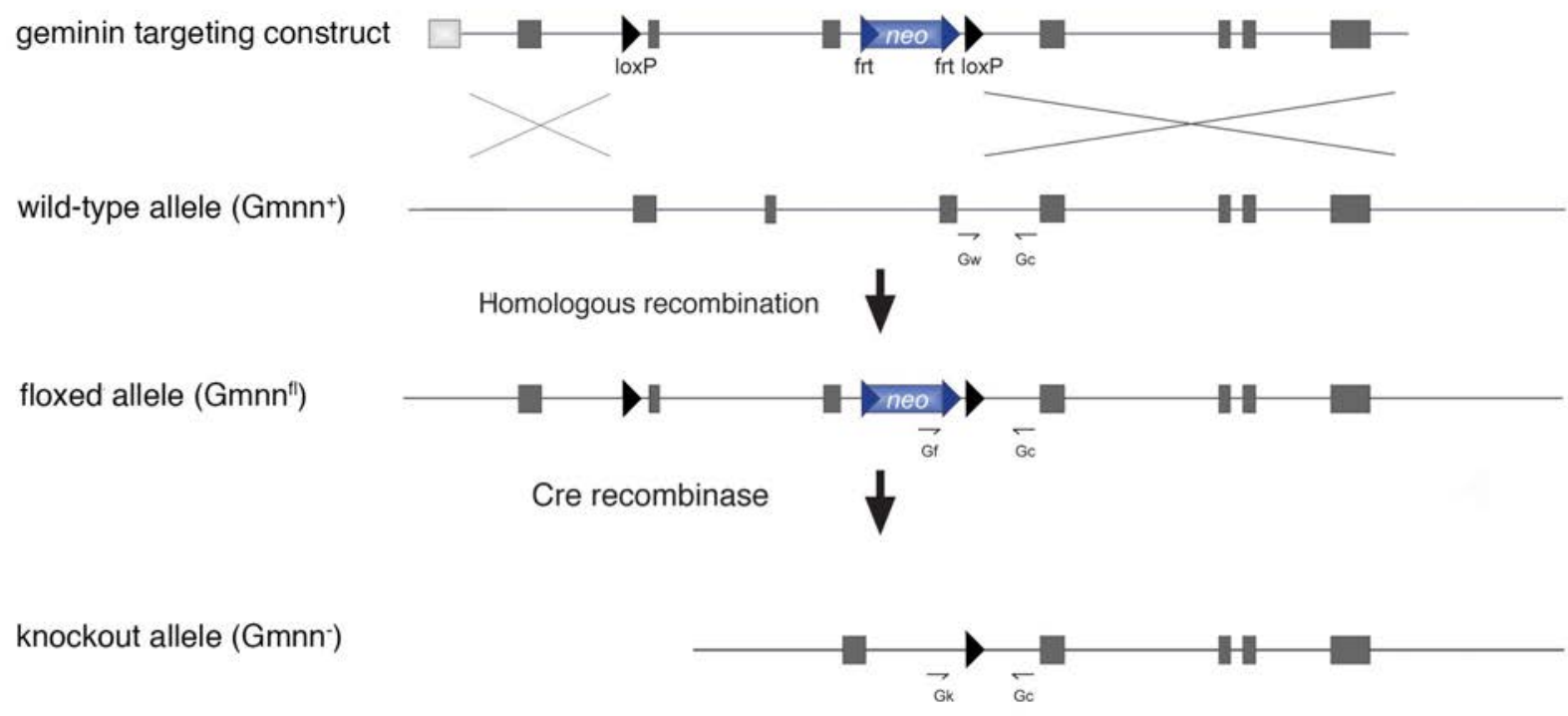

Figure 8. Targeting strategy to generate Geminin conditional knockout allele.

Two LoxP sites were inserted in the first and third introns of Geminin genomic locus upon sitespecific recombination. The floxed allele possesses exon 2 and 3 flanked by LoxP sites and upon Cre mediated recombination exons 2 and 3 are excised. Thus the remaining conditional knockout allele loses its ability to produce functional protein (adapted after $^{102}$ ).

The $G m n n^{f / /+}$ mice were mated to $C M V-C r e^{+}$transgenic animals and $G m n n^{A /+}$ $\mathrm{CMV}-\mathrm{Cre}^{+}$progeny were further bred with wild type animals to obtain $\mathrm{Gmnn}^{-/+}$ progeny. The heterozygous animals were further mated to each other in order to obtain knockout animals. Genotyping of 131 born animals (16 litters) confirmed an embryonic lethality of the Geminin null embryos (Fig. 9). 33.5\% (44/131) of the 
born animals were $\mathrm{Gmnn}^{+/+}$and $66.5 \%$ (87/131) were $\mathrm{Gmnn}^{-/+}$while no $\mathrm{Gmnn}{ }^{-/-}$ pubs were born. These data clearly indicate that recombination leads to the nonfunctional knockout allele and the homozygous knockout mouse are embryonic lethal as reported previously ${ }^{91}$.

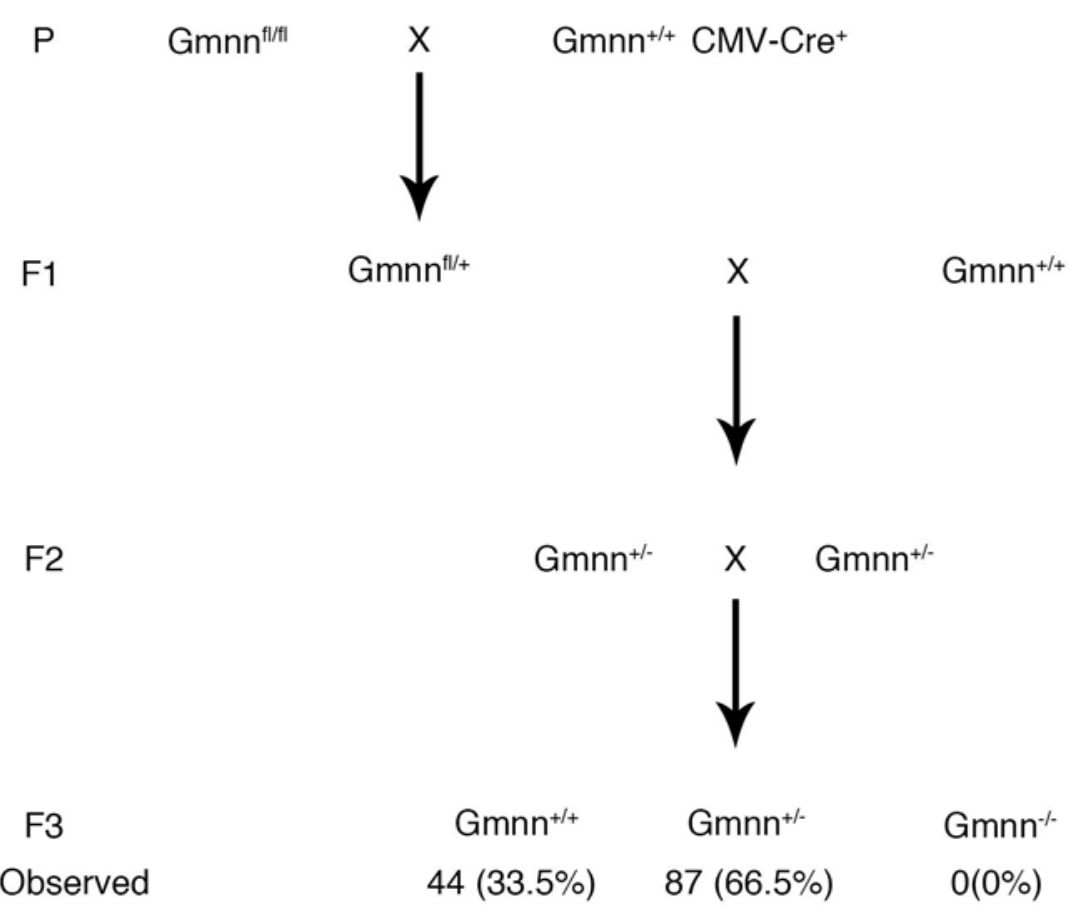

Figure 9. Genetic inactivation of Geminin leads to embryonic lethality. Mating scheme for the generation of the $\mathrm{Gmnn}^{-/-}$mice. 


\subsection{Establishment of iGmnn ESCs}

To investigate the role of Geminin in ESCs, the iGmnn ES cell line was established. Geminin transgenic mice were bred with the tamoxifen-inducible Cre recombinase coding $\operatorname{strain}^{111}\left(E R-C r e^{+}\right)$, in which, the recombination reaction can be triggered through administration of tamoxifen in vivo or 4-hydroxyl tamoxifen in vitro (Fig. 10A). Blastocysts were harvested and plated on the feeder-coated culture plates to outgrow to ESCs. The established ESC lines were genotyped and one line with the desired $G m n n^{\mathrm{fl} / \mathrm{fl}} E R-\mathrm{Cre}^{+}$genotype was selected. This line was named "iGmnn" and was further characterized to confirm its pluripotency. Morphology, alkaline phosphatase activity and the expression of pluripotency markers, Oct4, Sox2 and SSEA1 represented a pluripotent state (Fig. 10B). iGmnn ESCs were differentiated as EBs in order to investigate their differentiation potential (Fig. 10C). Immunofluorescence analysis of differentiated iGmnn ESCs revealed that they were able to give rise to all three germ layers upon EB differentiation shown by Sox1, Sox17 and Brachyury markers for the ectoderm, endoderm and mesoderm respectively (Fig. 10D). RT-PCR analysis of ESCs, 5 days old differentiated EBs, and 9 days old differentiated monolayer cultures showed a down regulation of the pluripotency markers Nanog and Zfp42 (also known as Rex1) and up-regulation of lineage specific markers such as Pax6 (ectoderm), Brachyury (mesoderm) and HNF4a (endoderm). Thus, iGmnn ESCs were able to differentiate into all three embryonic lineages.

Upon injection into 8-cell stage embryos, iGmnn ESCs were able to give rise to chimeric mice (7 chimeric animals out of 41 born animals, Fig. 10F), and the chimeric mice gave birth to iGmnn ES derived animals (3 out of 4 litters, Fig. 10G). Genotyping (data not shown) and agouti coat color of the pubs showed that the iGmnn ESC are germ line competent. These characteristics demonstrated that the iGmnn ESCs are a fully pluripotent cell line, and can be used for further investigation of the role of Geminin in the ESCs. 
A

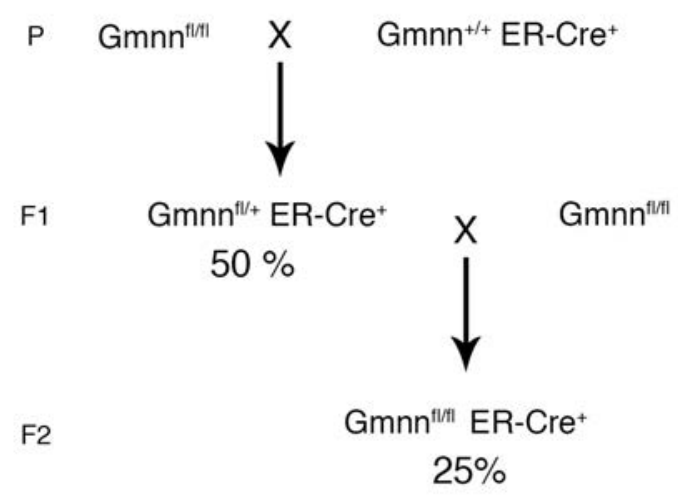

B

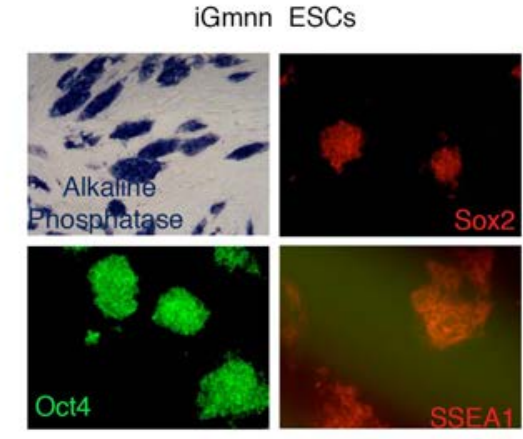

C

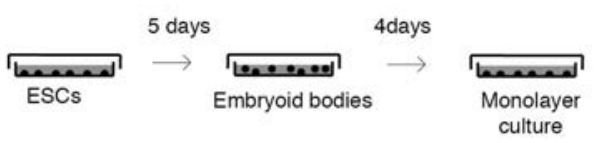

E

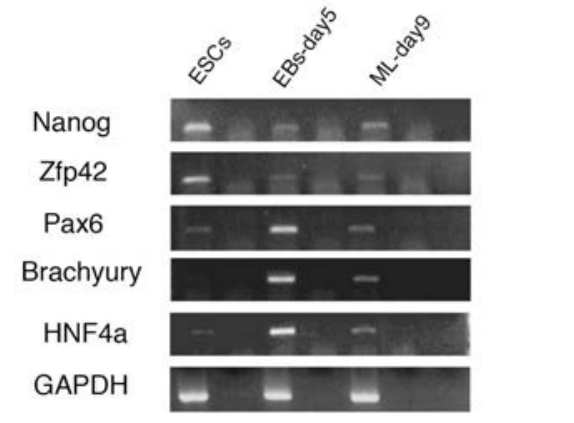

D

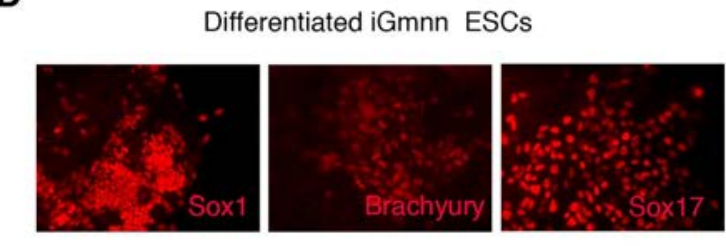

$\mathbf{F}$

G

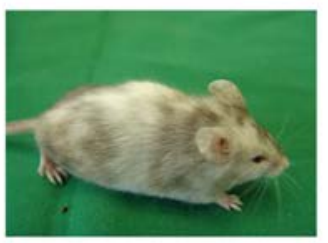

Figure 10. iGmnn ESCs are pluripotent.

A) mating schem for the generation of the iGmnn ESCs. B) The established iGmnn ESCs were positively stained for alkaline phosphatase activity and they were immuno-stained for the pluripotency markers (Sox2, Oct4 and SSEA1). C) iGmnn ESCs were differentiated for 9 days as floating EBs in petri dishes followed by re-plating on tissue culture plates. D) Differentiated iGmnn ESCs were immuno-stained for lineage specific differentiation markers (Sox1: ectoderm marker, Brachyury: mesoderm marker and Sox17: endoderm marker). E) iGmnn ESCs, 5 days old EBs, and 9 days old monolayer were analyzed by RT-PCR for the expression of the pluripotency markers (Nanog and Zfp42) and differentiation markers (Pax6: ectoderm marker, Brachyury: mesoderm marker and HNF4a: endoderm marker). Gapdh was used to control the amount of loaded mRNA. F) iGmnn ESCs were able to give rise to chimeric mice(white with agouti patches) upon injection into C57BI6/N blastocysts. G) An agouti animal (marked by arrowhead) is a progeny of an iGmnn ESC-derived chimeric female and a black male. 
Next, the efficiency of the recombination of the floxed allele with tamoxifen was tested. The iGmnn ESCs, cultured in ES-CM, were treated with 4-hydroxyl tamoxifen. At different time points, the cells were harvested and analyzed for genomic recombination and the loss of Geminin protein. Genotyping PCR revealed $80 \%$ recombination as soon as 24 hours of tamoxifen exposure increasing by the length of the exposure (Fig. 11A). Western blot analysis of the whole cell protein extracts revealed $90 \%$ loss of Geminin protein after $48 \mathrm{~h}$ of tamoxifen treatment increasing to more than $95 \%$ at $96 \mathrm{~h}$ (Fig. 11B).

A

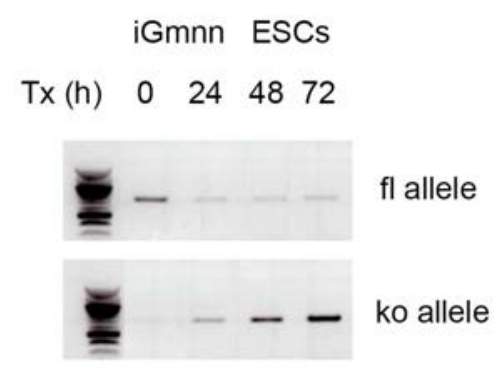

B

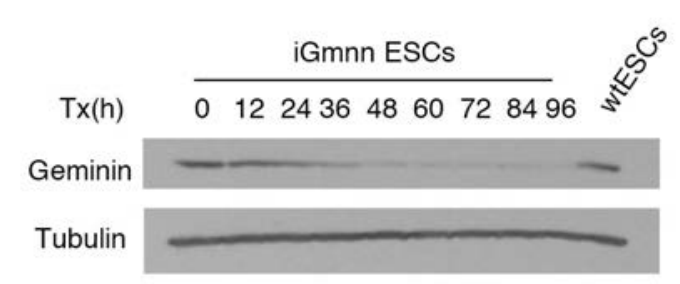

Figure 11. iGmnn ESCs lose Geminin upon tamoxifen treatment.

\begin{abstract}
A) iGmnn ESCs were cultured for 72 hours in ES-CM and were treated for different periods of time with tamoxifen. The genomic DNA was extracted and genotyped. Different combinations of primers in separate reactions were used to amplify the floxed and recombined knockout alleles. The same amount of genomic DNA was used for each reaction. B) iGmnn ESCs were cultured for 96 hours in ES-CM, and were treated for different time periods with tamoxifen. The whole cell lysates were harvested and analyzed by western blotting.
\end{abstract}




\subsection{Geminin is necessary for the self-renewal of the ESCs}

To investigate the role of the Geminin, the iGmnn ESC, cultured in ES-CM were treated with tamoxifen. After $48 \mathrm{~h}$, the cells were trypsinized and plated on feeder-coated plates in ES-CM. After a few days, the formed colonies were subcloned and expanded. $21.3 \%$ of the formed colonies (29/136) were nonrecombined $\mathrm{Gmnn}^{f / f t}$ and in $78.7 \%$ of them (107/131) one allele was recombined but no colony exhibited the complete recombination of both alleles (Fig. 12A).

A
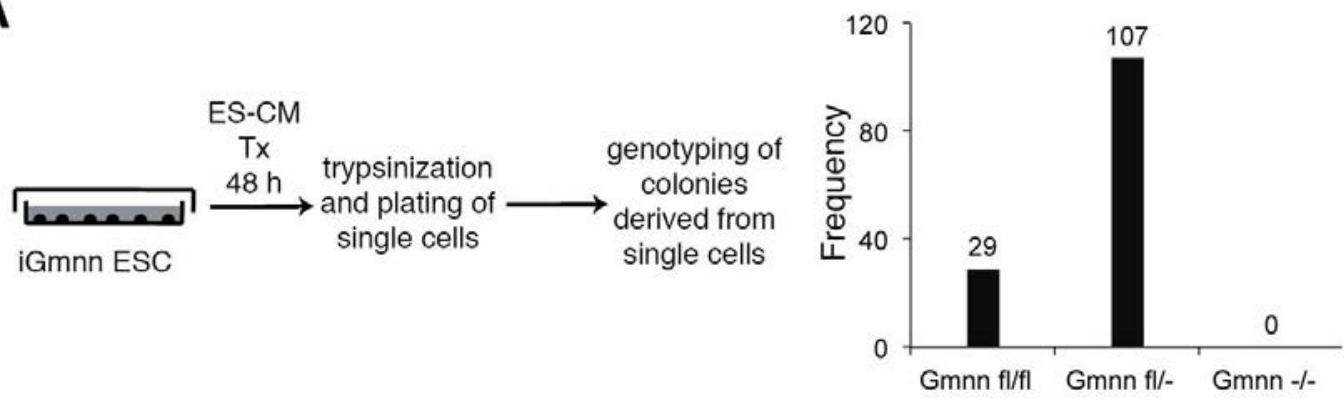

B
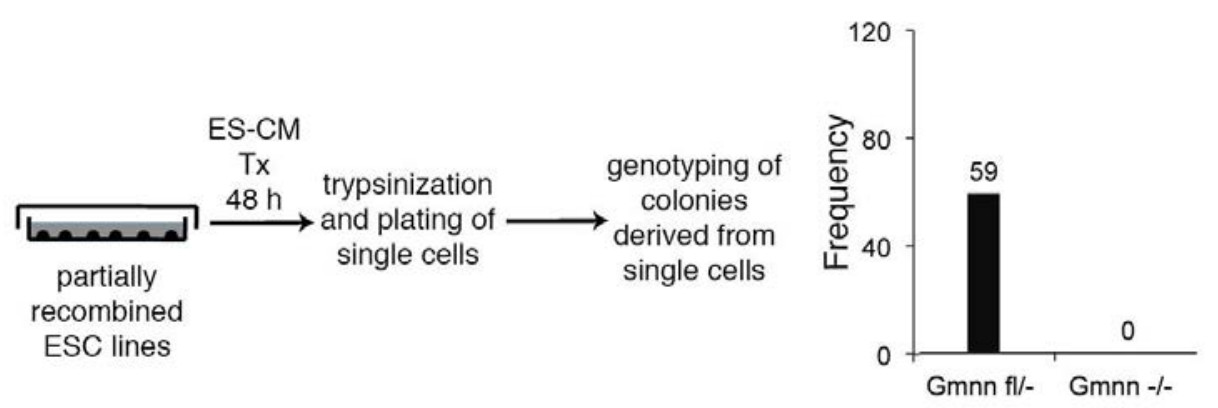

Figure 12. Geminin is essential for the self-renewal of ESCs.

A) iGmnn ESCs were treated with tamoxifen and were trypsinized into single cells. The cells were grown on feeder-coated plates in order to give rise to single-cell derived colonies. These colonies were expanded and their genomic DNA was extracted. Genomic DNA samples from the grown ESC colonies were analyzed by genotyping PCR. B) Three partially recombined Gmnn ${ }^{\text {fl/- }}$ colonies were re-exposed to tamoxifen and trypsinized into single cells. The cells were grown to give rise to single-cell derived colonies. These colonies were expanded and genotyped by PCR. 
This led to the conclusion that Geminin is necessary for the self-renewal of the pluripotent ESCs. To exclude the possibility of incomplete recombination we treated 3 of heterozygous $G m n n^{\mathrm{fl} / \mathrm{-}}$ formed colonies with tamoxifen once more. The cells were trypsinized onto single cells and the single cells were plated in order to form colonies. Genotyping of 59 new colonies revealed that these colonies were all $\mathrm{Gmnn}^{\mathrm{fl} /-}$ and no $\mathrm{Gmnn}^{-/}$ESC lines were formed (Fig. 12B). These data indicated that although recombination efficiency is more than $80 \%$ after $48 \mathrm{~h}$ of tamoxifen treatment (Fig. 11) but the Geminin deficient cells are unable to self-renew and form colonies.

\subsection{ESCs lose pluripotency markers upon loss of Geminin}

Lack of Geminin causes ESCs to lose their self-renewal ability. However, it was unclear what happens to the Geminin deficient ESCs. Do they undergo a cell cycle arrest, or they differentiate and lose their pluripotent state?

The iGmnn ESC were treated with tamoxifen for $48 \mathrm{~h}$ (iGmnn/48hTx) in the ES$\mathrm{CM}$ on the feeder layer (Fig. 13A). $48 \mathrm{~h}$ treatment is enough to efficiently recombine the genomic loci and abrogate the protein expression while the cells are not passaged or re-plated, thus the fate of the Geminin deficient cells can be determined. The iGmnn/48hTx cultures were stained for the alkaline phosphatase activity and were compared to the iGmnn cultures. Alkaline phosphatase activity is high in pluripotent cells, and it diminishes upon differentiation, therefore, it distinguishes the dome-shaped dark-blue undifferentiated from flattened light-blue differentiated colonies. After tamoxifen treatment, colonies were morphologically categorized either as differentiated (Fig. 13B: shown by white arrowheads) or ES-like undifferentiated (shown by black arrowheads). Quantification of colonies depicted a dramatic increase in the number of differentiated colonies after tamoxifen treatment. It seems that loss of Geminin triggers the differentiation of ESCs. Therefore, although the culture medium provides the signals necessary for the maintenance of the pluripotent state the recombined cells are not pluripotent anymore. In addition, after 
tamoxifen treatment the number of formed colonies reduced slightly (Fig. 13B). Immunostaining of Geminin confirmed that there is a mutual relationship between Geminin expression and the ESC-like colony morphology. In the iGmnn/48hTx cultures the few remaining Geminin positive colonies showed a dome-shaped ES-llike morphology and all the colonies with the flattened differentiated morphology were not stained for Geminin. Additionally, this staining revealed that the few remaining undifferentiated colonies in the tamoxifen treated cultures are the unrecombined colonies (Fig. 13C).

Quantitative RT-PCR analysis of the iGmnn/48hTx and iGmnn/72hTx ESCs showed a down-regulatation of Geminin as measured by two different primer pairs. In addition, Geminin inactivation abolishes the expression of pluripotency markers such as Nanog, Zfp42, and Sox2 (Fig. 13D). Notably however, in the iGmnn/48hTx, Oct4 levels remained as high as its levels in pluripotent cells.

Same results were observed when cells were stained for Oct4, Sox2 and Nanog protein (Fig. 13E). In contrast to the packed dome-shaped morphology of the pluripotent colonies the tamoxifen treated cells exhibit the flattened morphology. Colonies are flattened and dispersed, and the cells resemble differentiated cells. The cells are depleted from Sox 2 and Nanog, however, they express Oct4 at a level similar to the untreated pluripotent cells. 
Results 39

A

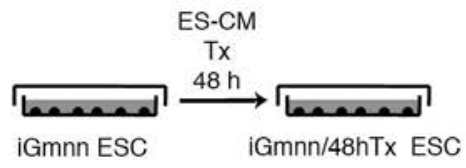

B

C
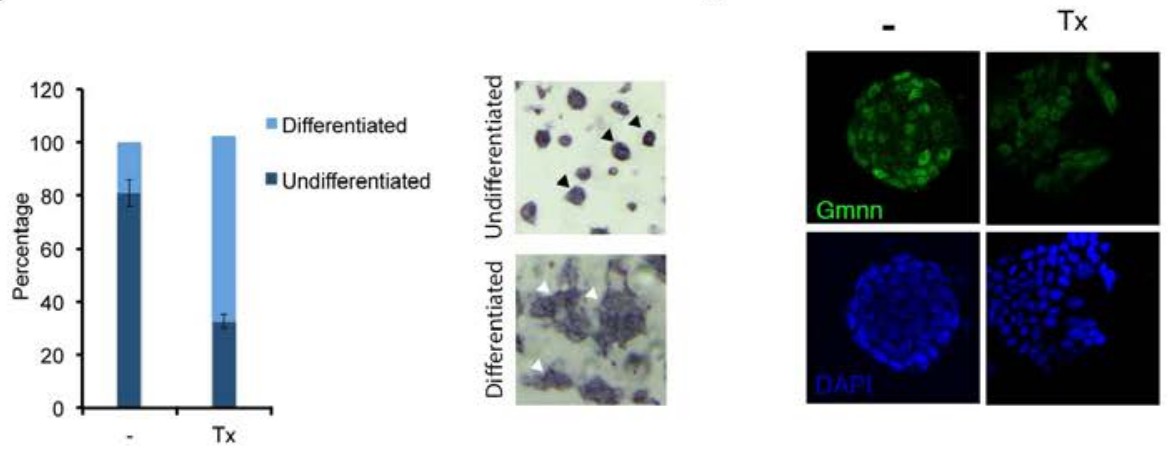

D

E
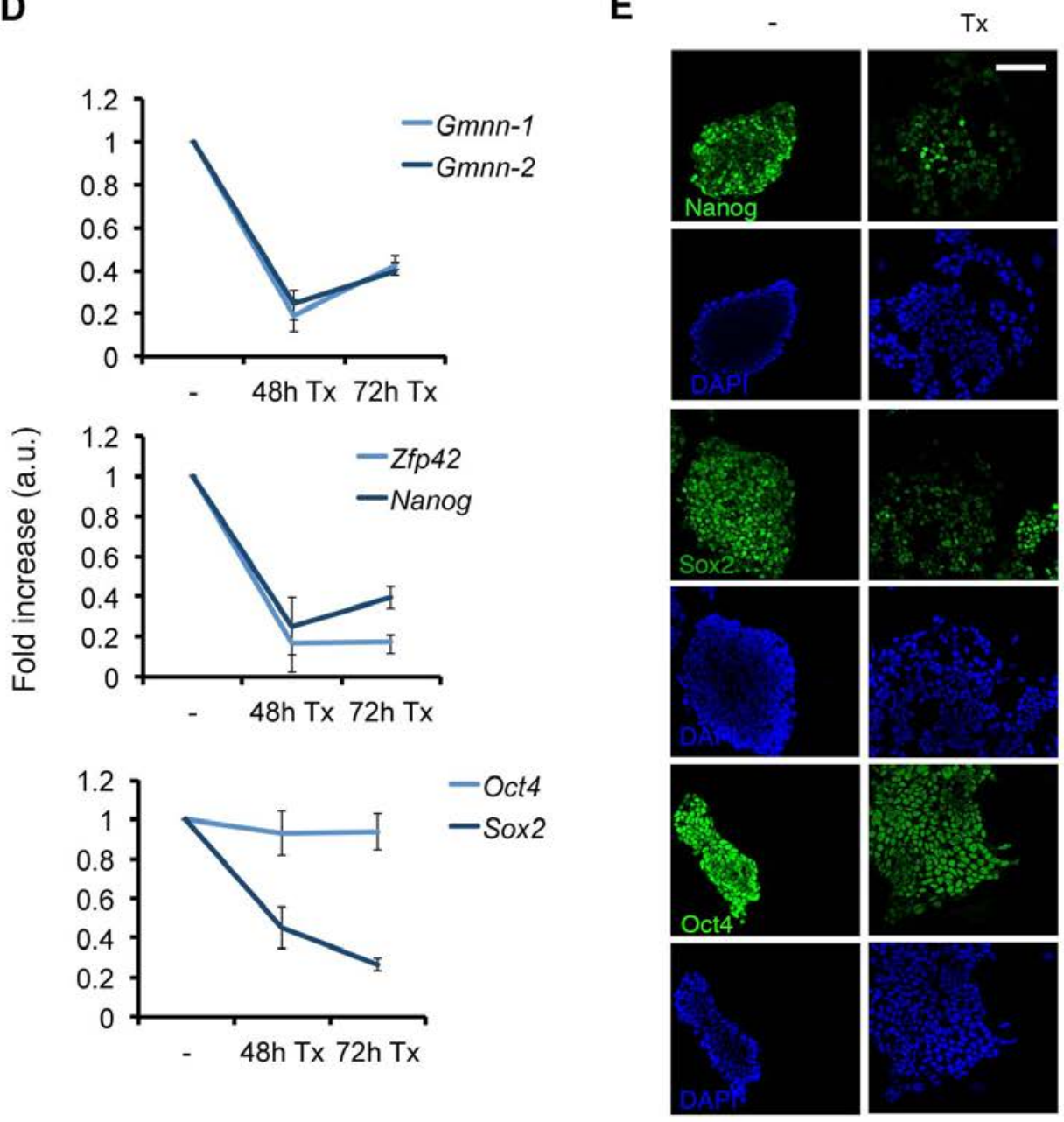
Figure 13. Geminin is essential for the pluripotent state of ESCs.

\begin{abstract}
A) iGmnn ESCs were treated with tamoxifen for 48h (iGmnn/48hTx). B) iGmnn ESCs were stained for Alkaline Phosphatase activity. The colonies were quantified according to their AP staining and morphology. On the right side, the two bright field images of AP-stained ESC colonies show examples of undifferentiated (black arrow heads) and differentiated (white arrow heads) colonies. C) iGmnn ESCs immunostained for Geminin. D) iGmnn ESCs were harvested for RNA extraction and mRNA was analyzed by quantitative RT-PCR. E) iGmnn ESCs were treated with tamoxifen for $48 \mathrm{~h}$ and immunostained for pluripotency markers. The white bar represents $100 \mu \mathrm{m}$.
\end{abstract}




\subsection{Geminin knockout cells exhibit a slightly lengthened G1 phase}

iGmnn/48hTx cells showed a differentiated morphology and loss of pluripotency transcription factor network. However, it was interesting to see if these cells undergo a cell cycle arrest or exhibit cell cycle perturbations. In order to investigate their cell cycle distribution, cells were cultured on gelatin-coated plates in the absence of feeder cells. After tamoxifen treatment the cells were trypsinized and harvested for flow cytometry. DNA content of the cells was visualized with propidium iodide and the cell cycle distributions of the cells were graphed (Fig. 14). Analysis of flow cytometry data detected a slight increase in the number of $\mathrm{G} 1$ phase cells (25\% to $28 \%$ ) at the expense of $\mathrm{G} 2 / \mathrm{M}$ phase. However, there were no evidences for cell cycle arrest in iGmnn/48hTx cells. These cells proliferate slightly slower (Data not shown) which may indicate that their cell cycle is longer than iGmnn cells.
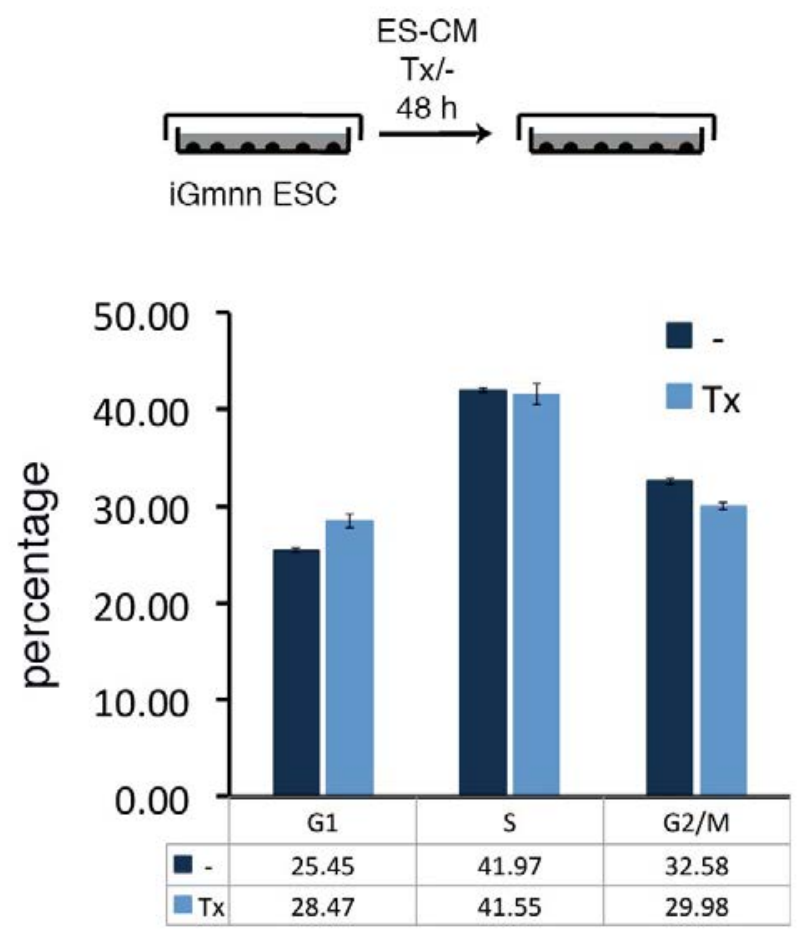

Figure 14. Geminin deficient ESCs possess a lengthened cell cycle.

iGmnn ESCs were treated with tamoxifen for $48 \mathrm{~h}$ and prepared for flow cytometry of DNA content. The chart represents the cell cycle distribution of the cells. 


\subsection{Geminin is necessary for commitment to the neural lineage}

Geminin was necessary for the self-renewal of the pluripotent cells and, lack of Geminin would cause the ESC to differentiate. However, it was interesting to know whether lack of Geminin would affect the differentiation of the ESC. In order to investigate this, the cells were plated on the gelatin-coated plates in differentiation medium, which allows the cells to differentiate and does not support the self-renewal of pluripotent cells. After $96 \mathrm{~h}$ the iGmnn/96hTx and iGmnn cells were immunostained for mesendoderm progenitor marker, Oct4, and the neuroectoderm progenitor marker, Sox2 (Fig. 15A).

A

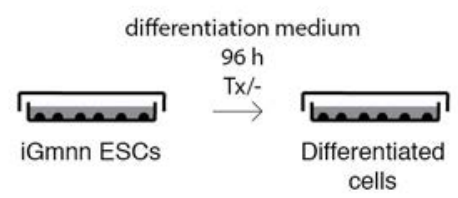

B

C
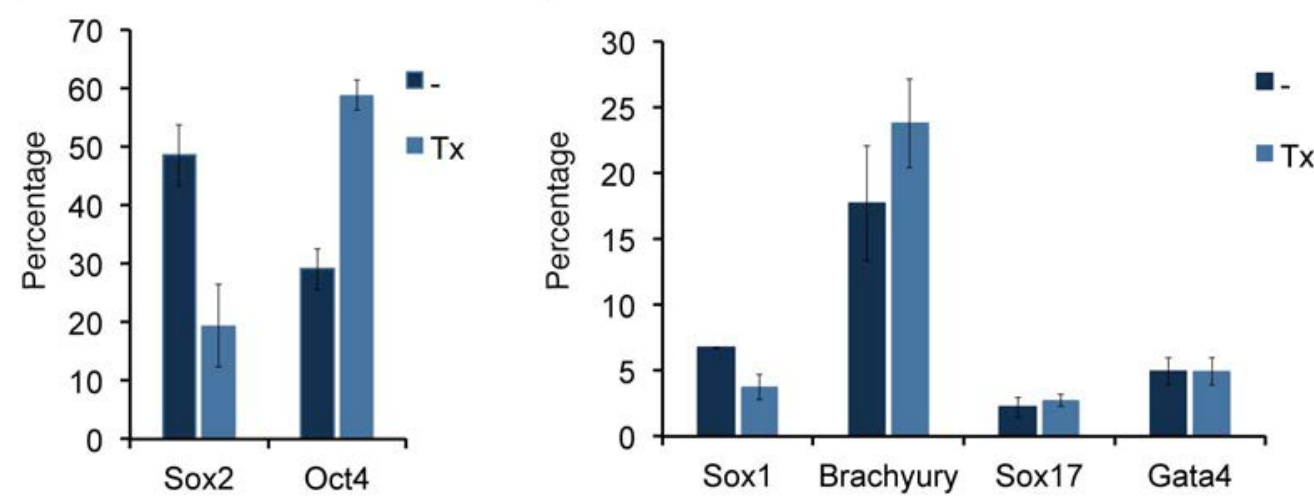

Figure 15. Geminin deficient ESCs give rise to less Sox2 positive neuroectoderm progenitors.

A) iGmnn ESCs were differentiated in the differentiation medium and treated with tamoxifen for 4 days. B) The differentiated ESCs were immuno-stained for Sox2 and Oct4 and quantified. C) The differentiated ESCs were immuno-stained for differentiation markers and quantified (Sox1: neural lineage, Brachyury: mesoderm, Sox17: Endoderm, Gata4: primitive endoderm).

Quantification of the stained cells revealed that tamoxifen treatment caused a statistically significant ( $p$-value $=0.0152$ ) increase in the number of the Oct4 positive cells accompanied with a significant ( $p$-value $=0.0109$ ) decrease in the 
number of Sox2 positive cells (Fig. 15B). In conclusion, Geminin deficient ESCs lost their Sox2 expression but not their Oct4 expression. Thus these cells tend to differentiate to mesendoderm rather than neuroectoderm. Next, the differentiated cultures were stained for Sox1, Brachyury, Sox17 and Gata4, markers for neural lineage, mesendoderm, endoderm and primitive endoderm respectively. Correspondingly, an increase in the Brachyury positive cells but no change in the number of other cell types was observed (Fig. 15C).

Additionally the ability of the cells to differentiate specifically into neural lineage was tested. The cells were plated in a low density on gelatin-coated plates in a chemically defined default medium (DDM) and were differentiated for 12 days (ref). Low density would abrogate the autonomous signaling and absence of serum and particularly BMP factors would let the intrinsic pathways of neural induction to be activated. ESCs would first differentiate into neural progenitors, which later give rise to neuronal progenitors. After 12 days the neuronal progenitors were re-plated onto laminin/poly-L-ornithine plates in N2B27 medium to give rise to neurons, oligodendrocytes and astrocytes (Fig. 16A). Immunofluorescence staining of the cells illustrated this gradual commitment and specification in iGmnn ESCs (Fig. 16B). At day 0 the undifferentiated ESCs express oct4 and E-cadherin. During the course of differentiation the colonies expand and epiblast like cells form. These cells still express many pluripotency markers such as Oct4 and SSEA1. At day 5, early neural progenitors are already formed and can be detected with Pax6 and Sox1 expression. Later these neural progenitors give rise to neuronal progenitors and neurons, detected with nestin and Tuj1 expression. After the neurogenesis has taken place, several astrocytes marked by GFAP expression arise in the cultures. 
A

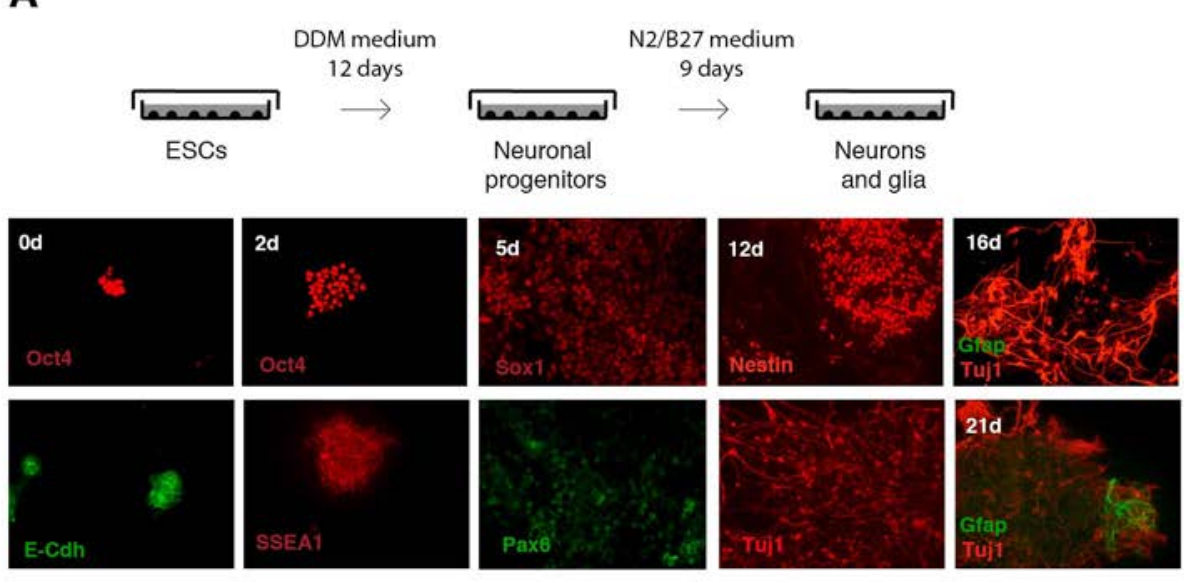

B

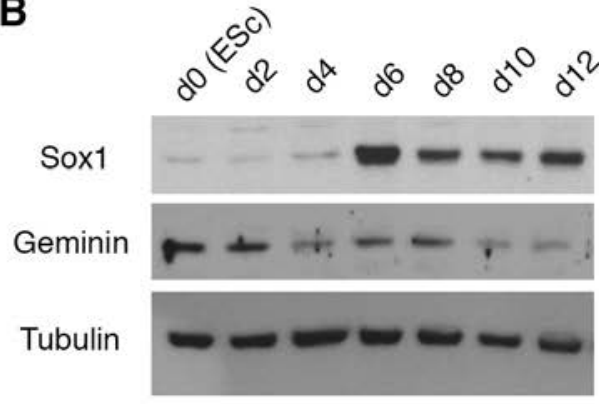

C
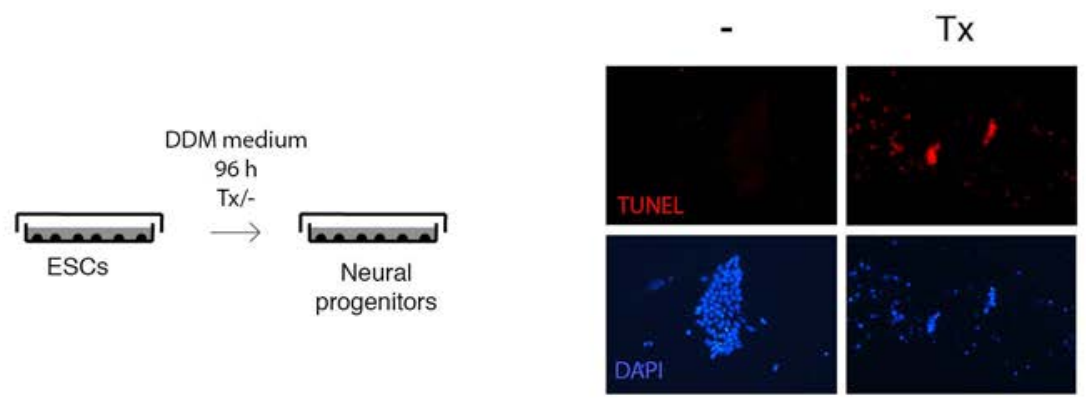

Figure 16. Geminin is necessary for the differentiation of ESCs to the neural lineage.

A) iGmnn ESCs were cultured in feeder free conditions and were plated on gelatin-coated dishes in DDM medium for 12 days, and then re-plated into poly-L-lysine and laminin coated plates in N2B27 to further differentiate. Immunostaining of pluripotency markers (Oct4, E-cadherin, SSEA1), neural markers (Pax6, Nestin and Sox1), neuronal marker (Tuj1) and astrocyte marker (GFAP) at different time points is shown. B) iGmnn ESCs were differentiated for only 12 days as described. Whole cell protein was harvested every $48 \mathrm{~h}$ and immunobloted for Geminin and Sox1 controlled by the amounts of a-Tubulin. C) iGmnn ESCs were differentiated to neural lineage in the presence and absence of tamoxifen for 4 days And stained for TUNEL activity. Genomic DNA was stained with DAPI. 
Whole cell protein analysis of these differentiating cells (Fig. 16B) revealed that although during neuronal differentiation, ESCs lose their Geminin levels but the intermediate neural progenitors (D6-D8) still contained Geminin. To investigate the necessity of Geminin expression during neural differentiation, iGmnn ESCs were differentiated specifically toward neural lineage and were treated with tamoxifen. Analysis of the 4 days old differentiated neural progenitors revealed that upon tamoxifen treatment apoptosis is highly up-regulated causing a population-wide cell loss (Fig. 16C). In summary, Geminin deficient cells cannot give rise to neural lineage and undergo apoptosis in the neural specification conditions.

\subsection{Geminin regulates Sox2 expression through chromatin remodeling complexes}

Previous data indicated that Geminin deficient cells lose their Sox2 expression. To investigate this regulation, the epigenetic signature of Sox2 and Oct4 genes was analyzed by chromatin immunoprecipitations (ChIPs). Cells were cultured on gelatin-coated dishes and were treated with tamoxifen. Then the cross-linked chromatin was precipitated for known regulatory chromatin modifications such as histone 4 lysine 9 di-methylation (H4K9me2), histone 4 hyperacetylation (H4ac) and histone 3 lysine 27 tri-methylation (H3K27me3) and in addition anti-histone 3 antibody was used as a positive control for the chromatin immunoprecipitation. After precipitations the DNA was extracted and analyzed by qPCR, for the presence of DNA representing previously described Sox2 and Oct4 enhancers. Sox2 and Oct4 are mainly regulated through their enhancer sequences during early mouse development and in vitro differentiation. The extracted precipitated DNA was analyzed for the abundance of regulatory epigenetic signals on Sox2 and Oct4 stem cell regulated enhancer regions (Fig. 17A). 
A

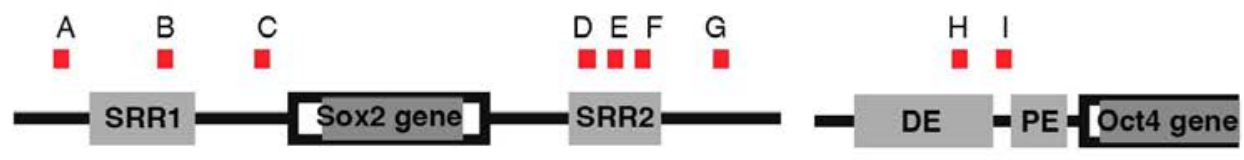

B

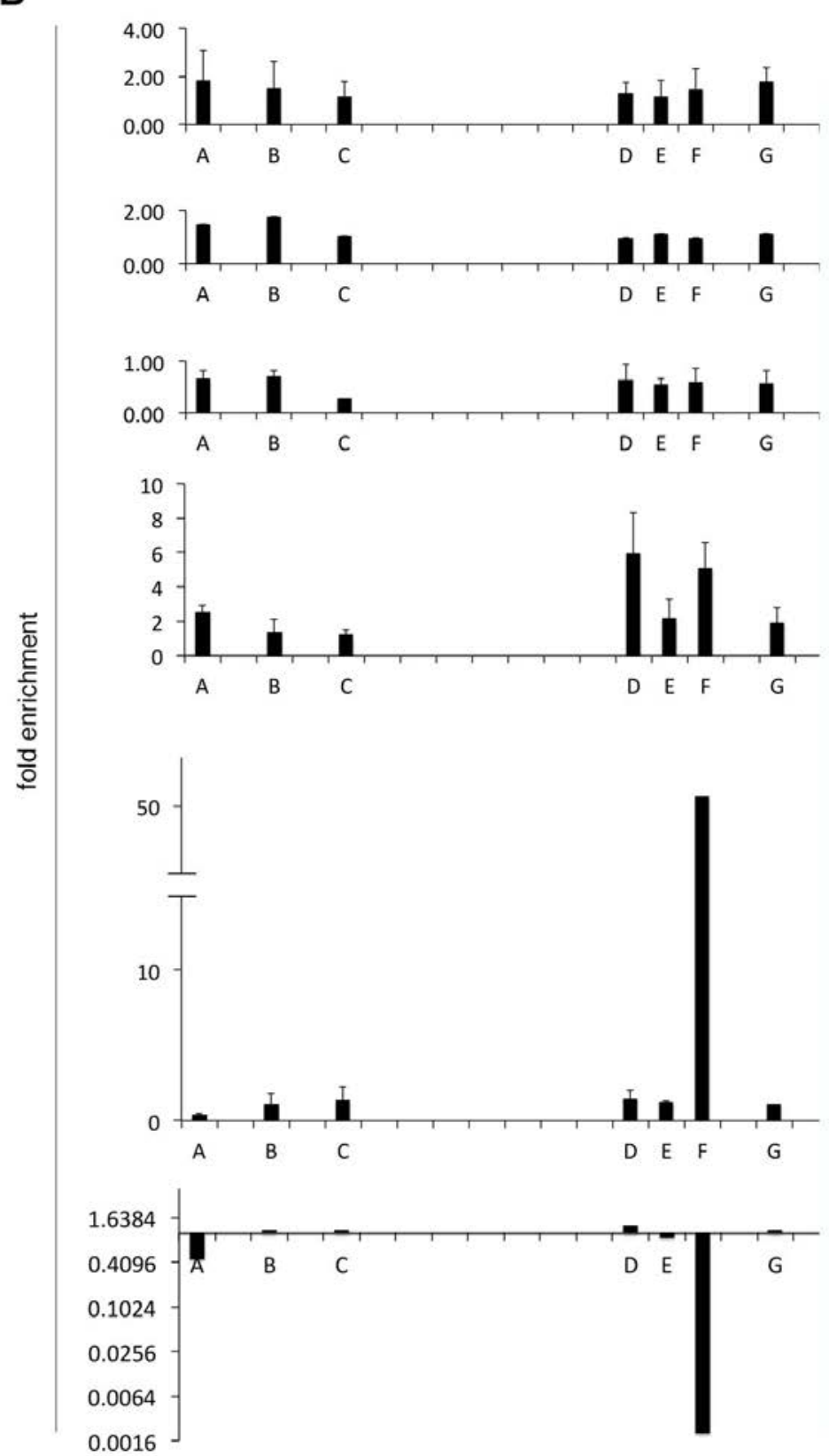

Histone 3

Histone $3 \mathrm{~K} 4 \mathrm{me} 2$

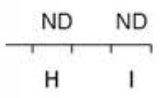

Histone 4Ac

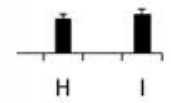

Histone 3 K27me3

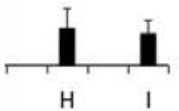

Ezh2

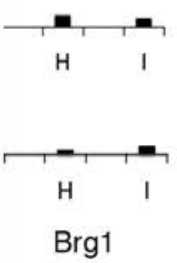


Figure 17. Chromatin immunoprecipitations on regulatory regions of Sox2 and Oct4.

A) Genomic loci of sox2 and Oct4 gene. Analyzed fragments of the DNA have been marked with red bars and capital letters (A-I)(SRR1: stem cell regulatory region $1^{112}$, SRR2: stem cell regulatory region $2^{112}$, DE: Oct4 distal enhancer region ${ }^{113}$, PE: Oct4 proximal enhancer region ${ }^{114}$ ). B) Precipitated DNA was analyzed by q-PCR for the regions A-I. The charts represent the relative changes in the modifications upon tamoxifen treatment (histone 4 lysine 9 di-methylation (H4K9me2), histone 4 hyperacetylation ( $\mathrm{H} 4 \mathrm{ac})$ and histone 3 lysine 27 tri-methylation (H3K27me3), PRC2 complex (EZH2) and SWI/SNF complex (BRG1)).

The data indicated that although the total histone 3 shows an increase in all the analyzed regions the activating signal, histone4 acetylation, and the inactivating signal, Histone 43 lysine 4 di-methylation, did not significantly change upon tamoxifen treatment. However, H3k27me3 ChIP represented a different pattern. While abundances of Histone 3 lysine 27 tri-methylation was not significantly different on the Oct4 enhancer (regions $\mathrm{H}$ and $\mathrm{I}$ ) and regions $\mathrm{A}-\mathrm{C}$ and $\mathrm{G}$ of the Sox2 gene, it showed a significant increase on the Stem cell regulatory region 2 (SRR2) enhancer ${ }^{112}$ (regions D-F). Polycomb repressive complex 2 is responsible for tri-methylation of the 27th lysine residue of the histone 3 . According to the increase in H3K27me3 modifications, the amount of bound Ezh2 protein, which is the catalytic subunit of the PRC2 complex, increased on the same regions especially on region F. PRC2 complex and SWI/SNF complex compete with each other on the pluripotency genes. Therefore, it was of interest to investigate the changes on the abundances of SWI/SNF complex on the enhancer regions of Sox2 and Oct4. Data indicated that Brg1, the core component of SWI/SNF complex dissociates from the SRR2 in tamoxifen treated cells. 


\subsection{Geminin is redundant in mouse embryonic fibroblasts}

In order to study the role of Geminin in somatic cells, mouse embryonic fibroblasts (MEFs) were prepared from E13.5 embryos. The conditional knockout mouse were bred to the tamoxifen inducible Cre line and $\mathrm{Gmnh}^{f /+}$ ER-Cre ${ }^{+}$ progeny were bred to $\mathrm{Gmnn} n^{\text {fl/f }}$ mice to give rise to embryos (Fig. 18A).

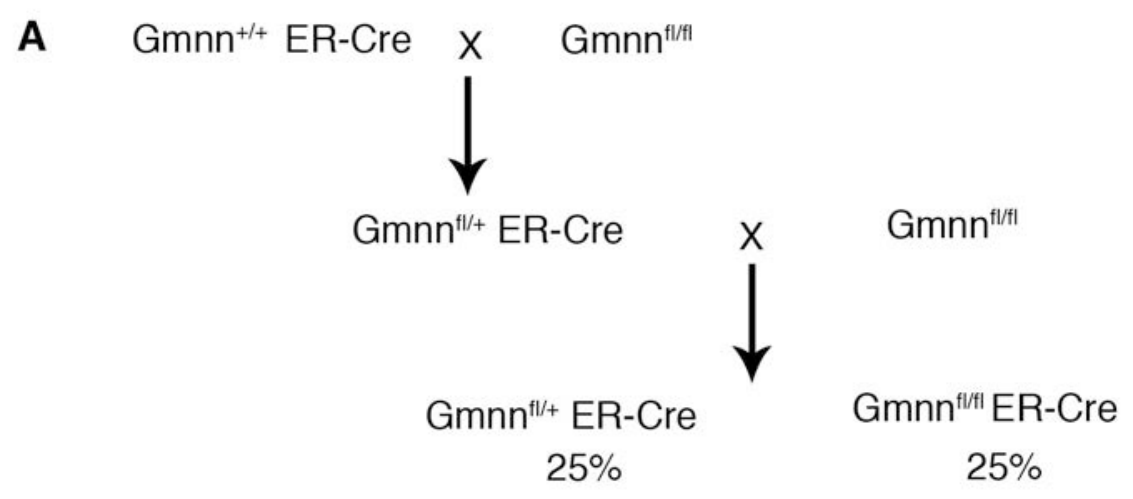

B

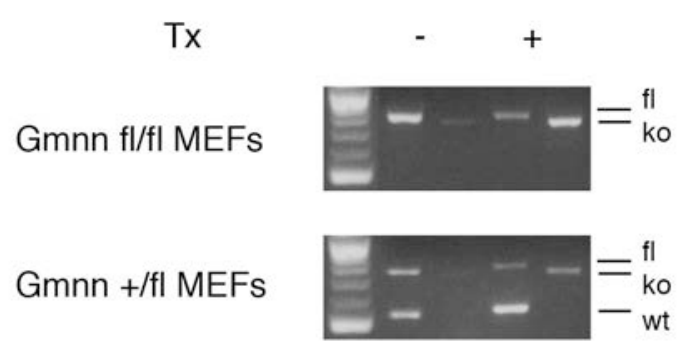

C

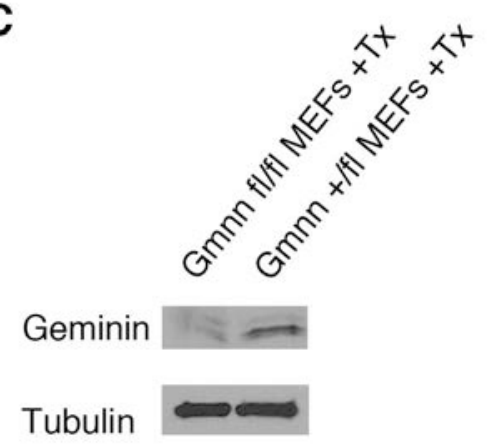

Figure 18. Inactivation of Geminin in mouse embryonic fibroblasts.

A) mating scheme for preparation of $\mathrm{Gmnn}^{\mathrm{fl} / \mathrm{fl}}$ ER1-Cre and Gmnn ${ }^{\mathrm{fl} /+}$ ER-Cre embryos. B) $\mathrm{Gmnn}{ }^{\mathrm{fl} / f l}$ ER1-Cre and Gmnn ${ }^{\mathrm{fl} /+}$ ER1-Cre MEFs were treated with tamoxifen for 48 hours. Genomic DNA was extracted and the efficiency of recombination was investigated by genotyping PCR with specific primers for each allele. Same amount of genomic DNA was used for each PCR reaction. C) Gmnn ${ }^{\text {fl/fl }}$ ER1-Cre and Gmnn ${ }^{\mathrm{fl} /+}$ ER1-Cre MEFs were treated with tamoxifen for 48 hours. Whole cell lysate was run on the SDS-PAGE gels and Geminin was immunobloted. The amount of loaded protein was controlled by Tubulin. 


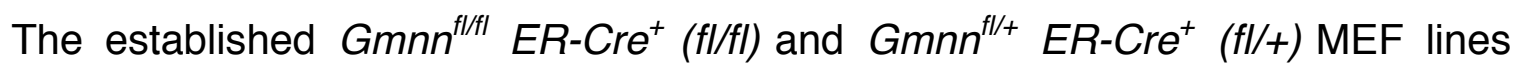
underwent recombination efficiently upon tamoxifen treatments as short as $48 \mathrm{~h}$. The loss of Geminin in MEFs was investigated by genotyping PCR (Fig. 18B). In the absence of tamoxifen, trace amounts of knockout allele were detectable probably due to basal activity of inducible Cre recombinase. Upon 48 hours of tamoxifen treatment a decrease in the amount of floxed allele and an increase in the knockout alleles was evident. Western blot analysis of tamoxifen treated MEFs revealed down-regulation of the Geminin protein in flff MEFs (Fig. 18C). Further analysis of these tamoxifen treated fibroblasts did not show any significant difference between the $f / f l$ and the $f l /+$ MEF cultures. Cells were stained for well-known cell cycle markers and the abundances of positive cells were calculated as percentage of the total population. Cyclin D1 is present during the $\mathrm{G} 1$ phase, cyclin $A 2$ increases during $S$ phase and $\mathrm{G} 2$ phase and cyclinB1 can be found in the nuclei during $G 2$ and in the cytoplasm during $M$ phase. $f / f l$ MEFs contained same number of positive cells for each marker depicting that Geminin knockout can not induce any cell cycle arrest in these cells (Fig. 19A). Ki67, a marker for proliferating cells, were found in the normal amounts in the fl/fl MEFs indicating that the knockout cells are proliferating with a rate comparable to the $f l /+$ cells (Fig. 19B).

fl/fl cells possessed comparable number of cells undergoing mitosis, marked by phosphorylated histone $3(\mathrm{pH} 3)$, and the same number of cells in the $\mathrm{S}$ phase labeled with a 4h Bromodeoxyuridine (BrdU) pulse (Fig. 19D). In addition, TUNEL staining indicated no significant increase in the apoptotic cells (Fig. 19E) and flow cytometric analysis of the PI stained cells revealed no cell cycle aberrations (Fig. 19F). Accordingly, the knockout MEFs proliferated with a rate comparable to $\mathrm{fl} /+$ cells and contained no cell cycle aberrations. 
Results 50
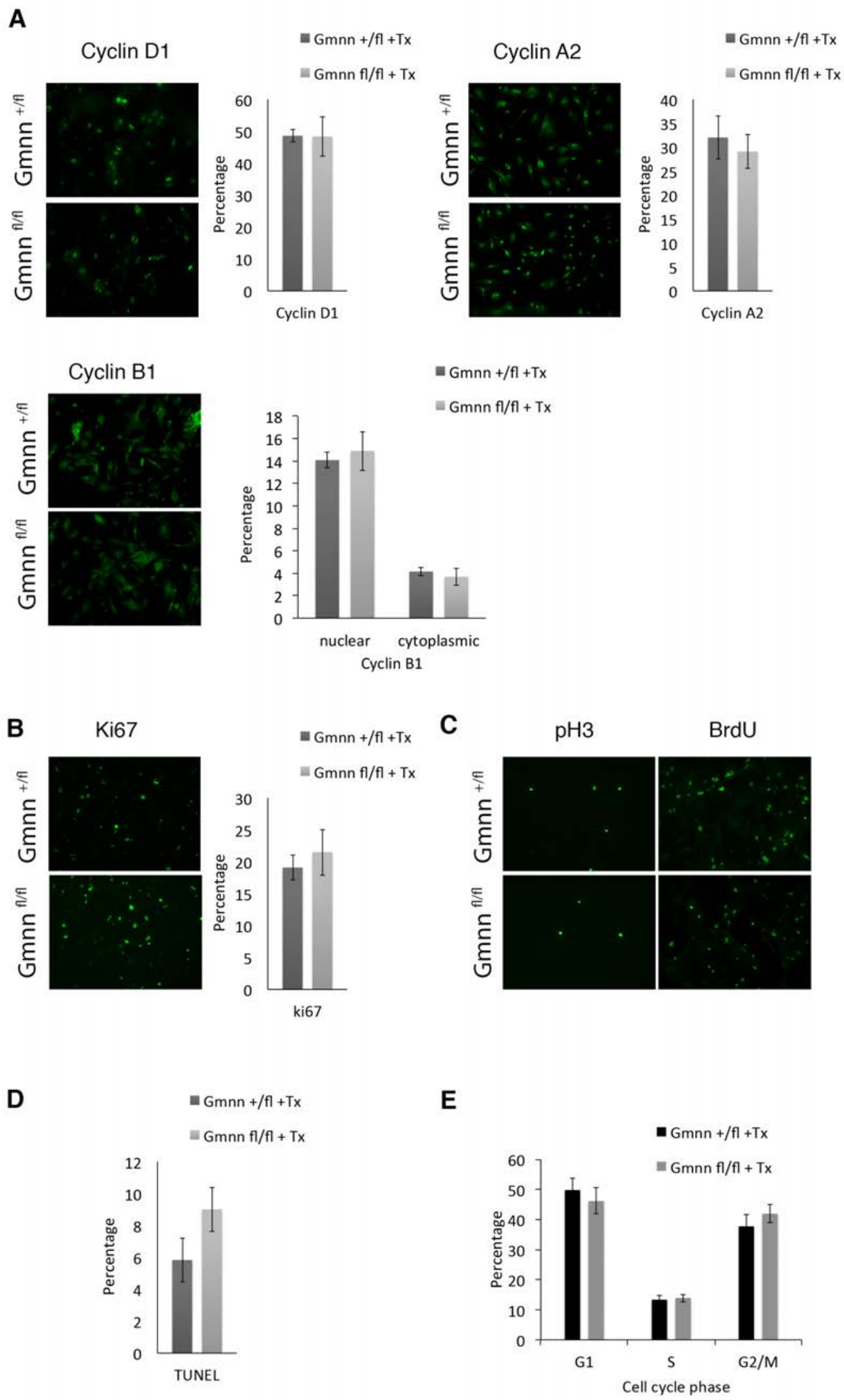
Figure 19. Loss of Geminin does not cause cell cycle abberations or apoptosis in MEFs.

\begin{abstract}
A) $\mathrm{fl} /+$ and $\mathrm{fl} / \mathrm{fl}$ MEFs were treated with tamoxifen for $48 \mathrm{~h}$ and immuno-stained for cyclins. Cells were counted and abundances were calculated relative to total number of the cells. B) $\mathrm{fl} /+$ and fl/fl MEFs were treated with tamoxifen for 48 hours and immuno-stained for Ki67, a marker for proliferating cells. Cells were counted and abundances were calculated relative to total number of the cells. C) $\mathrm{fl} /+$ and $\mathrm{fl} / \mathrm{fl}$ MEFs were treated with tamoxifen for $48 \mathrm{~h}$ and immuno-stained for phosho-histone 3, the $\mathrm{M}$ phase marker. In addition to tamoxifen MEFs received a $4 \mathrm{~h}$ pulse of $\mathrm{BrdU}$ to label the cells in the S phase and were stained for BrdU in order to visualize the $S$ phase. D) $\mathrm{fl} /+$ and $\mathrm{fl} / \mathrm{fl}$ MEFs were treated with tamoxifen for $48 \mathrm{~h}$ and stained for TUNEL (apoptosis marker). Treated cells were counted in each case and the percentage of positive cells is represented in the graph. E) $\mathrm{fl} /+$ and fl/fl MEFs were treated with tamoxifen for $48 \mathrm{~h}$, and analyzed with flow cytometry.
\end{abstract}

It appears that Geminin is redundant in MEFs and additional regulators such as cyclin A2 regulate the fidelity of DNA replication. Interestingly cyclin A2 knockout does not alter the cell cycle of the fibroblasts too. To investigate the cell cycle progression of the fibroblasts in the absence of both Geminin and cyclin A2, the MEFs were transfected with anti-cyclin A2 siRNA. It was hypothesized that this dual inactivation would challenge their ability to regulate the precision of their replication. Western blot analysis of transfected cells confirmed a high knockdown efficiency in MEFs transfected with cyclin A2 siRNA (Fig. 20A). Next $\mathrm{fl} /+$ and $\mathrm{fl} / \mathrm{fl}$ cells were transfected with anti-cyclin A2 siRNA and received tamoxifen treatment simultaneously. Flow cytometeric analysis of the PI-stained knockout and control cells revealed no significant difference in the distribution of the cells in different phases of the cell cycle (Fig. 20B). 
A

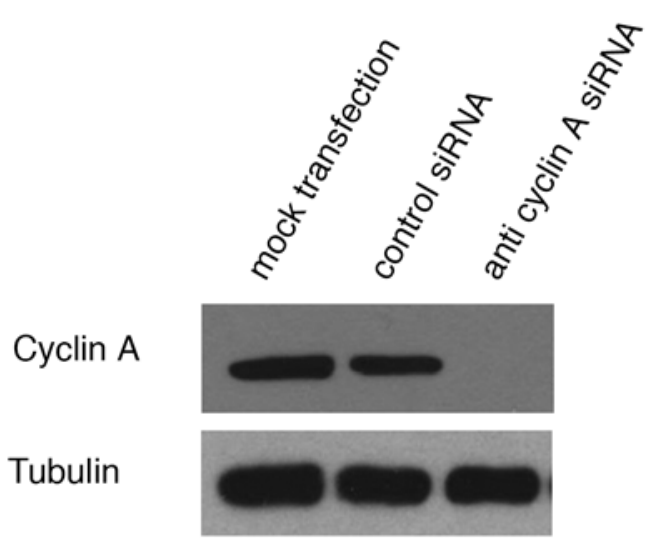

B

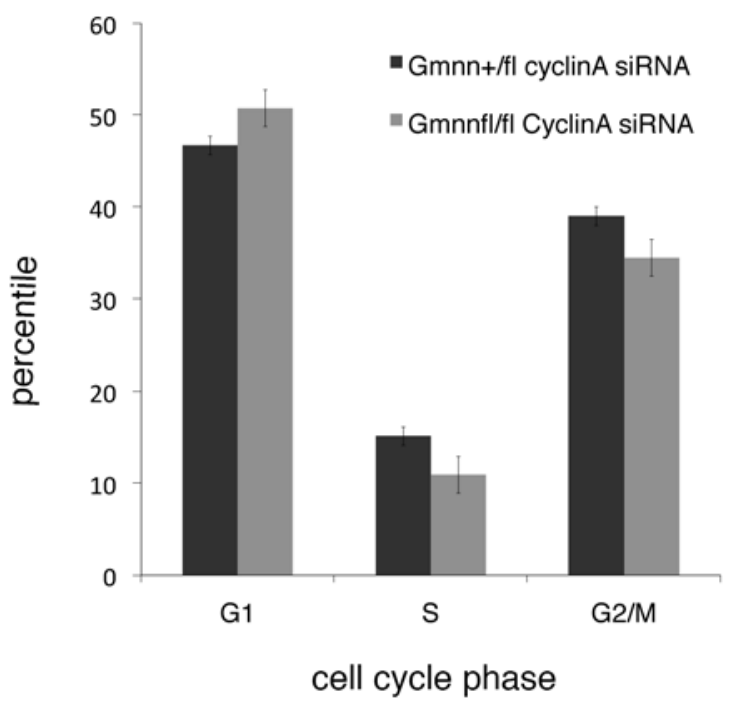

Figure 20. Concurrent loss of Geminin and cyclin A can be compensated in MEFs.

A) $\mathrm{fl} /+$ MEFs were transfected with anti-cyclin A2 siRNA or control siRNA using lipofectamine. Cells were harvested; total protein was immune-bloted against cyclin $A 2$ in order to measure the knockdown efficiency. B) $\mathrm{fl} /+$ and $\mathrm{fl} / \mathrm{fl}$ MEFs were treated with tamoxifen and transfected with anti cyclin A2 at the same time, and analyzed with flow cytometry. 


\subsection{Geminin is up-regulated during the reprogramming of MEFs to induced pluripotent stem cells (iPSCs)}

MEFs can be converted into pluripotent cells and the resulting induced pluripotent stem cells (iPSCs) are indistinguishable from ESCs in many aspects. In order to explore the role of Geminin in reprograming, transgenic inducible knockout MEFs were utilized. At first the efficiency of reprogramming was tested in our non-recombined MEFs. Retroviral particles containing Oct4 (O), Sox2 (S), KIF4 $(\mathrm{K})$ and c-Myc $(\mathrm{M})$ were prepared and MEFs were transduced with all four factors (OSKM) or combinations of three factors (OSK or OSM).

A

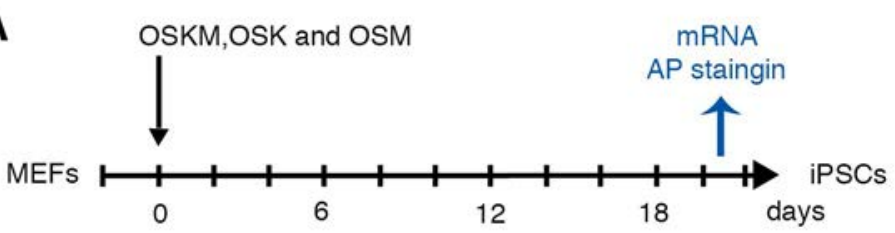

B

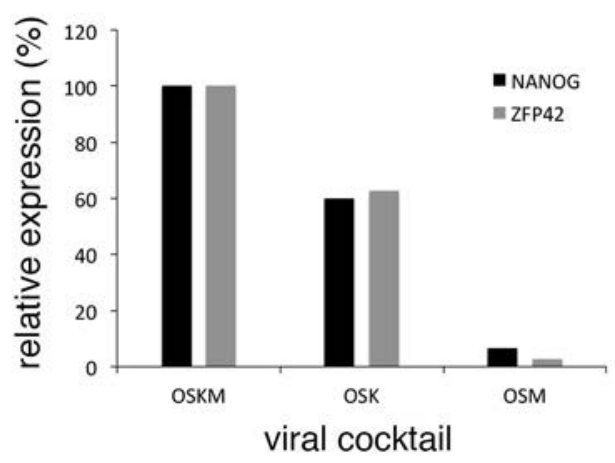

C

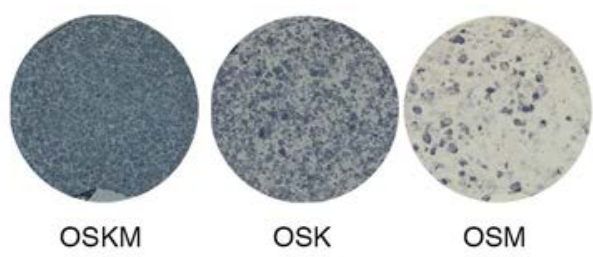

Figure 21. Mouse embryonic fibroblasts can undergo reprogramming upon overexpression of Oct4, Sox2, Klf4 and C-Myc.

A) MEFs were reprogrammed with OSKM (Oct4, Sox2, Klf4 and C-Myc), OSK and OSM viral particles. Transduced plates were cultured for 3 more weeks in order to obtain reprogrammed induced pluripotent stem cells. B) 3 weeks old reprogrammed cultures were harvested for RNA extraction and the pluripotency markers, Nanog and Zfp42 mRNA levels were analyzed by quantitative PCR. C) 3 weeks old reprogrammed MEF cultures were stained for Alkaline Phosphatase activity. 
48 hours after transduction cells were trypsinized and re-plated on the feedercoated plates and cultured for 18-21 days in ES-CM medium (Fig. 21A). Reprogramming efficiencies of different factor combinations were compared by quantitative PCR analysis of two known pluripotency markers and by alkaline phosphatase (AP) staining of the cultures. Cells were harvested and 18 days after transduction, total RNA was extracted and cDNA was reverse transcribed. Relative abundances of nanog and Zfp42 were calculated using quantitative PCR. These two markers are up-regulated upon maintenance of the pluripotent state and, therefore, their levels reflect the efficiency of reprogramming and numbers of formed iPSCs. While OSKM-transduced cultures were most efficiently reprogrammed (100\%), OSK led to about $60 \%$ efficiency of iPSCs production and OSM was capable to give rise to only $5-10 \%$ reprogrammed cells (Fig. 21B). Alkaline phosphatase staining of freshly fixed cultures gave similar results regarding the efficiency of reprogramming (Fig. 21C).

Geminin levels were determined in wild type MEFs, MPI-II ESCs and one established iPSC line (iPSC-37). Whole cell lysates were immuno-blotted for Geminin and an internal control, Tubulin (Fig. 22). Data represents a high elevation (more than 20 times) of Geminin protein in the pluripotent cells.

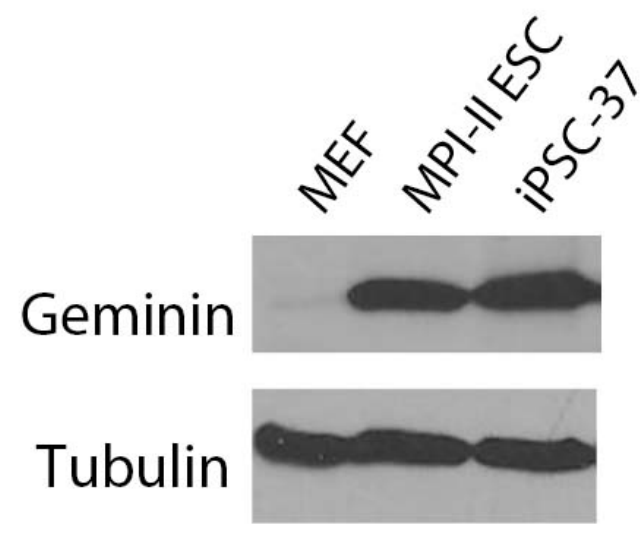

Figure 22. Geminin is up-regulated in the pluripotent cells.

Western blot analysis of MEFs, MPI-II ESCs and iPSC-37 shows up-regulation of Geminin in pluripotent cells. Geminin is present in fibroblasts in a low level, however, it can be visualized (Fig. 18C) 


\subsection{Geminin is indispensible for reprogramming}

The fact that Geminin levels increases in the reprogrammed cells, suggested a role for Geminin in the reprogramming of the somatic fibroblasts. Although Geminin is not necessary for the fibroblast cells, its augmentation on the way toward pluripotent cells may indicate a pivotal role in the reprogramming of the MEF cells. To study that, the established $\mathrm{fl} / \mathrm{fl}$ and $\mathrm{fl} / \mathrm{+} \mathrm{MEF}$ lines were treated with tamoxifen and transduced with OSKM coding viral particles as depicted in Fig.

23.

A

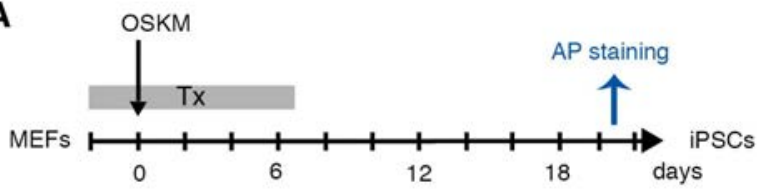

Gmnn +/fl Gmnn fl/fl

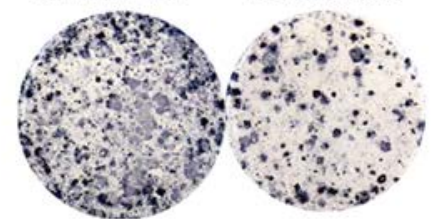

genotyping of iPSCs

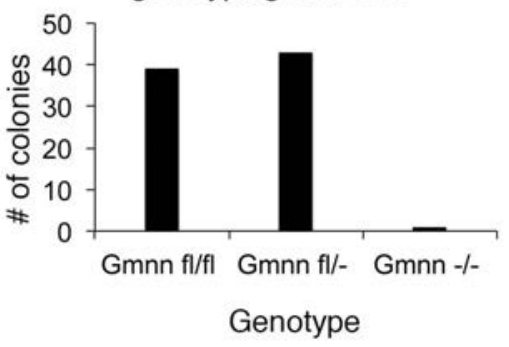

Figure 23. Geminin is necessary for the reprogramming.

A) $\mathrm{fl} /+$ and $\mathrm{fl} / \mathrm{fl}$ MEFs were reprogrammed with OSKM (Oct4, Sox2, KIf4 and C-Myc) viral particles in the presence of tamoxifen. Transduced plates were stained for alkaline phosphatase after 20 days. Data indicates a reduction of colony number in reprogrammed fl/fl cultures. B) Reprogrammed fl/fl MEFs were sub-cloned and genotyped. Lack of -/- colonies (1/83) suggested a role for Geminin in the reprogramming of MEFs. The only homozygous knockout line showed a differentiated morphology and failed to grow further. 
MEFs received tamoxifen and after 48 hours were transduced in the presence of tamoxifen. At day 2 after transduction, cells where re-plated on feeder-coated plates and tamoxifen treatment was continued until day 7. AP staining of plates at 20 days after transduction revealed a strong decrease in the number of stained colonies in fl/fl cultures (Fig. 23), which were picked and expanded individually. Genotyping of formed colonies showed the presence of $G m n n^{f / f t}$ and $G m n n^{f / /+}$ colonies but no $\mathrm{Gmnn}^{-/}$colonies were observed (Fig. 23). Notably, the only $\mathrm{Gmnn}^{-{ }^{-}}$cell line that was cloned, showed differentiated morphology and delayed growth kinetics, and failed to passage further. These data clearly reveal a vital role of Geminin for the induction of pluripotency. However, it remained unclear whether Geminin was necessary for the induction of reprogramming or maintenance of already induced cells.

A

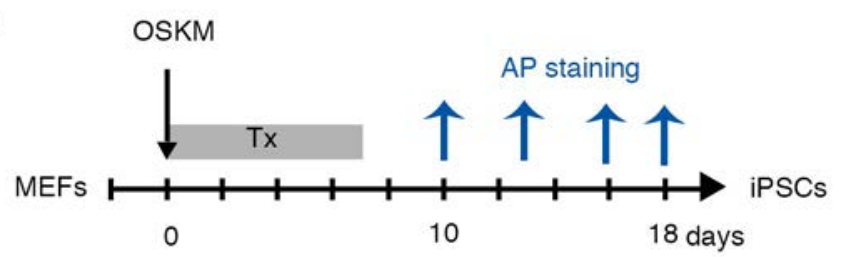

B

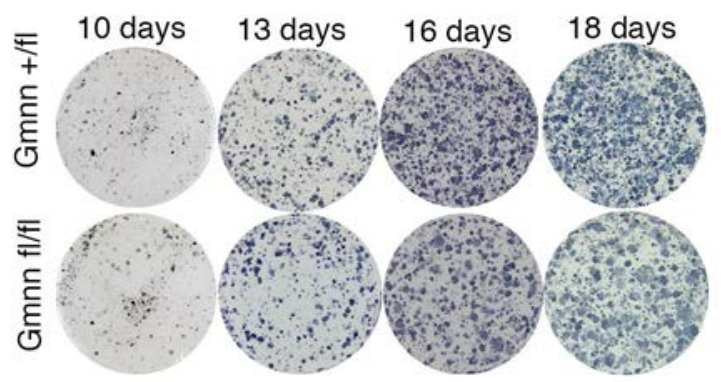

Figure 24. Geminin is necessary for the maintenance of reprogramming.

A) Gmnn ${ }^{f / /}$ ER1-Cre and Gmnn ${ }^{\text {fl/l1 }}$ ER1-Cre MEFs were reprogrammed with OSKM (Oct4, Sox2, Klf4 and C-Myc) viral particles in the presence of tamoxifen. B) Reprogrammed plates were stained for alkaline phosphatase at different time points. 
To investigate this question, inducible knockout and control cells were treated with tamoxifen and reprogrammed as described and then were investigated at different time points (Fig. 23A). The time course alkaline phosphatase staining illustrated that in the absence of Geminin the initial steps of reprogramming are intact, but the number of AP positive colonies is reduced in the fl/fl plates on day 13 and later (Fig. 24B). This observation suggests that Geminin deficient cells can be induced towards pluripotency, but they cannot maintain their pluripotent state.

In order to visualize the proliferating cells, iPSC cultures were treated with BrdU on day 7,11 and 15 after transduction, were fixed on the next day, and the BrdU positive cells were visualized and quantified (Fig. 25B). The graph represents the relative number of BrdU positive cells in $\mathrm{fl} /+$ and $\mathrm{fl} / \mathrm{fl}$ cultures. At day 8 , the number of BrdU positive cells is less among the fl/fl cells however, due to the high standard error the difference is not significant ( $p$-value= 0.7313). At day 12 , the difference between the number of the positive cells in different cultures increased but the differences are not statistically significant. High standard error illustrates a high heterogeneity among different colonies. A few days later, at day 16, the difference between the two cell lines became more evident and statistically significant ( $p$-value $=0.0232$ ). Thus, it was concluded that at earlier stages there is no difference between the numbers of proliferating cells. However, as reprogramming advances, in the $\mathrm{fl} / \mathrm{fl}$ cells the number of proliferating cells reduces and the difference becomes evident at later stages. This observation is consistent with aberrant maintenance of the reprogramming in Geminin deficient cells. 
A

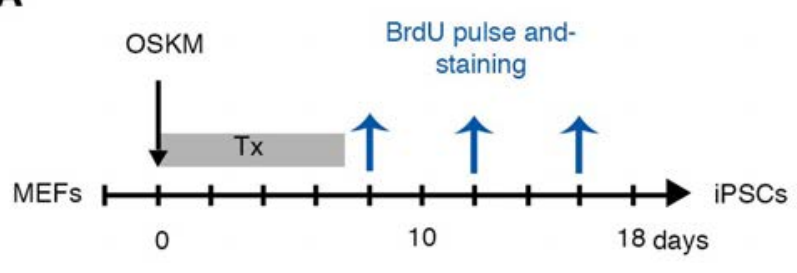

B

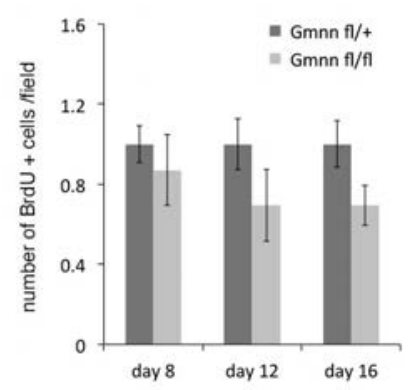

Figure 25. Geminin deficient cells fail to maintain their proliferation.

A) $\mathrm{fl} / \mathrm{fl}$ and $\mathrm{fl} /+$ MEFs were reprogrammed with OSKM (Oct4, Sox2, KIf4 and C-Myc) viral particles in the presence of tamoxifen. At different time points, the transduced plates were treated with BrdU and stained for it. B) The graph represents the number of BrdU incorporated cell per counted field relative to the control cells.

\subsection{Geminin cannot substitute any reprogramming factor}

Geminin is necessary for the maintenance of reprogramming, however, would it be able to induce reprogramming or enhance the induction of the reprogramming? To study that, the established OG2 MEF line was reprogrammed with different combinations of reprogramming factors and Geminin. OG2 MEFs contained a green fluorescent protein (GFP) reporter under the control of distal enhancer element of the Oct4 gene, which would express GFP upon reprogramming. This reporter would provide the possibility to visualize, quantify or sort the reprogrammed cells. MEFs were transduced with OSKM or different combinations of 3 factors (SKM, OKM, OSM and OSK) or different combinations of 3 factors and Geminin (GSKM, OGKM, OSGM and OSKG). The transduced cultures were stained for alkaline phosphatase activity after 14 days (Fig. 64). Comparison of AP staining showed a slight decrease in reprogramming efficiency upon removal of C-Myc factor and a stronger effect upon removal of Klf4, Sox2 and Oct4. In addition, data demonstrates that addition of Geminin to reprogramming cocktail cannot enhance the reprogramming and Geminin cannot substitute any of the reprogramming factors. 

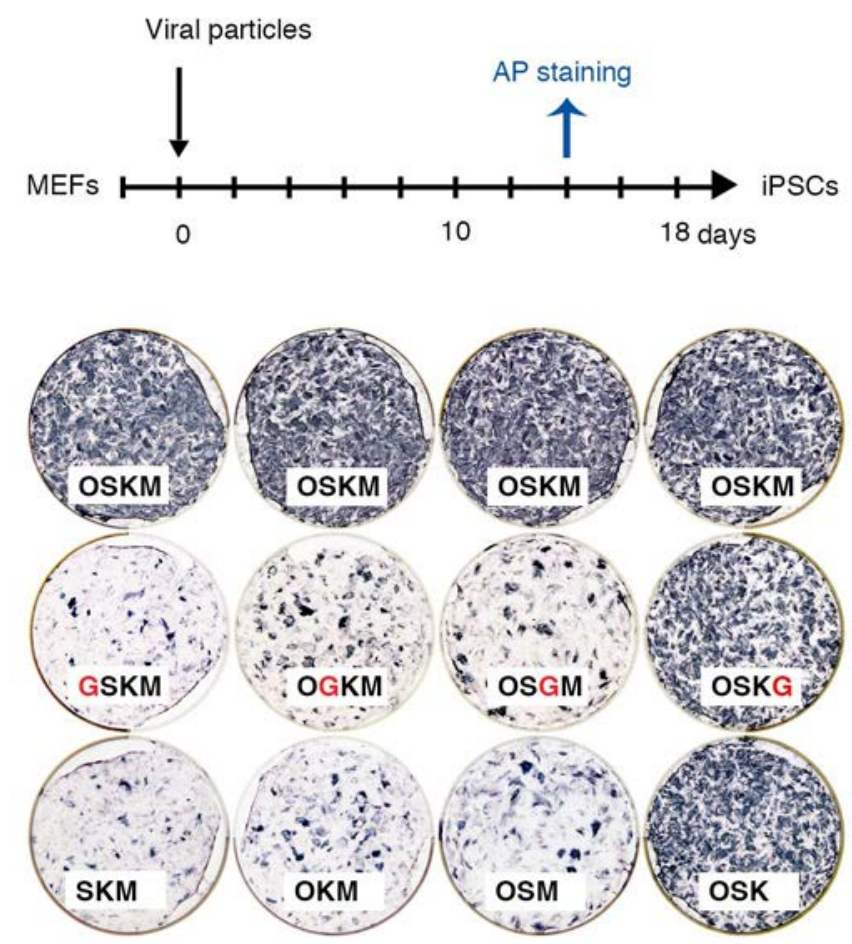

Figure 26. Geminin cannot substitude any reprogramming factor.

OG2 MEFs were reprogrammed with viral particles containing different combinations of reprogramming factors and Geminin (O: Oct4, S: Sox2, K: Klf4, M: C-Myc and G: Geminin). Transduced plates were stained for alkaline phosphatase 14 days after transduction. 


\section{Discussion}

\subsection{Replication and cell cycle regulation by Geminin}

\subsubsection{Geminin is degraded during the cell cycle of ESCs}

The cell cycle of ESCs is tightly bound to the undifferentiated state of these cells. It was reported that the majority of the regulatory factors including cyclins, Cdc6, and Geminin are rather constitutively expressed during the cell cycle of ES cells than being restricted to a specific phase ${ }^{35}$. It has been speculated that Geminin levels are high in all the phases of the cell cycle in ESCs, resulted by the inhibition of its recognition by the degradation machinery due to the presence of Emi, the inhibitor of the APC/C complex ${ }^{92}$. However, studies conducted under more efficient synchronization methods have illustrated a dynamically degrading Geminin in ESCs like other somatic cells ${ }^{38}$. Geminin and many other cell cycle regulatory proteins are degraded in a cell cycle-regulated manner; but, since the G1 phase of the ESCs is short in length, a homogenously synchronized cell population is necessary to observe it.

mAG-hGem construct codes a green fluorescence protein, Azumi green, fused to the destruction box of the Geminin. When the degradation machinery of the cell recognizes the Geminin destruction box, this fusion protein is degraded and no green fluorescence can be detected. Over-expression of mAG-hGem in ESCs resulted in an Azumi green positive population residing only in S/G2/M phases. This population lacked the cells in the G1 phase of the cell cycle, thus Geminin degradation box must be detected prior to entry into $\mathrm{G} 1$ and during the $\mathrm{G} 1$ phase. These data clearly illustrates a recognition and degradation of Geminin's destruction box. However, it is possible that in vivo, the endogenous full-length protein is protected against degradation due to the presence of the inhibitors which bind only to the full-length protein. 
Finally, investigation of the endogenous protein in a synchronized cell population confirmed the degradation of the Geminin in ESCs. The homogenously synchronized population of the ESCs showed a decrease in the endogenous Geminin upon entrance into the G1 phase. Although the efficiency of synchronization was about $85 \%$, it was possible to observe significant decrease in the level of the endogenous protein. This observation depicted that unlike previous reports ${ }^{35,92}$, the degradation machinery of the cells degrades the endogenous Geminin protein.

\subsubsection{Replication and cell cycle regulation in the absence of Geminin}

In rapidly proliferating cells such as cleavage stage embryos, pre-implantation embryos and cancer cells, Cdt1 activity is the rate-limiting factor for the origin licensing ${ }^{115}$. Geminin binds and inactivates Cdt1 while protecting it from ubiquitination and degradation. Therefore in fast proliferating cells such as ES cells, geminin deficiency would result in a loss of Cdt $1^{116}$. In two knockdown studies $^{116,117}$, no re-replication was observed while in contrast Yang and colleagues observed nuclei enlargement in $\mathrm{ESCs}^{118}$. This discrepancy could result from different residual levels of geminin after siRNA depletion. In our ESCs the inactivation of the geminin gene did not lead to re-replication, but resulted in a slightly longer cell cycle. Geminin down-regulation may have caused in a slower cell cycle, and this change led to the loss of the pluripotent identity. It is widely accepted that a fast, abbreviated cell cycle is necessary for the pluripotency of the ESCs ${ }^{115,119,120}$. Noteworthy, it was shown that upon cell cycle perturbations or depletion of some cell cycle regulators the pluripotency markers are still up regulated debating the connection between the fast cell cycle and the pluripotent identity ${ }^{121}$. On the other hand an induction of differentiation and reduction in the pluripotency gene expression, can lengthen the cell cycle of the ESCs ${ }^{36,46,119}$. In summary, we interpret the observed increased length of the cell cycle after geminin knockout as a consequence of differentiation of ESCs. 


\subsection{Geminin is required for pluripotency}

\subsubsection{Geminin is down regulated during differentiation}

Geminin is expressed in the mouse ESCs and its protein level decreases upon their differentiation as EBs (Fig. 4) ${ }^{35}$. However, mRNA level is not reduced as fast as the protein level is down regulated. This may indicate a posttranscriptional regulation of Geminin expression in differentiating cells. On the other hand, it may reflect the changes in the cell cycle of the differentiating ESCs. In an asynchronized ESC population only $10-15 \%$ of the cells are in the G1 phase, while, differentiation is coupled to an increase in the length of the G1 phase resulting in a population of the cells with more than $50 \%$ G1 phase cells. Knowing the fact that during the cell cycle Geminin is only found in the S/G2/early $M$ phases, and it is absent in the late M/G1 phase. It can be concluded that in a differentiating population the ratio of the Geminin expressing to the total cells decreases. Thus, this dramatic change in the cell cycle can alone cause a reduction in the total Geminin content of the cells even if there is no change in the expression of the Geminin mRNA.

Geminin was known as a neuralizing factor, expressed in the Sox $2^{+}$cells of the neural lineage (reviewed in the introduction). In this study, Geminin is expressed in the neuroectoderm (Fig. 5), and during neural induction but not in the later stages where neurogenesis takes place (Fig. 16B). However, upon differentiation to mesendoderm Geminin level decreases (Fig. 5). Presence of Geminin protein in neural lineage is in accordance with the former observation that Geminin decreases during spontaneous differentiation of ESCs. The majority of differentiating cells gives rise to mesoderm and endoderm rather than ectoderm. Therefore, a reduction of Geminin in meso- and endoderm progenitors is sufficient to cause a reduction in the total amount of geminin in the whole population of differentiating EBs. In summary, Geminin is expressed in 
pluripotent cells and neuroectoderm and it is down-regulated in the differentiating mesendoderm progenitors.

\subsubsection{Geminin expression is tightly bound to the pluripotent state}

Geminin-deficient embryos arrest their development at 8-cell stage and never give rise to the ICM, suggesting that Geminin is necessary for the totipotency ${ }^{90,}$

${ }^{91}$. Additionally, It was shown that while 8-cell embryos can give rise to ESCs, the Geminin-deficient 8-cell morulas couldn't give rise to ESCs if cultured in vitro ${ }^{91}$. Therefore, Geminin is necessary for the derivation of the pluripotent ESCs.

Gmnn ${ }^{\mathrm{f} / \mathrm{fl}}$ ER-Cre ESCs (iGmnn ESCs), which were established in this study, carry both alleles of Geminin gene flancked by loxP sites and express a tamoxifen inducible Cre recombinase transgene ${ }^{111,}{ }^{122}$. The genotype of these cells, provides the possibility of Geminin genetic inactivation upon administration of a small chemical named tamoxifen. Protein analysis clearly depicted that these cells lose more than $90 \%$ of their Geminin protein as early as $48 \mathrm{~h}$ after induction. Thus a minority stays unrecombined or partially recombined; therefore, the iGmnn/48hTx cells are a heterogeneous population consisting of $\mathrm{Gmnn}^{\mathrm{f} / \mathrm{fl} \text {, }}$ $\mathrm{Gmnn}^{\mathrm{fl} / \mathrm{-}}$, and $\mathrm{Gmnn}^{-/-}$cells. These cells provide a suitable system to study the role of Geminin in pluripotent cells. Up to now, these cells are the only available system to study the events following the Geminin knockout in ESCs.

In this study, after tamoxifen treatment of iGmnn ESCs, these cells were plated as single cells in order to give rise to pluripotent colonies. Genotyping of the formed colonies clearly indicated an absence of the $\mathrm{Gmnn}^{-/}$ESCs (Fig. 12). This experiment indicates a pivotal role for Geminin in the maintenance of the pluripotent state. Therefore, Geminin is not only necessary for the derivation of ESCs but it is necessary for the self-renewal of pluripotent ES cells.

iGmnn/48hTx ESCs give rise to less colonies and the majority of the colonies exhibited a flattened differentiated colony morphology. Additionally the cells down-regulated their pluripotency marker expression, such as Sox2, Nanog and Zfp42 expression but Oct4 levels retained as high as undifferentiated cells. The 
expression of differentiation markers such as Sox1, Brachyury or Sox17 was not significantly changed. $\mathrm{Cdx} 2$, the trophectoderm marker was not expressed and the cells did not contain p-cadherin (unpublished data). The expression of Gata6 was slightly up-regulated but not Gata4 (unpublished data).

Although there are no other genetic inactivation studies on Geminin in ESCs, but there are a few reports characterizing the ESCs treated with anti Geminin siRNA ${ }^{92,123}$ or inducible shRNA ${ }^{99}$ exhibiting a fundamental discrepancy among their findings. The first study reports a role for Geminin in the pluripotent state of the cells, showing a down regulation of Sox2 and loss of pluripotent cell morphology upon treatment of the ESCs with anti-Geminin siRNA ${ }^{123}$. Geminin is shown to contribute to the expression of Oct4, Sox2, and Nanog, maintaining the pluripotency ${ }^{92}$. Same study reports an expression of the trophoblastic lineage markers such as Troma1 and p-cadherin coupled to increase in the size of the nuclei in ESCs treated with siRNA against Geminin. However, they fail to detect early trophoblastic markers such as Cdx2 or Tead4 in their cells. A third study, characterizes an ES line expressing an inducible shRNA against Geminin ${ }^{99}$. In the context of pluripotent state these study reveals a slight decrease in the number of formed colonies upon Geminin depletion. However, they fail to detect any changes in the pluripotency governing transcription factors such as Nanog.

The discrepancy among these studies can be resulted from the fact that although they have down-regulated the Geminin levels but its expression is not completely diminished. In addition the first two studies, are characterizing a heterogeneous population, transfected with siRNA. In these populations there are differences in the remaining Geminin levels of each cell compared to the others and the Geminin levels can be recovered upon degradation of the siRNA. Additionally not all the studies have investigated the same criteria of the cells. To sum it up, this study is the only genetic inactivation study providing a population of ESCs, in which the majority of the cells are completely depleted from Geminin.

This study has led to the conclusion that Geminin contributes to the stabilization of the pluripotent state by modulating the expression of pluripotency genes such 
as Sox2 and Nanog rather than regulating the cell cycle progression of the cells. However, a more detailed analysis of the iGmnn/48hTx cells' transcriptome can shed light on the Geminin effect entirely.

\subsubsection{Geminin expression is necessary for neural lineage commitment}

We concluded from our data that Geminin depletion causes the ESCs to lose their Sox2 expression, relinquish their pluripotency network and differentiate while they still express considerable amount of Oct4. It was shown that both Oct4 and Sox 2 contribute to the pluripotent state ${ }^{19}$ through maintaining the expression of each other and of other pluripotency factors. Oct4 is required for the mesendodermal lineage, which is suppressed by Sox2. Additionally, Sox2 is required for the neuroectodermal lineage, which is suppressed by Oct4.

In order to investigate the ability of the iGmnn ESCs to differentiate into different lineages these cells have been differentiated spontaneously toward all three lineages. Accordingly, Geminin depletion decreased the number of Sox2 positive cells and increased the number of Oct4 positive cells in the differentiating ESCs. Additionally, iGmnn ESCs were differentiated into the neural lineage in a stringent condition, which selects neural progenitors and does not support the survival of mesendoderm lineage. Notably, Geminin-deficient cells committed apoptosis and failed to differentiate into the neural lineage.

Many studies have suggested a transcription-modulating role for Geminin during the neural induction and formation of neuronal progenitors ${ }^{97,98,109} 99$. Kroll and colleagues showed a similar phenotype in the ESCs expressing an inducible shRNA against Geminin ${ }^{99}$. They showed that Geminin depletion impairs the ability of the ES cells to form neural lineage, while its overexpression promoted neural fate even in the presence of the mesendoderm inducing signals. In addition it is shown before that Geminin regulates the expression of the Sox2 gene in chicken neurogenesis ${ }^{109}$ however, the interaction partner, involved in the regulation, does not have a homolog in the other organisms. Collectively the data 
presented here indicates an essential role of Geminin for the expression of Sox2. Bothe genes are essential for the pluripotency and the neural lineage.

\subsubsection{Geminin is necessary for the maintenance of reprogramming}

Gmnn fl/fl MEFs did not show any significant phenotypes. Early passages of tamoxifen treated MEFs neither showed a cell cycle arrest nor a significant difference in proliferation or apoptosis. This data in in accordance with former studies done in the immortalized fibroblasts ${ }^{124}$. As discussed in section 1.4.1 cells have different mechanisms to safeguard the fidelity of their DNA expression. Down-regulation of one of these mechanisms can be compensated with upregulation of other, redundant pathways. For example MEFs can tolerate the lack of Cyclin A2 through up-regulation of their Cyclin $E^{42}$. In summary, these results provided evidence for a redundant role of Geminin in mouse embryonic fibroblasts.

The importance of Geminin for pluripotency suggests that it is also essential for the induction of the pluripotency. Indeed Geminin deficient fibroblasts cannot form iPSCs, however, Gmnn ${ }^{f / f l}$ cultures exhibit a similar cell number and proliferation rate until around 13 days after transduction and they start to fail at later stages. It was shown that after transduction of OSKM, the cell proliferation rate increase massively, the cells which escape the cell cycle arrest caused by entrance of reprogramming factors, proliferate and become the progenitors of iPSCs. A few days later an extensive remodeling of the epigenetic marks is necessary to re-set the epigenetic state into an Open state and to allow the endogenous pluripotency transcription factors to be expressed and access their target in the genome in order to maintain the pluripotent state ${ }^{125}$ (for more see ${ }^{65}$ ). It was shown that pluripotency transcription factors such as Oct4 and Nanog are indispensible from reprogramming and their genetic inactivation would not allow any iPSC to from ${ }^{18,125}$. Therefore, the re-expression of the endogenous genes is a rate-limiting step in the maintenance of the reprogrammed state and mature iPSCs. In this study, a role for Geminin in the maintenance of Sox2 expression 
was suggested; therefore, this is of high interest to investigate the dynamics of endogenous Sox2 expression in these cells. Geminin deficient pre-iPS cells fail to maintain their pluripotent state due to failure in re-establishing their endogenous Sox2 expression (preliminary data). In addition it predicts that Geminin expression is only necessary at later stages of reprogramming, when the endogenous Geminin protein is enough for maintenance of reprogramming. Thus addition of Geminin to the viral cocktail would not affect the reprogramming.

To sum up, Geminin is redundant in MEFs but the absence of Geminin constitutes a major barrier for re-maintaining the pluripotency in vitro most probably due to an inability to re-express the endogenous Sox2.

\subsection{Geminin regulates the Sox2 expression through modulating its epigenetic signature}

In different developmental contexts, Geminin was shown to interact with SWI/SNF complex ${ }^{97,109}$ and Polycomb group proteins ${ }^{98}$ in order to contribute to the maintenance of the neural genes and inhibition of the mesendoderm lineage. In addition it was shown that Geminin is associated to the hyper-acetylated chromatin and regulates the neural lineage commitment through maintaining the hyper-acetylated state ${ }^{99}$. In this study, Geminin depletion has no effect neither on the histone 4 hyper-acetylation nor on the histone 3 lysine 4 di-methylations of the Sox2 enhancers or any other tested region, including the oct4 enhancer. Rather in the absence of Geminin, the inactivating signal, histone 3 lysine 27 trimethylations increased on the SRR2 enhancer of the Sox2 gene, followed by an enrichment of the catalytic subunit of the PRC2 complex. In exchange, the presence of the SWI/SNF complex was diminished on the SRR2 enhancer of the Sox2 gene.

This finding can be summarized in a model (Fig. 27). In the presence of Geminin, Brg1 is recruited to SRR2 enhancer and therefore, Sox2 gene is expressed. In the absence of Geminin the activating SWI/SNF complex is dissociated, and 
PRC2, the inactivating competitor complex, occupies the enhancer region causing accumulation of the inactivating signals and loss of Sox2 expression. This model is in agreement with former observations. SWI/SNF complex is associated with pluripotency genes and pluripotency factors target genes, and contributes to the fine-tuning of their expression, and upon Brg1 depletion, the SWI/SNF binding sites are occupied by PRC2 complex ${ }^{96}$.

Geminin is specifically controlling the biding of the SWI/SNF complex to the Sox2 enhancer region and its absence is not affecting the other pluripotency gene, Oct4. It is of high interest to decipher the molecular details of this gene-specific regulation. Geminin may recruit the SWI/SNF complex to the Sox2 enhancer. However, the direct interaction between Geminin and Brg1 was reported only in an in vitro system ${ }^{97}$. Many immunoprecipitation of Geminin and its overexpressed tagged version was performed and the precipitated samples were analyzed by mass spectrometry (unpublished data). Except Cdt1, which was precipitating with Geminin in all samples, no other SWI/SNF or Polycomb member was detected. In addition, co-immunoprecipitation experiment with Brg1 And Geminin in ESCs did not show any direct interaction (unpublished data). In addition to explore the possibility of Geminin interaction with chromatin, or its enrichment at the SRR2 site, many chromatin immunoprecipitations in the presence of protein-protein cross-linkers was done. However, none of these experiments was able to confirm an association of Geminin with chromatin.

On other hand, Geminin may contribute to the inhibition of the PRC2 complex ${ }^{98,}$ ${ }^{126}$, however, no direct evidence was observed for such an interaction in ESCs. Notably, in ESCs PRC2 and PRC1 complexes are actively binding and silencing the developmental genes even in the presence of Geminin. Noteworthy, it is known that these protein complexes can have different compositions. Therefore, further investigations are necessary to exclude the possibility that a different composition of PRC2 complex is present on the Sox2 enhancer.

In conclusion, It has been shown that Geminin maintains the expression of Sox2. Therefore, it seems necessary to investigate if the rescue of Sox2 expression can 
retrieve the pluripotent state and the ability to differentiate into the neural lineage in iGmnn/Tx ESCs.
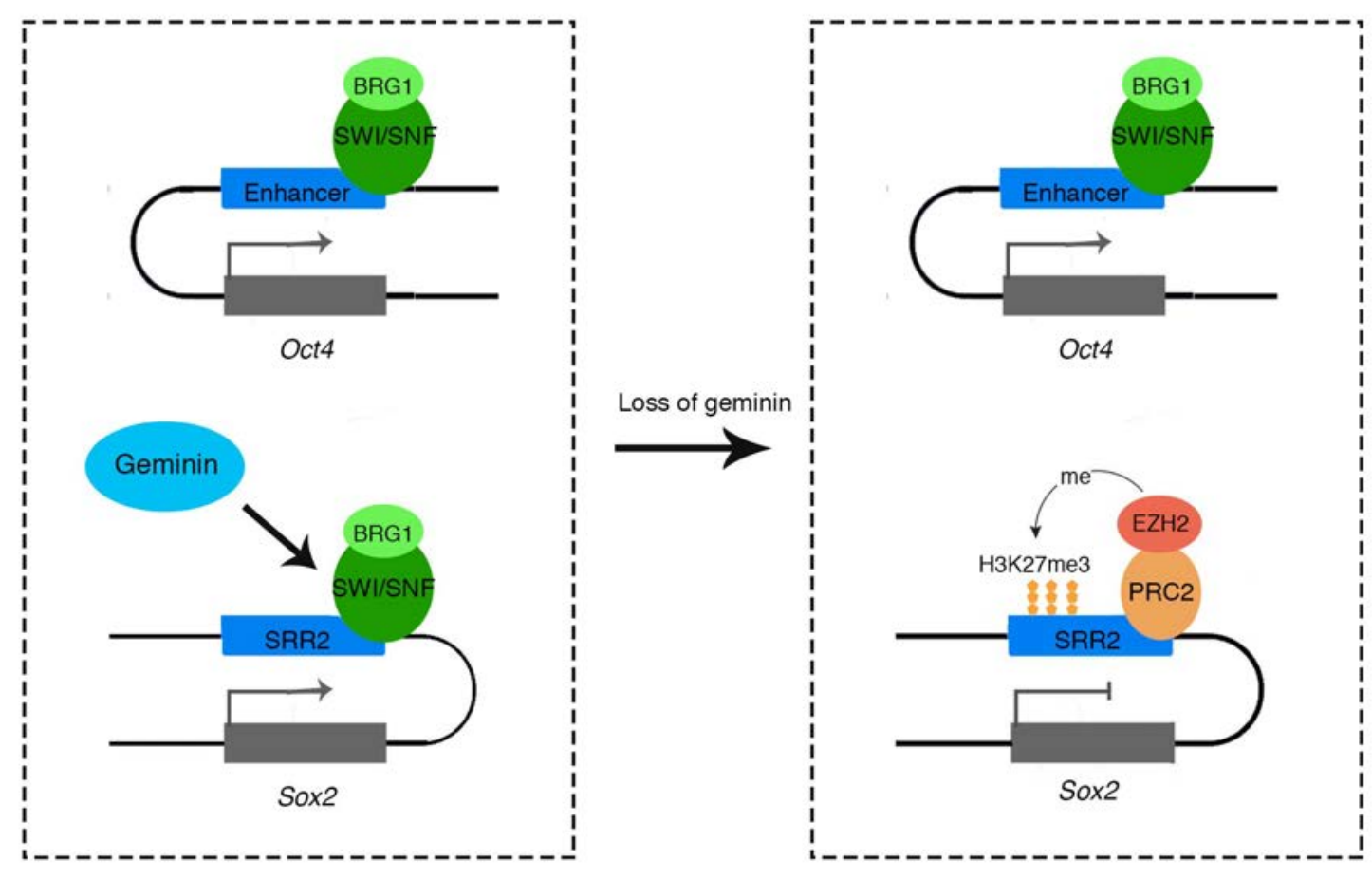

Figure 27. Geminin regulates Sox2 through regulation of the epigenetic signature of SRR2.

A model summarizing the findings of chromatin immunoprecipitation depicts a change in the active state of SRR2 enhancer to an inactive state.

\subsection{Geminin is indispensable to toti-pluri-neural lineages}

Previous studies ${ }^{90,91}, 99$ and this study depict a lineage-specific role for Geminin. Geminin is present and necessary in the totipotent cells and its loss abrogates the totipotency. Geminin is present in pluripotent cells and its loss caused an exit from the pluripotent state and finally Geminin was necessary for the commitment into neural lineage. Therefore, Geminin functions as a key factor for the formation of the totipotent-pluripotent-neural lineage during the development. This study nominates Sox2 as the key target gene which expression is necessary for the 
establishment of this axis (Fig. 28) and predicts that Geminin is necessary for the maintenance of epiblast stem cells ${ }^{127,128}$, the in vitro equivalent of the pluripotent late epiblast.

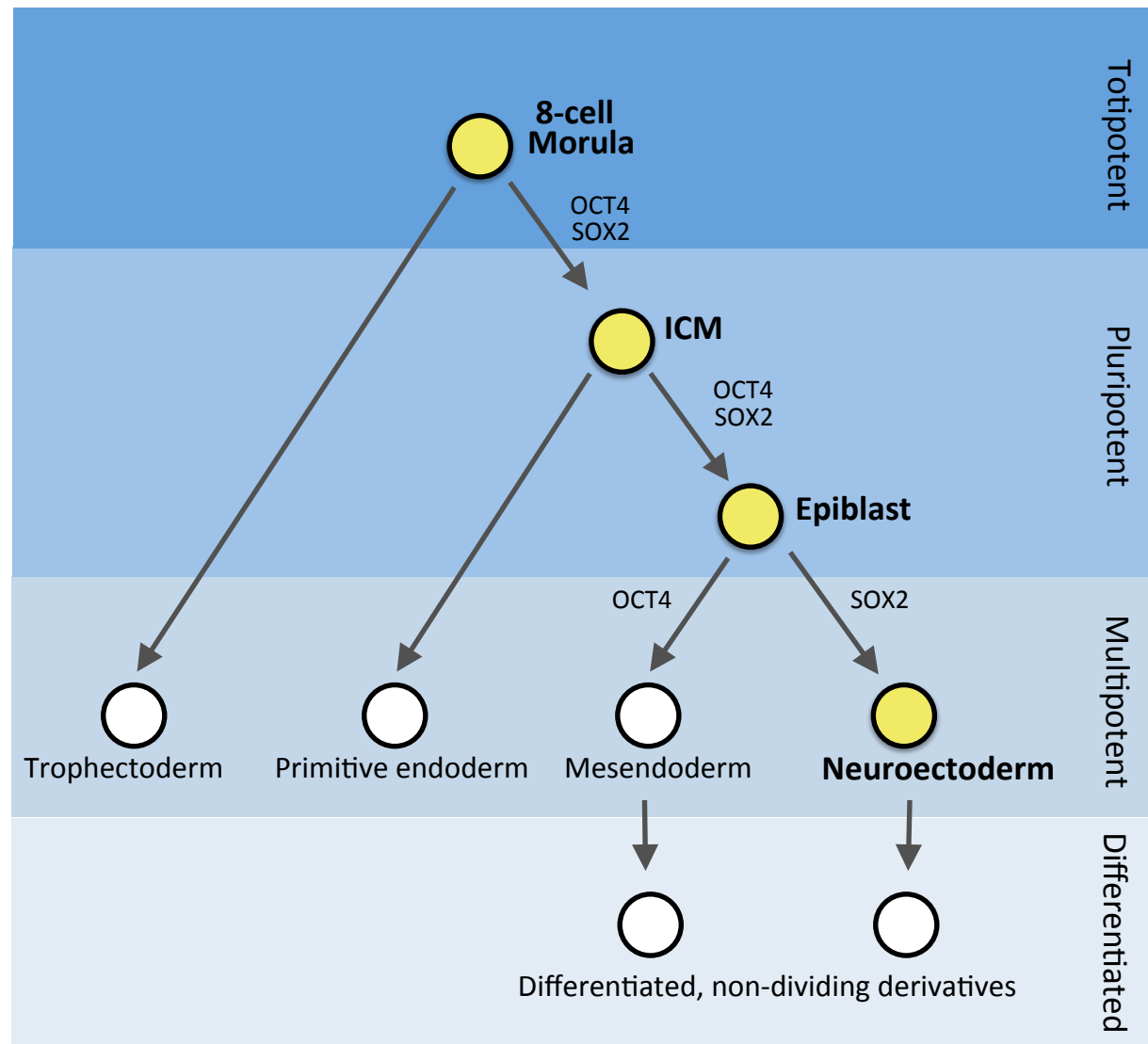

Figure 28. Geminin safeguards the toti-pluri-neural fate determination in the embryonic development.

Geminin (shown in yellow) is expressed in totipotent, pluripotent and neuroectoderm cells together with Sox2, and required for these lineages.

This study defined a transcription-modulating role for Geminin in the lineage commitments of the early embryo. However, Geminin was known for its role in the inhibition of re-replication and as discussed extensively before, in nonembryonic tissues the Geminin expression marks the proliferating cells. In addition Geminin was reported to interact and regulate many transcription factors, chromatin remodeling complexes and the basic transcription machinery. Finally it seems that Geminin interacts with many complexes simultaneously. 
These findings suggest a complex mechanism for Geminin's action in regulation of the embryonic lineage commitment.

Geminin is only present in the multi-cellular organisms and no Geminin homolog was found in uni-cellular organisms. This differences cause the metazoan cells to have an extra mechanism for regulation of their DNA replication fidelity compared to yeast or other unicellular eukaryotes. For that reason it was speculated ${ }^{129}$ that in higher eukaryotes the presence of a more than one mechanisms has provided the possibility for Geminin to acquire additional roles during the regulation in the embryonic development. It seems more probable to consider a gene, which for the first time appears in the multicellular organisms to be involved with the most pivotal aspect of multi-cellularity, the cell specifications. Therefore, it can be hypothesized that Geminin has evolved as a transcription modulator, which was regulated during the cell cycle, in order to facilitate the coordination of proliferation and differentiation. In this respect, Geminin acquired the DNA rereplication inhibition as a secondary role, which may guarantee a higher regulation on the fidelity of genomic replication during a fast cell cycle. 


\section{Materials and Methods}

\subsection{Cell Biology}

\subsubsection{Cell lines}

Table 1. Cell lines used in this study

\begin{tabular}{|lc|}
\hline Cell line & Reference \\
\hline Wild type ES cells (MPI-II, 129Sv strain, XY karyotype) & \\
\hline Plat-E cells & 130 \\
\hline
\end{tabular}

\subsubsection{Mouse lines}

Table 2. Mouse lines used in this study

\begin{tabular}{ll}
\hline Mouse line & Reference \\
\hline Wild type B6N (C57B|6/N) & - \\
Geminin conditional knockout & 102 \\
ER-Cre & 111 \\
CMV-Cre & 131 \\
Oct4-GFP & 132 \\
\hline
\end{tabular}

\subsubsection{Isolation of mouse embryonic fibroblasts}

Appropriate matings were set up and females were checked every day. Vaginal plug positive females were considered to be pregnant and staged as embryonic day 0.5 (E0.5). Pregnant females were euthanized by the $\mathrm{CO}_{2}$ exposure 13 days after copulation (E13.5) followed by cervical dislocation. Uterus was dissected out and transferred to a 50- $\mathrm{ml}$ tube containing $20-30 \mathrm{ml}$ cold sterile PBS. In a laminar flow cabinet, uterus was transferred into a $10 \mathrm{~cm}$ tissue culture dish containing $10 \mathrm{ml}$ sterile PBS. The uterus and yolk sacs were cut to expose the 
embryos. After the embryo were cut out, each fetus were transferred individually in a new dish containing $10 \mathrm{ml}$ sterile PBS. The limbs, liver, heart, tail and the head (brain) were cut. Tail or limb biopsies were used for DNA extraction followed by genotyping. Each embryo (the remaining trunk) was transferred to a well of a 6-well plate. $2-3 \mathrm{ml} 0.25 \%$ Trypsin/EDTA (GIBCO) was added to each embryo and the embryos were incubated at $37^{\circ} \mathrm{C}$ for $10-15$ minutes. Afterwards embryos were disrupted, using two forceps until only small cell clusters remained. MEF culture medium (DMEM (Invitrogen) supplemented with 10\% fetal bovine serum (FBS; PAN-Biotech)) was added to each sample and pipetted vigorously and repeatedly up and down to break up the digested tissues into a cell suspension. Samples were transferred into $15 \mathrm{ml}$ tubes and the total volume was adjusted to $10 \mathrm{ml}$ per sample by addition of medium. The samples were placed for 2-3 min under the flow cabinet to let the cell clumps sediment in order to get rid of the bigger clumps. The cell suspensions were pipetted into culture dishes containing $15 \mathrm{ml}$ fresh medium. Then, the cells were cultured at $37{ }^{\circ} \mathrm{C}$ under $5 \% \mathrm{CO}_{2}$ concentration. On the next day, the MEF cells were categorized based on the genotyping results; they were washed with PBS and trypsinized with $4 \mathrm{ml} 0.25 \%$ Trypsin/EDTA. Cells with the same genotype were pooled; the cells were counted and were frozen as $10^{6}$ cells/vial (for more details on cell passage, freezing and revival check the following sections).

\subsubsection{Cell passage and freeze}

The cells were passaged as soon as they were reaching $70-90 \%$ confluency. The cells were washed with pre-warmed PBS. $0.25 \%$ Trypsin/EDTA (Invitrogen) solution was equally distributed onto the washed cells, and the cells were incubated at $37^{\circ} \mathrm{C}$ for about 5 minutes. The dish was shaken until all the cells became floating. Culture medium (containing FBS) was added to stop the trypsin digestion, pipetted up and down for several times to dissociate the cells, and then transferred into a 15-ml Falcon tube. Centrifugation was carried out at 1,000 rpm for 5 minutes to pellet the cells. The cell pellet was dissociated by tapping the 
falcon tube gently 4-5 times. For passage, the cell pellet was re-suspended in appropriate amount of medium necessary for 3-4 culture plates. To freeze, the cell pellet was re-suspended in $3 \mathrm{ml}$ culture medium. $3 \mathrm{ml} 2 \mathrm{x}$ freezing medium (DMEM (GIBCO) supplemented with 16\%DMSO and 25\%FBS) was added and mixed and immediately $1.5 \mathrm{ml}$ cell suspension was transferred into each cryotube. The cryotubes were transferred to a Cryo-safe ${ }^{\mathrm{TM}}$ cooler (Bellart products) containing isopropanol and were frozen at $-80^{\circ} \mathrm{C}$. the cells were kept at $-80^{\circ} \mathrm{C}$ for a week to 2 months. For longer storage the cells were transferred in liquid nitrogen at least 1 day after they were frozen.

\subsubsection{Cell revival}

Cells from liquid nitrogen or $-80^{\circ} \mathrm{C}$ freezer were thawed at $37^{\circ} \mathrm{C}$ as quickly as possible and were transferred gently into a $15 \mathrm{ml}$ Falcon tube containing 3-5 ml pre-warmed culture medium. Cells were collected by centrifugation at $1000 \mathrm{rpm}$ for 5 min. appropriate amount of fresh medium was added to the cell pellet and mixed well in order to break down cell clumps. The cells were transferred into the desired culture plate. The cells were cultured at $37^{\circ} \mathrm{C}$ in $5 \% \mathrm{CO}_{2}$.

\subsubsection{Gelatin coating of culture plates}

Plates were coated with gelatin $(0.2 \%$ in PBS) for $10 \mathrm{~min}$. Gelatin was removed before use. Glass surfaces needed a longer coating time (1-2 h). For plating embryonic stem cells coating time was increased to $2 \mathrm{~h}$ (for culture plates) until overnight (for glass surfaces) in order to achieve better results.

\subsubsection{Preparation of mitotically inactivated feeder cells}

B6J derived MEFs from liquid nitrogen or $-80^{\circ} \mathrm{C}$ freezer were revived. As soon as the cells became confluent, the cultures were passaged 1:4-1:8. As soon as the passaged fibroblasts reached the $90-100 \%$ confluency, the cells were inactivated by treatment with Mitomycin-C $(10 \mathrm{mg} / \mathrm{ml})$ for $2.5 \mathrm{~h}$ at $37{ }^{\circ} \mathrm{C}$. Afterwards the cells were washed with PBS twice and trypsinized. The 
trypsinized cells were either re-plated on gelatin-coated plates as feeder layers for further usage or frozen.

\subsubsection{Embryonic stem cell derivation}

Female mice were induced for superovulation. Appropriate matings were set up and females were checked for the vaginal plug on the next day. Vaginal plug positive females were considered to be pregnant and staged as embryonic day 0.5 (E0.5). Pregnant females were euthanized by cervical dislocation 3 days after copulation (E3.5). The uteri were cut out and blastocysts were flushed in ES-CM (embryonic stem cells conventional medium: Knockout ${ }^{\mathrm{TM}}$ DMEM (GIBCO) supplemented with 20\% FBS (PAN-biotech), $1 \mathrm{mM} \beta$ - mercaptoethanol (SigmaAldrich), 2 mM L-Glutamine (GIBCO), 1\% non essential amino acids (GIBCO), 1 $\mathrm{mM}$ Sodium Pyruvate (GIBCO) and $1000 \mathrm{u} / \mathrm{ml}$ LIF (Invitrogen)).

The blastocysts were immediately transferred to a laminar flow cabinet and plated on feeder-coated 35-mm culture plates (4-6 blastocyst on each plate). The medium was changed after 2 days and once more 2 days later. 5-6 days after plating the blastocysts were grown into out-growths containing ESCs. Outgrowths were cut with 20- $\mu \mathrm{l}$ pipette tips and transferred into 50- $\mu$ ES trypsin/EDTA (8g/l $\mathrm{NaCl}, 0.4 \mathrm{~g} / \mathrm{l} \mathrm{KCl}, 0.1 \mathrm{~g} / / \mathrm{Na}_{2} \mathrm{HPO}_{4}, 1 \mathrm{~g} / \mathrm{l}$ Glucose, $3 \mathrm{~g} / \mathrm{l}$ Tris Base and 2.5g/l Trypsin) and incubated for $3 \mathrm{~min}$ at $37^{\circ} \mathrm{C}$. Afterwards the trypsin was stopped with 100- $\mu \mathrm{l}$ ES-CM followed by pipetting up and down vigorously in order to create shearing force to dissociate the cells. The cell suspension from each blastocyst was transferred to each well of a 24-well plate coated with feeders and containing ES-CM. The single cells formed colonies and reached $90 \%$ confluency after 2-3 days. After reaching confluency the cells were trypsinized and divided into three equal volumes, of which two volumes were used for freezing and one for genomic DNA extraction. 


\subsubsection{ES cells maintenance and passage}

Mouse ES cells were routinely maintained on gelatin-coated, feeder-coated 35$\mathrm{mm}$ plates and fed daily with ES-CM or any other specified medium. ESCs were passaged every 2-3 days depending on the level of confluency. To passage the cultures were washed with PBS and trypsinized by ES trypsin/EDTA for $3 \mathrm{~min}$ until the colonies detached from the culture plates. Then trypsin activity was stopped by the addition of culture medium. The cell supernatant was vigorously pipetted up and down using 2-ml pipettes, transferred to a Falcon tube and centrifuged for $5 \mathrm{~min}$ at $1000 \mathrm{rpm}$. The pellet was reconstituted in medium and the cells were re-plated on desired plates in desired abundance.

\subsubsection{Tamoxifen (4-hydroxyl tamoxifen) treatment of the cells}

$100 \mathrm{mg}$ 4-hydroxil tamoxifen (Sigma-Aldrich) was dissolved in $10 \mathrm{ml}$ ethanol (Merck) at $37^{\circ} \mathrm{C}$ for 1 hour. The solution was filter-sterilized, aliquoted and stored at $-20{ }^{\circ} \mathrm{C}$. Frozen tamoxifen solutions were used up to three months after the preparation. Fibroblast growth medium was supplemented with 100-500 nM tamoxifen and ES-CM medium was supplemented with $1 \mu \mathrm{M}$ tamoxifen for 48 hours or longer.

\subsubsection{Feeder layer free culture of ESCs}

Embryonic stem cells were plated on gelatin-coated plates in ES-CM medium as single cells. Cells were harvested or passaged 3-4 days after plating.

\subsubsection{Sub-cloning of the ES Cells}

The formed ES clones were cut with $20-\mu \mathrm{l}$ pipette tips and transferred into $50-\mu \mathrm{l}$ drops of ES trypsin/EDTA and incubated for $3 \mathrm{~min}$ at $37{ }^{\circ} \mathrm{C}$. Afterwards the trypsin was stopped with $100 \mu \mathrm{l}$ ES-CM followed by pipetting up and down vigorously in order to create shearing force to dissociate the cells. The cell suspension from each clone was transferred to each well of a 24-well plate coated with feeders and containing ES-CM. The single cells formed clones and 
reached confluency after 2-3 days. Afterwards, the cells were trypsinized and divided into three equal volumes, 2 used for freezing and one used for genomic DNA extraction.

\subsubsection{ES differentiation}

ESCs were differentiated using four different methods:

\section{Embryoid Body differentiation ${ }^{133}$}

ESCs were trypsinized into single cells and were counted using a hemocytometer (Neobar). $2-8 \times 10^{6}$ cells were diluted in $20 \mathrm{ml}$ differentiation medium: IMDM (GIBCO) supplemented with 20\% FBS (PANbiotech), $450 \mathrm{nM}$ monothioglycerol (Sigma-Aldrich), $2 \mathrm{mM}$ L-Glutamine (GIBCO) and 1\% non essential amino acids (GIBCO). Cell suspension was transferred into a $15-\mathrm{cm}$ bacterial grade culture plate and cultured further for 5 days. After 24 hours the cells formed aggregates. Medium was changed every 2 days. After 5 days, the EBs were collected, centrifuged and medium was discarded. EBs were washed with PBS once and treated with $2 \mathrm{ml} 0.25 \%$ trypsin/EDTA for 5 minutes. The aggregates were dissociated by pipetting and the trypsin was inactivated by addition of $18 \mathrm{ml}$ differentiation medium. The cell solution was transferred to gelatin-coated culture plates or glass chamber slides. The cells were cultured for 4 additional days in differentiation medium.

\section{Monolayer differentiation}

ESCs were trypsinized into single cells and were counted using a hemocytometer (Neobar). $1.5 \times 10^{4}$ cells $/ \mathrm{cm}^{2}$ were diluted in appropriate amount of differentiation medium. Cell suspension was transferred into gelatin coated culture plates or glass chamber slides. These plates were cultured further for 4 days. 


\section{Generation of cortical neurons from ESCs ${ }^{134}$}

ESCs were differentiated into neural and neuronal progenitors, neurons as well as astrocytes as described ${ }^{134}$.

\section{Differentiation toward neuroectoderm and mesendoderm progenitors ${ }^{8}$}

ESCs were trypsinized into single cells and were counted using a hemocytometer (Neobar). $1.5 \times 10^{4}$ cells $/ \mathrm{cm}^{2}$ were diluted in appropriate amount of N2B27 medium $^{135}$ (50\% DMEM/F12 (GIBCO) supplemented with $1 \mathrm{mM} \quad \beta$ mercaptoethanol (Sigma-Aldrich), $2 \mathrm{mM}$ L-Glutamine (GIBCO), 1\% non essential amino acids (GIBCO), $1 \mathrm{mM}$ sodium pyruvate (GIBCO), $50 \mu \mathrm{g} / \mathrm{ml}$ bovine serum albumin fraction V (Invitrogen) and N2 supplement (Invitrogen) mixed with 50\% Neurobasal medium (GIBCO) supplemented with $2 \mathrm{mM}$ L-Glutamine (GIBCO) and B27 supplement without retinoic acid (Invitrogen)).

Cell suspension was transferred into a gelatin coated culture plates or glass chamber slides and the cells were cultured for 48 hours. After 48 hours the medium was changed to N2B27 medium supplemented with $3 \mathrm{mM}$ Chirion (CHIR99021, StemGent) for mesendodermal differentiation or $500 \mathrm{nM}$ RA (retinoic acid, Sigma-Aldrich) for neuroectodermal differentiation. For differentiation experiments, cells were immunostained 36 hours after addition of the differentiation signal. ESCs were propagated in N2B27 media supplemented with LIF and 2i: $3 \mathrm{mM}$ Chirion and $100 \mathrm{nM}$ MEK1/2 inhibitor III PD0325901 (Calbiochem).

\subsubsection{Transfection of plasmid DNA}

ESCs were plated in gelatin-coated plates in ES-CM until they reached $60 \%$ confluency. The cells were transfected with mAG-hGem(1/110)pcDNA3 plasmid $^{110}$ and Lipofectamine ${ }^{\mathrm{TM}} 2000$ (Invitrogen) according to manufacturer's instructions. 


\subsubsection{Transfection of SiRNA}

MEFs were trypsinized into single cells. The siRNA (cyclin A siRNA (sc-29283, Santa Cruz Biotechnologies) or non-targeting siRNA (Dharmacon) and Lipofectamine $^{\mathrm{TM}} 2000$ (Invitrogen) were mixed according to manufacturer's instructions. After the second incubation time the siRNA/lipofectamine mixture was mixed with the cell suspension and transferred to gelatin-coated plates. The cells were cultured for 2 more days before analysis.

\subsubsection{Reprogramming}

PlatE cells (Platinum-E retroviral packaging cell line, Ecotrophic) were maintained in DMEM (GIBCO) supplemented with 10\% FBS, $1 \mu \mathrm{g} / \mathrm{ml}$ Puromycin and 10 $\mu \mathrm{g} / \mathrm{ml}$ Blasticidin on gelatin-coated plates. For production of viral particles the cells have been plated at $6 \times 10^{6}$ cells $/ 10-\mathrm{cm}$ plate without antibiotics (Blasticidin and Puromycin) overnight and on the next day each $10-\mathrm{cm}$ plate was transfected with $27 \mu$ l Fugene $6^{\mathrm{TM}}$ (Roche, Promega) and $9 \mu \mathrm{g}$ of one of the pMXs plasmids: pMXs-Oct3/4 (Addgene-plasmid 13366), pMXs-Sox2 (Addgene-plasmid 13367), pMXs-Klf4 (Addgene-plasmid 13370), pMXs-c-Myc (Addgene-plasmid 13375), pMXs-Gmnn (Provided by Dr. K. Boese). Transfection was done according to instruction provided by Fugene $6^{\mathrm{TM}}$ 's manufacturer. The cells were cultured overnight and the medium was changed on the next day. 24 hours later the medium was collected from culture plates and filtered with a $0.45 \mu \mathrm{m}$ cellulose filter (Millipore). $4 \mu \mathrm{g} / \mathrm{ml}$ Polybrene (Sigma-Aldrich) was added to the viral particle containing medium and it was used for transduction of fibroblasts.

One day before transduction the early passage primary fibroblasts (passages 13) were plated at $5 \times 10^{5}$ cells $/ 10-\mathrm{cm}$ plate in MEF medium. On the transduction day, the viral particle-containing medium was used to transduce the MEFs. In order to obtain OSKM (Oct4, Sox2, Klf4 and c-Myc) viral particle containing medium, equal amounts of each supernatant was mixed together. Three-factor reprogramming (OSK, OSM, SKM and OKM) was done with combining one part MEF medium supplemented with $4 \mu \mathrm{g} / \mathrm{ml}$ Polybrene to three parts viral particle 
containing mediums. 2-3 days after transduction the cells were plated on feedercoated plates in ES-CM at $1-2 \times 10^{4}$ cell/ $1 \mathrm{ml}$ medium. Medium was changed every 1-2 days depending on the cell proliferation rate (every 2 days at the beginning and from day 10 onwards on a daily basis).

\subsubsection{Visualization of alkaline phosphatase activity}

The culture plates containing ESCs or reprogrammed MEFs were washed once with PBS and were fixed in 4\% paraformaldehyde in PBS for 30 min. Next the plates were washed three times with PBS and once with alkaline phosphatase buffer (100 mM Tris. $\mathrm{HCl} \mathrm{pH} \mathrm{9.5,} 100 \mathrm{mM} \mathrm{NaCl}$ and $50 \mathrm{mM} \mathrm{MgCl}_{2}$ ). Next, the cells were stained in blue by exposure to NBT/BCIP working solution ( $2 \%$ NBT/BCIP enzyme substrate (Roche) in alkaline phosphatase buffer) for 10-30 minutes in dark. Afterwards the solution was discarded and the plates were washed once with PBS and kept in PBS at $4{ }^{\circ} \mathrm{C}$. The colonies were imaged under bright field microscope. The plates were imaged using a digital camera (Canon).

\subsubsection{Immunofluorescence analysis of cultured cells}

For immunofluorescence analysis of the expressed proteins or protein modifications, the cells were plated on glass chamber slides (Thermo-Fischer) or glass coverslips (gelatin-coated or feeder-coated depending on the cell type or the experiment). The cells were transferred to the bench and they were stained as below:

$\begin{array}{lll}\text { Step } & \text { Treatment } & \text { Time }(\mathrm{min}) \\ 1 & 4 \%(\mathrm{w} / \mathrm{v}) \text { Paraformaldehyde in PBS } & 15-20 \\ 2,3,4 & \text { PBS } & 3 \times 5 \\ 5 & \text { PBS-0.5\% Triton X100 } & 5 \\ 6,7 & \text { PBT (0.1\% tween in PBS) } & 2 \times 5 \\ 8 & 10 \% \text { FBS in PBT } & 60 \\ 9 & \text { Primary antibody in 10\% FBS in PBT } & \text { Overnight at } 4^{\circ} \mathrm{C} \\ 10,11,12 & \text { PBT } & 3 \times 5\end{array}$


After last PBT washing, the glass surface was washed once more with $\mathrm{ddH}_{2} \mathrm{O}$ and mounted with VECTASHIELD mounting medium with DAPI (Vector laboratories, Inc.). The sample was applied to a BX-60 fluorescence microscopy (Olympus) or a Leica TCS SP5 confocal microscope.

Table 3. Antibodies used for immunofluorescence analysis

\begin{tabular}{|c|c|c|}
\hline Primary and secondary antibodies & Manufacturer & Dilution \\
\hline Brachyury & $R \& D$ & $1: 100$ \\
\hline BrdU & Roche & $1: 25$ \\
\hline Cyclin A2 & Santa Cruz Biotechnologies & $1: 100$ \\
\hline Cyclin B1 & Santa Cruz Biotechnologies & $1: 100$ \\
\hline Cyclin D & Santa Cruz Biotechnologies & $1: 100$ \\
\hline E-cadherin & BD Bioscience & $1: 200$ \\
\hline Gata4 & Santa Cruz Biotechnologies & $1: 100$ \\
\hline Geminin & Santa Cruz Biotechnologies & $1: 50$ \\
\hline GFAP & Chemicon & $1: 1000$ \\
\hline Ki67 & Abcam & $1: 100$ \\
\hline Nanog & ABGent, Cosmobio & $1: 100$ \\
\hline Nestin & BD Bioscience & $1: 100$ \\
\hline Oct3/4 & BD Bioscience & $1: 200$ \\
\hline Pax6 & DSHB & $1: 100$ \\
\hline Phospho-histone 3 (pH3) & Cell signaling & $1: 200$ \\
\hline Sox1 & $R \& D$ & $1: 100$ \\
\hline Sox2 & Santa Cruz Biotechnologies & $1: 100$ \\
\hline Sox17 & $R \& D$ & $1: 100$ \\
\hline SSEA1 & Santa Cruz Biotechnologies & $1: 400$ \\
\hline Tuj1 & Covance & $1: 100$ \\
\hline Alexa Fluor 488 goat anti-mouse F(ab') & Molecular Probes & $1: 1000$ \\
\hline
\end{tabular}


Alexa Fluor 568 goat anti-mouse $\operatorname{lgM}(\mathrm{m})$

Alexa Fluor 594 goat anti-mouse $F(a b$ ')

Alexa 488 goat anti-rabbit ig $\mathrm{G}(\mathrm{H}+\mathrm{L})$

Alexa 594 goat anti-rabbit ig $\mathrm{G}(\mathrm{H}+\mathrm{L})$

Alexa 568 donkey anti-goat ig $\mathrm{G}(\mathrm{H}+\mathrm{L})$

Alexa 488 chicken anti-goat ig $\mathrm{G}(\mathrm{H}+\mathrm{L})$
Molecular Probes

Molecular Probes

Molecular Probes

Molecular Probes

Molecular Probes

Molecular Probes
$1: 1000$

$1: 1000$

$1: 1000$

$1: 1000$

$1: 1000$

$1: 1000$

\subsubsection{Synchronization of ESCs}

Synchronization was done according to this publication $^{35}$ with some modifications. Mouse embryonic stem cells were cultured on gelatin coated plates in ES-CM medium supplemented with 2i. After 48 hours the cultures became $60 \%$ confluent. The medium was changed to pre-warmed ES-CM supplemented freshly with $2.5 \mathrm{mM}$ thymidine (Sigma) and the cells were incubated for 12 hours. Next, the medium was changed to pre-warmed ES-CM supplemented with $150 \mathrm{ng} / \mathrm{ml} \mathrm{TN}-16$ (Enzo life sciences) and incubated for 7 hours. Later, the medium was changed to pre-warmed fresh ES-CM in order to let the cells to release from the cell cycle arrest. The cells were harvested at different time points for analysis of the cell cycle and Geminin protein levels.

\subsubsection{Flow cytometric analysis of the cell cycle}

Cells were trypsinized into single cells; the cell suspension was centrifuged in order to obtain the cells. The pellet was washed twice with $10 \mathrm{ml}$ ice cold PBS. The cells were pelleted each time by $1,000 \mathrm{rpm}$ centrifugation at $4^{\circ} \mathrm{C}$ for 5 minutes. The supernatant was discarded and the pellet was re-suspended in $1 \mathrm{ml}$ ice cold PBS. The falcon tubes were already cooled on ice and filled with $3 \mathrm{ml}$ $100 \%$ ethanol pre-cooled at $-20^{\circ} \mathrm{C}$. The cells were aspirated into $1 \mathrm{ml}$ syringe with a 20 gauge needle attached, and were injected into the cold ethanol with pressure. The cells were incubated at least 1 hour on ice before the analysis, and can be stored for weeks at $-20^{\circ} \mathrm{C}$.

Shortly before the analysis, the cells were spun down at $500 \mathrm{~g}(1,400 \mathrm{rpm})$ in a 
Heraeus centrifuge for 5 minutes at $4{ }^{\circ} \mathrm{C}$. The ethanol was carefully removed immediately after the centrifugation, and the pellet was let to dry by putting the tube over head on a tissue paper ( 2 to 5 minutes). The rest of the ethanol was removed from the walls of the tube with tissue paper. The cells were resuspended in $425 \mu \mathrm{l}$ PBS. The re-suspended cells were vortexed to break the cell clumps. RNase A (Roche) dissolved in $10 \mathrm{mM}$ Tris, pH 7.5 was incubated for 15 minutes at $95^{\circ} \mathrm{C}$ in order to inactivate the DNases, aliquoted and frozen at -20 ${ }^{\circ} \mathrm{C} .50 \mu \mathrm{l}$ of $1 \mathrm{mg} / \mathrm{ml}$ RNase A was added to each sample, followed by $25 \mu \mathrm{l}$ of 1 $\mathrm{mg} / \mathrm{ml}$ propidium iodide (Sigma-Aldrich). The staining was performed for 30 minutes at RT in the dark. All the measurements must be performed within the next 3 hours upon staining.

The cells were analyzed for cell cycle distribution using FACSCalibur ${ }^{\mathrm{TM}}$ Flow Cytometer (BD biosciences). The samples were vortexed immediately before measurement. The collected data were analyzed using the FlowJo software (Tree Star Inc.). The program determined control values and the indistinct peaks were located according to the control values.

\subsubsection{Terminal deoxynucleotidyl transferase dUTP nick labeling (TUNEL) assay}

The apoptotic cells were detected using the ApopTag® Plus Fluorescein In Situ Apoptosis Detection Kit (Chemicon, Millipore). Percentage of apoptotic cells was determined by counting the number of the TUNEL positive cells in comparison to DAPI positive nuclei.

\subsubsection{Annexin V staining}

In ESCs apoptosis was detected by The Annexin V-Cy3 ${ }^{\mathrm{TM}}$ apoptosis detection kit (Sigma-Aldrich) and fluorescence microscopy according to manufacturer's instructions. 


\subsubsection{BrdU staining}

In order to visualize the replicating cells in the S-phase of the cell cycle, the cells have been incubated with BrdU 2 hours to overnight. $140 \mathrm{mg}$ of BrdU (sigma) was dissolved in $877 \mu \mathrm{PBS}$ at $37^{\circ} \mathrm{C}$. This solution was aliquoted and frozen at $20^{\circ} \mathrm{C}$ and was diluted 1 to 100 in fresh medium before treatment of the cells. The cultures were stained for incorporated BrdU and DAPI.

\subsubsection{Quantification and statistical analysis of immunofluorescence staining}

Stained cultures were quantified manually or by ImageJ software $(\mathrm{NIH})$.

Statistical analysis of data was done with an on-line tool (http://www.graphpad.com/quickcalcs). 


\subsection{Protein Biochemistry}

\subsubsection{Protein Extraction}

The cells were washed with PBS and appropriate amounts of RIPA buffer (50 $\mathrm{mM}$ Tris- $\mathrm{HCl} \mathrm{pH} 8.0,150 \mathrm{mM} \mathrm{NaCl}, \mathrm{NaDOC}, 1 \%$ SDS) supplemented freshly with protease inhibitor cocktail (Roche), was added to the plates. The plates were incubated for $5 \mathrm{~min}$ on ice and the cell lysate was scraped into Eppendorf tubes and were mixed with $4 x$ laemmli buffer.

\subsubsection{Western blot analysis}

The glass plates, spacers and comb were washed with ethanol, air-dried and fashioned into the gel cassette. The separation gel's ingredients were mixed (table below) and poured into the cassette to $0.5 \mathrm{~cm}$ below the tip of the combs and covered with $0.5 \mathrm{ml}$ of isopropanol to prevent contact with air before polymerization. After polymerization the isopropanol was discarded. The stacking gel's components were mixed (table below) and poured into the cassette over the separation gel and the comb was inserted into the space between glass plates.

After the polymerization of the stacking gel, the comb was removed and the gel was inserted into the tank filled with electrophoresis buffer (table below). 25 -40 $\mu \mathrm{l}$ of each sample were boiled for $5 \mathrm{~min}$ and loaded on 15\% poly acrylamide gels using a Hamilton syringe. $10 \mu \mathrm{l}$ of benchmark ${ }^{\mathrm{TM}}$ protein marker (Invitrogen) was loaded in one well of the gel and the gel was run with $22 \mathrm{~mA}$ for $1.5-2$ hours. The protein was transferred on nitrocellulose membrane. The membrane was blocked with blocking buffer, stained with appropriate primary antibody diluted in blocking buffer overnight at $4{ }^{\circ} \mathrm{C}$. The membrane was washed with PBS-T tree times and incubated with the HRP-conjugated secondary antibody diluted in the blotting buffer for 2 hours at room temperature. It was washed with PBS-T and the signal was detected using SuperSignal® West Femto Maximum Sensitivity Substrate 
(Thermo), SuperSignal® West pico Maximum Sensitivity Substrate (Thermo) or homemade-ECL (table below).

Table 4. Buffers and solutions used in western blotting analysis

\begin{tabular}{|c|c|}
\hline Buffer & Buffer composition \\
\hline RIPA Buffer. & $\begin{array}{l}50 \mathrm{mM} \text { Tris (pH7.4), } 1 \% \mathrm{NP} 40,0.25 \% \mathrm{NaPO}_{3}, 150 \\
\mathrm{mM} \mathrm{NaCl}, 1 \mathrm{mM} \text { EDTA }\end{array}$ \\
\hline Laemmli Buffer (4x) & $\begin{array}{l}250 \mathrm{mM} \text { Tris } \mathrm{pH} \text { 6.8, } 40 \% \text { glycerol, } 0.04 \% \\
\text { bromophenol Blue, } 4 \% \text { 2-mercaptoethanol, } 8 \% \text { SDS, } \\
0.05 \mathrm{M} \text { DTT }\end{array}$ \\
\hline Stacking Gel Buffer (4x) & $0.5 \mathrm{M}$ Tris, $0.4 \%$ SDS, pH 6.8 \\
\hline Separation Gel Buffer (4x) & $1.5 \mathrm{M}$ Tris, $0.4 \%$ SDS, $\mathrm{pH} 8,8$ \\
\hline Stacking gel components $(5 \%)$ : & $\begin{array}{l}1.25 \mathrm{ml} 4 \mathrm{x} \text { stacking buffer, } 830 \mu \mathrm{l} \text { acrylamide } 30 \% \text {, } \\
2.92 \mathrm{ml} \mathrm{ddH}_{2} \mathrm{O}, 30 \mu \mathrm{l} \text { APS } 10 \%(\mathrm{w} / \mathrm{v}), 10 \mu \mathrm{I} \text { TEMED }\end{array}$ \\
\hline Separation gel components (15\%): & 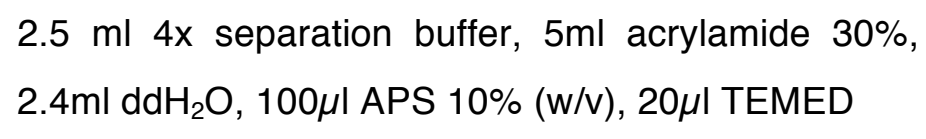 \\
\hline Electrophoresis Buffer & 12,5 mM Tris, $96 \mathrm{mM}$ glycine, 0,05\% SDS \\
\hline Transfer Buffer & $\begin{array}{l}48 \mathrm{mM} \text { Trisbase, } 3.9 \mathrm{mM} \text { glycine, } 0.037 \% \text { SDS, } 20 \% \\
\text { methanol }\end{array}$ \\
\hline PBS-T & $0.1 \%$ Tween 20 in PBS \\
\hline Blocking buffer & $5 \% \mathrm{w} / \mathrm{v}$ milk powder in PBS-T \\
\hline Homemade ECL & $\begin{array}{l}100 \mathrm{mM} \text { glycine } \mathrm{pH} 10 \text { (with } \mathrm{NaOH} \text { ), } 0.4 \mathrm{mM} \text { luminol } \\
\text { (Sigma-Aldrich), } 8 \mathrm{mM} \text { 4-iodophenol (Sigma-Aldrich), } \\
0.12 \% \text { (w/w) hydrogen peroxide in water }\end{array}$ \\
\hline
\end{tabular}


Table 5. Antibodies used in western blotting analysis

\begin{tabular}{lll}
\hline Primary and secondary antibodies & Manufacturer & Dilution \\
\hline Brachyury & R\&D & $1: 1000$ \\
Cyclin A2 & Santa Cruz Biotechnologies & $1: 1000$ \\
Geminin (FL209) & Santa Cruz Biotechnologies & $1: 500$ \\
Histone 2B & Active motif & $1: 1000$ \\
Klf4 & ABGent & $1: 1000$ \\
Nanog & ABGent, Cosmobio, Abcam & $1: 1000$ \\
Oct3/4 & BD Bioscience & $1: 1000$ \\
Sox1 & R\&D & $1: 1000$ \\
Sox2 & Santa Cruz Biotechnologies & $1: 1000$ \\
Tubulin & Cell signaling & $1: 2000$ \\
Goat-anti-rabbit-HRP & Covance & $1: 10000$ \\
Goat-anti-mouse-HRP & Dianova & $1: 10000$ \\
Rabbit-anti-goat-HRP & Abcam & $1: 10000$ \\
\hline
\end{tabular}




\subsection{Molecular Biology}

\subsubsection{DNA isolation from mouse}

The tail-tips or tissue was incubated overnight at $55{ }^{\circ} \mathrm{C}$ with lysis buffer $(50 \mathrm{mM}$ Tris $/ \mathrm{HCl} \mathrm{pH}$ 7.5, $150 \mathrm{mM} \mathrm{NaCl}, 1 \mathrm{mM}$ EDTA, 1\% (w/v) Triton-X100) supplemented with proteinase $\mathrm{K}$ (Roche). DNA was precipitated after lysis with isopropanol and washed with $70 \%$ ethanol. DNA extraction from the blood was conducted with DNeasy ${ }^{\text {TM }}$ blood and tissue kit (Qiagen).

\subsubsection{DNA isolation from cell culture}

The mammalian cells were incubated with $0.5-1 \mathrm{ml}$ of DNA lysis buffer containing freshly added Proteinase $\mathrm{K}$ at the $37{ }^{\circ} \mathrm{C}$ room for $10-15$ minutes followed by $2-3$ hours incubation at $55^{\circ} \mathrm{C}$. The lysis product was spun down at $13,000 \mathrm{rpm}$ for 5 minutes and the supernatant was mixed with isopropanol. The precipitated pellet was washed with $70 \%$ ethanol, air dried, and dissolved in $\mathrm{ddH}_{2} \mathrm{O}$.

\subsubsection{Genotyping PCR}

For genotyping of mice, the GoTaq DNA Polymerase (Promega) was used. All the reactions contained $10 \mathrm{pmol}$ of forward and reverse primers (Sigma), and 20 $\mathrm{mM}$ of dNTPs (Genecraft). The PCR was done using a Mastercycler ${ }^{\circledR}$ Gradient (Eppendorf). All the primers and the PCR program were designed previously ${ }^{102}$.

PCR Program for Genotyping:

Initial denaturation $\quad 94^{\circ} \mathrm{C} \quad 5$ minutes

$\begin{array}{lll}\text { Denaturation } & 94^{\circ} \mathrm{C} & 30 \text { seconds } \\ \text { Annealing } & 55-65^{\circ} \mathrm{C} & 45 \text { seconds } \\ \text { Elongation } & 72^{\circ} \mathrm{C} & 45 \text { seconds } \\ \text { Final elongation } & 72^{\circ} \mathrm{C} & 5-10 \text { minutes }\end{array}$


Table 6. Genotyping primers

\begin{tabular}{ll}
\hline Genotyping Primers & Sequence (5' to $\mathbf{3}^{\prime}$ ) \\
\hline Gmnn allele common forward & GAAAAGCGACAGGCAGTTGAG \\
Gmnn wild type allele reverse & GTCCCAAGGAGAACGCTGAAG \\
Gmnn Floxed allele reverse & CAGCGCATCGCCTTCTATC \\
Gmnn Knockout allele reverse & GTACCAGGAACTGAGCTGAG \\
Cre forward & ATGCTTCTGTCCGTTTGCCG \\
Cre reverse & CCTGTTTTGCACGTTCACCG \\
\hline
\end{tabular}

\subsubsection{DNA electrophoresis}

$0.8-1.5 \%(w / v)$ Agarose was dissolved in the TBE buffer in order to prepare the gels. Electrophoresis was conducted according to previously established protocols $^{102}$.

\subsubsection{RNA extraction}

Cells were washed with PBS twice and were scraped in RNAlater ${ }^{\mathrm{TM}}$ buffer (Qiagen). For extraction cells were centrifuged and the pellet were lysed in RLT buffer supplemented with $\beta$-mercaptoethanol according to the instruction provided for RNeasy ${ }^{\mathrm{TM}}$ mini kit (Qiagen). RNA extraction was performed with RNeasy $^{\mathrm{TM}}$ mini kit (Qiagen) and extracted RNA was treated with RNase free DNase (Qiagen). The concentration of the extracted RNA was measured and RNA samples were frozen as $5-10 \mu$ aliquots.

\subsubsection{Reverse transcription of mRNA}

1-2 $\mu \mathrm{g}$ of each RNA sample was used to prepare cDNA. Reverse transcription was conducted with the Omniscript ${ }^{\mathrm{TM}}$ kit (Qiagen), random primers (Promega), oligo(dT) Primers (Promega) and RNasin ${ }^{\mathrm{TM}}$ RNase inhibitor (Promega) according to the instruction provided by manufacturers. Negative samples were prepared with addition of all required components except reverse transcriptase (provided in the Omniscript ${ }^{\mathrm{TM}}$ kit). 


\subsubsection{Semi-quantitative analysis of gene expression}

For the amplification of cDNA the GoTaq DNA Polymerase (Promega) was used. All the reactions contained $10 \mathrm{pmol}$ of forward and reverse primers and $20 \mathrm{mM}$ of dNTPs (Genecraft) and the PCR was done using a MastercyclerR Gradient (Eppendorf).

Table 7. RT-PCR primers

\begin{tabular}{|c|c|c|c|}
\hline Gene & & Primer squence & Reference \\
\hline \multirow[t]{2}{*}{ Geminin } & forward & GCA GAG AAA ATG AGT TGC CAA & Provided by Dr. \\
\hline & reverse & ACT CAG CCT CTC GAT TAC C & A. Klimke \\
\hline \multirow[t]{2}{*}{ Oct4 } & forward & $\begin{array}{l}\text { CTG AGG GCC AGG CAG GAG CAC } \\
\text { GAG }\end{array}$ & $\begin{array}{l}\text { Provided by Dr. } \\
\text { A. Klimke }\end{array}$ \\
\hline & reverse & CTG TAG GGA GGG CTT CGG GAC TT & \\
\hline \multirow[t]{2}{*}{ Pax6 } & forward & TCA CAG CGG AGT GAA TCA G & 136 \\
\hline & reverse & CCC AAG CAA AGA TGG AAG & \\
\hline \multirow[t]{2}{*}{ Nanog } & forward & CAC CCA CCC ATG CTA GTC TT & 136 \\
\hline & reverse & ACC CTC AAA CTC CTG GTC CT & \\
\hline \multirow[t]{2}{*}{ Zfp42 } & forward & TGT CCT CAG GCT GGG TAG TC & 28 \\
\hline & reverse & TGA TTT TCT GCC GTA TGC AA & \\
\hline \multirow[t]{2}{*}{ Brachyury } & forward & CGC TGT GAC TGC CTA CCA GAATG & 136 \\
\hline & reverse & GAG AGA GAG CGA GCC TCC AAA C & \\
\hline \multirow[t]{2}{*}{ HNF4a } & forward & СТT ССТ TСТ TCA TGC CAG & 136 \\
\hline & reverse & ACA CGT CCC CAT CTG AAG & \\
\hline \multirow[t]{2}{*}{ GAPDH } & forward & CCA TGT TTG TGA TGG GTG TGAACC & 136 \\
\hline & reverse & TGT GAG GGA GAT GCT CAG TGTTGG & \\
\hline \multirow[t]{2}{*}{ Tubulin } & forward & TCA CTG TGC CTG AAC TTA CC & 136 \\
\hline & reverse & GGA ACA TAG CCG TAA ACT GC & \\
\hline
\end{tabular}




\subsubsection{Quantitative analysis of gene expression (qPCR)}

mRNA of interest was quantified by real time quantitative PCR using SYBER Green. Reactions were hold in triplicates and each reaction contained $25 \mathrm{ng}$ cDNA, $10 \mu \mathrm{l} \mathrm{KAPA} \mathrm{SYBR}{ }^{\text {TM }}$ FAST qPCR Master Mix (Qiagen) and 4 pmol of each primer in $d_{d d} \mathrm{H}_{2} \mathrm{O}$. The PCR was done using a Realplex ${ }^{2}$ thermocycler (Eppendorf). The relative abundances of the mRNA was calculated based on the $\Delta \triangle C T$ method $^{137}$ and the melting curve analysis was performed in order to make sure that a unique product is amplified. Negative samples were analyzed as single reactions in order to rule out the possibility of contaminations.

Table 8. qPCR primers

\begin{tabular}{|c|c|c|c|}
\hline Gene & & Primer squence & reference \\
\hline \multirow[t]{2}{*}{ Geminin1 } & forward & GCA GAG AAA ATG AGT TGC CAA & Self-designed \\
\hline & reverse & ACT CAG CCT CTC GAT TAC C & \\
\hline \multirow{2}{*}{ Geminin2 } & forward & ACGCTGAAGATGATCCAGCCTTCT & Self-designed \\
\hline & reverse & TAGCTGGTCATCCCAAAGCTTCCT & \\
\hline \multirow[t]{2}{*}{ Oct4 } & forward & CTG AGG GCC AGG CAG GAG CAC GAG & Self-designed \\
\hline & reverse & CTG TAG GGA GGG CTT CGG GAC TT & \\
\hline \multirow[t]{2}{*}{ Nanog } & forward & CAC CCA CCC ATG CTA GTC TT & 136 \\
\hline & reverse & АСС СТС AАA СТC CTG GTC СТ & \\
\hline \multirow[t]{2}{*}{ Zfp42 } & forward & TGT CCT CAG GCT GGG TAG TC & 28 \\
\hline & reverse & TGA TTT TCT GCC GTA TGC AA & \\
\hline \multirow[t]{2}{*}{ Sox2-tot } & forward & GGT TAC CTC TTC CTC CCA CTC CAG & Provided by Dr. \\
\hline & reverse & TCA CAT GTG CGA CAG GGG CAG & K. Boese \\
\hline \multirow[t]{2}{*}{ Sox2-endo } & forward & TAG AGC TAG ACT CCG GGC GA TGA & \\
\hline & reverse & TTG CCT TAA ACA AGA CCA CGA AA & \\
\hline \multirow[t]{2}{*}{ Ubiquitun C } & forward & AGGTCAAACAGGAAGACAGACGTA & www.rtprimerdb.org \\
\hline & reverse & TCACACCCAAGAACAAGCACA & \\
\hline \multirow[t]{2}{*}{ HPRT } & forward & GTC CTG TGG CCA TCT GCC TA & www.rtprimerdb.org \\
\hline & reverse & GGG ACG CAG CAA CTG ACA TT & \\
\hline \multirow[t]{2}{*}{ GAPDH } & forward & CCA TGT TTG TGA TGG GTG TGAACC & \\
\hline & reverse & TGT GAG GGA GAT GCT CAG TGTTGG & \\
\hline
\end{tabular}




\subsubsection{Chromatin immuno-precipitation (ChIP)}

ESCs were washed with PBS and the chromatin was cross-linked by exposure to $1 \%$ formaldehyde (Pierce) for $10 \mathrm{~min}$. The cross-linked chromatin was harvested in lysis buffer and sonicated using a Bioruptor ${ }^{\circledR} \mathrm{XL}$ sonicator (Diagenode) for 35 $\min \left(30 \mathrm{sec}\right.$ on/off) at $4^{\circ} \mathrm{C}$. Sonicated chromatin was examined for the size of the sonicated fragments by reverse cross-linking and electrophoresis. The sonicated chromatin was diluted with dilution buffer and pre-cleared using Protein A/G Agarose beads (Santa Cruz Biotechnologies). After pre-clearing the beads were separated with centrifugation, the samples were divided in different Eppendorf tubes and $10 \%$ of the sample volumes were kept at $4{ }^{\circ} \mathrm{C}$ as "input samples". 1-2 $\mu \mathrm{g}$ of primary antibodies were added to each Eppendorf tube and were incubated on the shaker at $4{ }^{\circ} \mathrm{C}$ overnight. Protein A/G Agarose beads (Santa Cruz Biotechnologies) were added to antibody-chromatin complexes for 2 hours at $4^{\circ} \mathrm{C}$. Beads were washed once with Low Salt Immune Complex Wash Buffer, once with High Salt Immune Complex Wash Buffer, once with $\mathrm{LiCl}$ Immune Complex Wash Buffer and twice with TE Buffer. DNA was eluted from the beads and the samples were reverse cross-linked and treated with RNase and proteinase K. DNA was extracted with the PCR purification kit (Qiagen). Further information regarding the buffer compositions, detailed steps and troubleshooting can be found in the EZ ChIP ${ }^{\mathrm{TM}}$, Chromatin Immuno-precipitation Kit's Instruction Manual (Upstate, Millipore). Used Antibodies are listed in the tables below.

Table 9. Antibodies used in chromatin immuno-precipitations

\begin{tabular}{ll}
\hline Antibodies & Manufacturer \\
\hline Histone 3 & Abcam \\
Histone 3 lysine 4 trimethylation & Active motif \\
Histone 3 lysine 27 trimethylation & Active motif \\
Histone 4 hyperacetylation & Millipore \\
EZH2 & Cell signaling \\
BRG1 & Santa Cruz Biotechnologies \\
Rabbit lgG & Santa Cruz Biotechnologies \\
\hline
\end{tabular}




\subsubsection{Quantitative analysis of ChIP}

Extracted precipitated DNA was analyzed by qPCR as explained before. The relative fold enrichment was calculated with $\Delta \Delta C T$ method $^{137}$ primer specific efficiencies (AB: antibody precipitated sample, Tx: tamoxifen treated, control: untreated cells).

Fold enrichment $=$ primer efficiency $\frac{C t(\text { input }, T x)-C t(A B, T x)}{\operatorname{ct(\text {input},\text {control})-Ct(AB,\text {control})}}$

Primer-specific efficiencies (1.90 -2) were calculated from the standard curve made by measurements of the serial dilutions of the input samples.

Table 10. Primers for the detection of Sox2 and Oct 4 genomic regions used in ChIP analysis

\begin{tabular}{|c|c|c|c|}
\hline Primer & & Sequence ( $5^{\prime}$ to $\left.3^{\prime}\right)$ & Reference \\
\hline \multirow[t]{2}{*}{ A } & Forward & CATAGCGTGTCAGTGATCTCC & Self-designed \\
\hline & Reverse & GCTTCCAAACCCATCCTTACAG & \\
\hline \multirow[t]{2}{*}{ B } & Forward & СССТССТСТССТААТСТССТТАТGG & 109 \\
\hline & Reverse & ААСTCTCATAGCССТАACTGTC & \\
\hline \multirow[t]{2}{*}{ C } & Forward & GAGTTCCAGCTTTGCCTTTG & Self-designed \\
\hline & Reverse & TTGTTCCCAGCCTTTTCCTAG & \\
\hline \multirow[t]{2}{*}{$\mathrm{D}$} & Forward & CTCAGCCTCTAGGCCTGTGT & 8 \\
\hline & Reverse & СССТTCCСАGTACСТTACCC & \\
\hline \multirow[t]{2}{*}{$\mathrm{E}$} & Forward & GCACAGTCGACAGTTCTTGC & 20 \\
\hline & Reverse & AGGCTGAGTCGGGTCAATTA & \\
\hline \multirow[t]{2}{*}{$\mathrm{F}$} & Forward & GATAAACTGCAGCGCTACCC & 20 \\
\hline & Reverse & CCTCGGAAAGAAGTCACAGG & \\
\hline \multirow[t]{2}{*}{ G } & Forward & CAAGGACAACTGCTAAACTGC & Self-designed \\
\hline & Reverse & GACAGACCGATAAGAGATGCC & \\
\hline \multirow[t]{2}{*}{$\mathrm{H}$} & Forward & AGGGCACATCTGTTTCAAGC & 8 \\
\hline & Reverse & CTGGCCAGGACAAGAGACAT & \\
\hline \multirow[t]{2}{*}{ I } & Forward & CTCTCGTCCTAGCCСTTCCT & 20 \\
\hline & Reverse & АTСTСTCTGGCССТСТССАТ & \\
\hline
\end{tabular}




\section{Bibliography}

1. Dyce, J., George, M., Goodall, H. \& Fleming, T.P. Do trophectoderm and inner cell mass cells in the mouse blastocyst maintain discrete lineages? Development 100, 685-98 (1987).

2. Pedersen, R.A., Wu, K. \& Balakier, H. Origin of the inner cell mass in mouse embryos: cell lineage analysis by microinjection. Dev Biol 117, 581-95 (1986).

3. Gardner, R.L. \& Rossant, J. Investigation of the fate of 4-5 day postcoitum mouse inner cell mass cells by blastocyst injection. J Embryol Exp Morphol 52, 141-52 (1979).

4. Gardner, R.L. An in situ cell marker for clonal analysis of development of the extraembryonic endoderm in the mouse. J Embryol Exp Morphol 80, 251-88 (1984).

5. Gardner, R.L. Investigation of cell lineage and differentiation in the extraembryonic endoderm of the mouse embryo. J Embryol Exp Morphol 68, 175-98 (1982).

6. Takaoka, K. \& Hamada, H. Cell fate decisions and axis determination in the early mouse embryo. Development 139, 3-14 (2012).

7. Cockburn, K. \& Rossant, J. Making the blastocyst: lessons from the mouse. J Clin Invest 120, 995-1003 (2010).

8. Thomson, M. et al. Pluripotency factors in embryonic stem cells regulate differentiation into germ layers. Cell 145, 875-89 (2011).

9. Strumpf, D. et al. Cdx2 is required for correct cell fate specification and differentiation of trophectoderm in the mouse blastocyst. Development 132, 2093-102 (2005).

10. Ralston, A. \& Rossant, J. Cdx2 acts downstream of cell polarization to cell-autonomously promote trophectoderm fate in the early mouse embryo. Dev Biol 313, 614-29 (2008).

11. Palmieri, S.L., Peter, W., Hess, H. \& Scholer, H.R. Oct-4 transcription factor is differentially expressed in the mouse embryo during establishment of the first two extraembryonic cell lineages involved in implantation. Dev Biol 166, 259-67 (1994).

12. Chambers, I. et al. Functional expression cloning of Nanog, a pluripotency sustaining factor in embryonic stem cells. Cell 113, 643-55 (2003).

13. Avilion, A.A. et al. Multipotent cell lineages in early mouse development depend on SOX2 function. Genes Dev 17, 126-40 (2003).

14. Koutsourakis, M., Langeveld, A., Patient, R., Beddington, R. \& Grosveld, F. The transcription factor GATA6 is essential for early extraembryonic development. Development 126, 723-32 (1999).

15. Morrisey, E.E. et al. GATA6 regulates HNF4 and is required for differentiation of visceral endoderm in the mouse embryo. Genes Dev 12, 3579-90 (1998). 
16. Meilhac, S.M. et al. Active cell movements coupled to positional induction are involved in lineage segregation in the mouse blastocyst. Dev Biol 331, 210-21 (2009).

17. Mitsui, K. et al. The homeoprotein Nanog is required for maintenance of pluripotency in mouse epiblast and ES cells. Cell 113, 631-42 (2003).

18. Silva, J. et al. Nanog is the gateway to the pluripotent ground state. Cell 138, 722-37 (2009).

19. Masui, S. et al. Pluripotency governed by Sox2 via regulation of Oct3/4 expression in mouse embryonic stem cells. Nat Cell Biol 9, 625-35 (2007).

20. Petropoulou, C., Kotantaki, P., Karamitros, D. \& Taraviras, S. Cdt1 and Geminin in cancer: markers or triggers of malignant transformation? Front Biosci 13, 4485-94 (2008).

21. Ralston, A. \& Rossant, J. The genetics of induced pluripotency. Reproduction 139, 35-44 (2010).

22. Evans, M.J. \& Kaufman, M.H. Establishment in culture of pluripotential cells from mouse embryos. Nature 292, 154-6 (1981).

23. Martin, G.R. Isolation of a pluripotent cell line from early mouse embryos cultured in medium conditioned by teratocarcinoma stem cells. Proc Natl Acad Sci U S A 78, 7634-8 (1981).

24. Smith, A.G. et al. Inhibition of pluripotential embryonic stem cell differentiation by purified polypeptides. Nature 336, 688-90 (1988).

25. Williams, R.L. et al. Myeloid leukaemia inhibitory factor maintains the developmental potential of embryonic stem cells. Nature 336, 684-7 (1988).

26. Nichols, J. et al. Formation of pluripotent stem cells in the mammalian embryo depends on the POU transcription factor Oct4. Cell 95, 379-91 (1998).

27. Niwa, H., Miyazaki, J. \& Smith, A.G. Quantitative expression of Oct-3/4 defines differentiation, dedifferentiation or self-renewal of ES cells. Nat Genet 24, 372-6 (2000).

28. Niwa, $\mathrm{H}$. et al. Interaction between Oct3/4 and $\mathrm{Cdx} 2$ determines trophectoderm differentiation. Cell 123, 917-29 (2005).

29. Kunath, T. et al. FGF stimulation of the Erk1/2 signalling cascade triggers transition of pluripotent embryonic stem cells from self-renewal to lineage commitment. Development 134, 2895-902 (2007).

30. Wang, J. et al. A protein interaction network for pluripotency of embryonic stem cells. Nature 444, 364-8 (2006).

31. Chambers, I. et al. Nanog safeguards pluripotency and mediates germline development. Nature 450, 1230-4 (2007).

32. Ivanova, N. et al. Dissecting self-renewal in stem cells with RNA interference. Nature 442, 533-8 (2006).

33. Liang, J. et al. Nanog and Oct4 associate with unique transcriptional repression complexes in embryonic stem cells. Nat Cell Biol 10, 731-9 (2008). 
34. Pardo, M. et al. An expanded Oct4 interaction network: implications for stem cell biology, development, and disease. Cell Stem Cell 6, 382-95 (2010).

35. Fujii-Yamamoto, H., Kim, J.M., Arai, K. \& Masai, H. Cell cycle and developmental regulations of replication factors in mouse embryonic stem cells. The Journal of biological chemistry 280, 12976-87 (2005).

36. White, J. et al. Developmental activation of the Rb-E2F pathway and establishment of cell cycle-regulated cyclin-dependent kinase activity during embryonic stem cell differentiation. Mol Biol Cell 16, 2018-27 (2005).

37. Savatier, P., Lapillonne, H., Jirmanova, L., Vitelli, L. \& Samarut, J. Analysis of the cell cycle in mouse embryonic stem cells. Methods $\mathrm{Mol}$ Biol 185, 27-33 (2002).

38. Ballabeni, A. et al. Cell cycle adaptations of embryonic stem cells. Proceedings of the National Academy of Sciences of the United States of America 108, 19252-7 (2011).

39. Stead, E. et al. Pluripotent cell division cycles are driven by ectopic Cdk2, cyclin A/E and E2F activities. Oncogene 21, 8320-33 (2002).

40. Berthet, C., Aleem, E., Coppola, V., Tessarollo, L. \& Kaldis, P. Cdk2 knockout mice are viable. Curr Biol 13, 1775-85 (2003).

41. Ortega, S. et al. Cyclin-dependent kinase 2 is essential for meiosis but not for mitotic cell division in mice. Nat Genet 35, 25-31 (2003).

42. Kalaszczynska, I. et al. Cyclin A is redundant in fibroblasts but essential in hematopoietic and embryonic stem cells. Cell 138, 352-65 (2009).

43. Menchon, C., Edel, M.J. \& Izpisua Belmonte, J.C. The cell cycle inhibitor p27Kip(1) controls self-renewal and pluripotency of human embryonic stem cells by regulating the cell cycle, Brachyury and Twist. Cell Cycle 10, 1435-47 (2011).

44. Neganova, I. et al. An important role for CDK2 in G1 to S checkpoint activation and DNA damage response in human embryonic stem cells. Stem Cells 29, 651-9 (2011).

45. Ruiz, S. et al. A high proliferation rate is required for cell reprogramming and maintenance of human embryonic stem cell identity. Curr Biol 21, 4552 (2011).

46. Filipczyk, A.A., Laslett, A.L., Mummery, C. \& Pera, M.F. Differentiation is coupled to changes in the cell cycle regulatory apparatus of human embryonic stem cells. Stem Cell Res 1, 45-60 (2007).

47. Singh, A.M. \& Dalton, S. The cell cycle and Myc intersect with mechanisms that regulate pluripotency and reprogramming. Cell Stem Cell 5, 141-9 (2009).

48. Lange, C. \& Calegari, F. Cdks and cyclins link G1 length and differentiation of embryonic, neural and hematopoietic stem cells. Cell Cycle 9, 1893-900 (2010). 
49. Neganova, I. \& Lako, M. G1 to S phase cell cycle transition in somatic and embryonic stem cells. J Anat 213, 30-44 (2008).

50. Gaspar-Maia, A., Alajem, A., Meshorer, E. \& Ramalho-Santos, M. Open chromatin in pluripotency and reprogramming. Nat Rev Mol Cell Biol 12, 36-47 (2011).

51. Efroni, S. et al. Global transcription in pluripotent embryonic stem cells. Cell Stem Cell 2, 437-47 (2008).

52. Lessard, J.A. \& Crabtree, G.R. Chromatin regulatory mechanisms in pluripotency. Annual review of cell and developmental biology 26, 503-32 (2010).

53. Hochedlinger, K. \& Plath, K. Epigenetic reprogramming and induced pluripotency. Development 136, 509-23 (2009).

54. Bernstein, E. et al. Mouse polycomb proteins bind differentially to methylated histone $\mathrm{H} 3$ and RNA and are enriched in facultative heterochromatin. Mol Cell Biol 26, 2560-9 (2006).

55. Margueron, R. \& Reinberg, D. The Polycomb complex PRC2 and its mark in life. Nature 469, 343-9 (2011).

56. Lee, T.I. et al. Control of developmental regulators by Polycomb in human embryonic stem cells. Cell 125, 301-13 (2006).

57. Boyer, L.A. et al. Polycomb complexes repress developmental regulators in murine embryonic stem cells. Nature 441, 349-53 (2006).

58. Sauvageau, M. \& Sauvageau, G. Polycomb group proteins: multi-faceted regulators of somatic stem cells and cancer. Cell Stem Cell 7, 299-313 (2010).

59. Jaenisch, R. Stem cells, pluripotency and nuclear reprogramming. $J$ Thromb Haemost 7 Suppl 1, 21-3 (2009).

60. Yamanaka, S. \& Blau, H.M. Nuclear reprogramming to a pluripotent state by three approaches. Nature 465, 704-12 (2010).

61. Takahashi, K. \& Yamanaka, S. Induction of pluripotent stem cells from mouse embryonic and adult fibroblast cultures by defined factors. Cell 126, 663-76 (2006).

62. Okita, K., Ichisaka, T. \& Yamanaka, S. Generation of germline-competent induced pluripotent stem cells. Nature 448, 313-7 (2007).

63. Wernig, M. et al. A drug-inducible transgenic system for direct reprogramming of multiple somatic cell types. Nat Biotechnol 26, 916-24 (2008).

64. Boland, M.J. et al. Adult mice generated from induced pluripotent stem cells. Nature 461, 91-4 (2009).

65. Hanna, J.H., Saha, K. \& Jaenisch, R. Pluripotency and cellular reprogramming: facts, hypotheses, unresolved issues. Cell 143, 508-25 (2010).

66. Dejosez, M. \& Zwaka, T.P. Pluripotency and nuclear reprogramming. Annu Rev Biochem 81, 737-65 (2012). 
67. Stadtfeld, M., Maherali, N., Breault, D.T. \& Hochedlinger, K. Defining molecular cornerstones during fibroblast to iPS cell reprogramming in mouse. Cell Stem Cell 2, 230-40 (2008).

68. Hanna, J. et al. Direct cell reprogramming is a stochastic process amenable to acceleration. Nature 462, 595-601 (2009).

69. McGarry, T.J. \& Kirschner, M.W. Geminin, an inhibitor of DNA replication, is degraded during mitosis. Cell 93, 1043-53 (1998).

70. Kroll, K.L., Salic, A.N., Evans, L.M. \& Kirschner, M.W. Geminin, a neuralizing molecule that demarcates the future neural plate at the onset of gastrulation. Development 125, 3247-58 (1998).

71. Quinn, L.M., Herr, A., McGarry, T.J. \& Richardson, H. The Drosophila Geminin homolog: roles for Geminin in limiting DNA replication, in anaphase and in neurogenesis. Genes \& development 15, 2741-54 (2001).

72. Wohlschlegel, J.A. et al. Inhibition of eukaryotic DNA replication by geminin binding to Cdt1. Science 290, 2309-12 (2000).

73. Tada, S., Li, A., Maiorano, D., Mechali, M. \& Blow, J.J. Repression of origin assembly in metaphase depends on inhibition of RLF-B/Cdt1 by geminin. Nature cell biology 3, 107-13 (2001).

74. Ballabeni, A. et al. Human geminin promotes pre-RC formation and DNA replication by stabilizing CDT1 in mitosis. The EMBO journal 23, 3122-32 (2004).

75. Arias, E.E. \& Walter, J.C. Strength in numbers: preventing rereplication via multiple mechanisms in eukaryotic cells. Genes \& development 21, 497518 (2007).

76. Nishitani, $\mathrm{H}$. et al. Two E3 ubiquitin ligases, SCF-Skp2 and DDB1-Cul4, target human Cdt1 for proteolysis. The EMBO journal 25, 1126-36 (2006).

77. Petropoulou, C., Kotantaki, P., Karamitros, D. \& Taraviras, S. Cdt1 and Geminin in cancer: markers or triggers of malignant transformation? Frontiers in bioscience : a journal and virtual library 13, 4485-94 (2008).

78. Montanari, M. et al. Increased expression of geminin stimulates the growth of mammary epithelial cells and is a frequent event in human tumors. Journal of cellular physiology 202, 215-22 (2005).

79. Nishihara, K. et al. Immunohistochemical expression of geminin in colorectal cancer: Implication of prognostic significance. Oncology reports 21, 1189-95 (2009).

80. Salabat, M.R. et al. Geminin is overexpressed in human pancreatic cancer and downregulated by the bioflavanoid apigenin in pancreatic cancer cell lines. Molecular carcinogenesis 47, 835-44 (2008).

81. Shomori, K. et al. Geminin, Ki67, and minichromosome maintenance 2 in gastric hyperplastic polyps, adenomas, and intestinal-type carcinomas: pathobiological significance. Gastric cancer : official journal of the International Gastric Cancer Association and the Japanese Gastric Cancer Association 13, 177-85 (2010). 
82. Yamazaki, M., Fujii, S., Murata, Y., Hayashi, R. \& Ochiai, A. High expression level of geminin predicts a poor clinical outcome in salivary gland carcinomas. Histopathology 56, 883-92 (2010).

83. Tamura, T. et al. Minichromosome maintenance-7 and geminin are reliable prognostic markers in patients with oral squamous cell carcinoma: immunohistochemical study. Journal of oral pathology \& medicine : official publication of the International Association of Oral Pathologists and the American Academy of Oral Pathology 39, 328-34 (2010).

84. Kayes, O.J. et al. DNA replication licensing factors and aneuploidy are linked to tumor cell cycle state and clinical outcome in penile carcinoma. Clinical cancer research : an official journal of the American Association for Cancer Research 15, 7335-44 (2009).

85. Gonzalez, M.A. et al. Geminin predicts adverse clinical outcome in breast cancer by reflecting cell-cycle progression. The Journal of pathology 204, 121-30 (2004).

86. Blanchard, Z. et al. Geminin overexpression induces mammary tumors via suppressing cytokinesis. Oncotarget 2, 1011-27 (2011).

87. Haruki, T. et al. Geminin expression in small lung adenocarcinomas: implication of prognostic significance. Lung cancer 71, 356-62 (2011).

88. Zhu, W. \& Depamphilis, M.L. Selective killing of cancer cells by suppression of geminin activity. Cancer research 69, 4870-7 (2009).

89. Gardner, L., Malik, R., Shimizu, Y., Mullins, N. \& ElShamy, W.M. Geminin overexpression prevents the completion of topoisomerase Ilalpha chromosome decatenation, leading to aneuploidy in human mammary epithelial cells. Breast cancer research : BCR 13, R53 (2011).

90. Hara, K., Nakayama, K.I. \& Nakayama, K. Geminin is essential for the development of preimplantation mouse embryos. Genes to cells : devoted to molecular \& cellular mechanisms 11, 1281-93 (2006).

91. Gonzalez, M.A. et al. Geminin is essential to prevent endoreduplication and to form pluripotent cells during mammalian development. Genes \& development 20, 1880-4 (2006).

92. Yang, V.S. et al. Geminin escapes degradation in G1 of mouse pluripotent cells and mediates the expression of Oct4, Sox2, and Nanog. Current biology : CB 21, 692-9 (2011).

93. Ho, L. et al. An embryonic stem cell chromatin remodeling complex, esBAF, is an essential component of the core pluripotency transcriptional network. Proceedings of the National Academy of Sciences of the United States of America 106, 5187-91 (2009).

94. Ho, L. et al. An embryonic stem cell chromatin remodeling complex, esBAF, is essential for embryonic stem cell self-renewal and pluripotency. Proceedings of the National Academy of Sciences of the United States of America 106, 5181-6 (2009).

95. Novershtern, N. \& Hanna, J.H. esBAF safeguards Stat3 binding to maintain pluripotency. Nature cell biology 13, 886-8 (2011). 
96. Ho, L. et al. esBAF facilitates pluripotency by conditioning the genome for LIF/STAT3 signalling and by regulating polycomb function. Nature cell biology 13, 903-13 (2011).

97. Seo, S. et al. Geminin regulates neuronal differentiation by antagonizing Brg1 activity. Genes \& development 19, 1723-34 (2005).

98. Lim, J.W., Hummert, P., Mills, J.C. \& Kroll, K.L. Geminin cooperates with Polycomb to restrain multi-lineage commitment in the early embryo. Development 138, 33-44 (2011).

99. Yellajoshyula, D., Patterson, E.S., Elitt, M.S. \& Kroll, K.L. Geminin promotes neural fate acquisition of embryonic stem cells by maintaining chromatin in an accessible and hyperacetylated state. Proceedings of the National Academy of Sciences of the United States of America 108, 32949 (2011).

100. Yellajoshyula, D. et al. Geminin regulates the transcriptional and epigenetic status of neuronal fate promoting genes during mammalian neurogenesis. Mol Cell Biol (2012).

101. Spella, M. et al. Geminin regulates cortical progenitor proliferation and differentiation. Stem Cells 29, 1269-82 (2011).

102. Uerlings, Y. (Georg August Universität, 2008).

103. Schultz, K.M. et al. Geminin-deficient neural stem cells exhibit normal cell division and normal neurogenesis. PLoS One 6, e17736 (2011).

104. Shinnick, K.M., Eklund, E.A. \& McGarry, T.J. Geminin deletion from hematopoietic cells causes anemia and thrombocytosis in mice. The Journal of clinical investigation 120, 4303-15 (2010).

105. Ohtsubo, M. et al. Polycomb-group complex 1 acts as an E3 ubiquitin ligase for Geminin to sustain hematopoietic stem cell activity. Proceedings of the National Academy of Sciences of the United States of America 105, 10396-401 (2008).

106. Ohno, Y. et al. Hoxb4 transduction down-regulates Geminin protein, providing hematopoietic stem and progenitor cells with proliferation potential. Proceedings of the National Academy of Sciences of the United States of America 107, 21529-34 (2010).

107. Pitulescu, M.E., Teichmann, M., Luo, L. \& Kessel, M. TIPT2 and geminin interact with basal transcription factors to synergize in transcriptional regulation. BMC biochemistry 10, 16 (2009).

108. Luo, L. \& Kessel, M. Geminin coordinates cell cycle and developmental control. Cell cycle 3, 711-4 (2004).

109. Papanayotou, C. et al. A mechanism regulating the onset of Sox2 expression in the embryonic neural plate. PLoS Biol 6, e2 (2008).

110. Sakaue-Sawano, A. et al. Visualizing spatiotemporal dynamics of multicellular cell-cycle progression. Cell 132, 487-98 (2008).

111. Hayashi, S. \& McMahon, A.P. Efficient recombination in diverse tissues by a tamoxifen-inducible form of Cre: a tool for temporally regulated gene activation/inactivation in the mouse. Dev Biol 244, 305-18 (2002). 
112. Tomioka, M. et al. Identification of Sox-2 regulatory region which is under the control of Oct-3/4-Sox-2 complex. Nucleic Acids Res 30, 3202-13 (2002).

113. Yeom, Y.I. et al. Germline regulatory element of Oct-4 specific for the totipotent cycle of embryonal cells. Development 122, 881-94 (1996).

114. Schoorlemmer, J. et al. Characterization of a negative retinoic acid response element in the murine Oct4 promoter. Mol Cell Biol 14, 1122-36 (1994).

115. Zhu, W. \& Depamphilis, M.L. Selective killing of cancer cells by suppression of geminin activity. Cancer Res 69, 4870-7 (2009).

116. Ballabeni, A. et al. Cell cycle adaptations of embryonic stem cells. Proc Natl Acad Sci U S A 108, 19252-7 (2011).

117. Yellajoshyula, D., Patterson, E.S., Elitt, M.S. \& Kroll, K.L. Geminin promotes neural fate acquisition of embryonic stem cells by maintaining chromatin in an accessible and hyperacetylated state. Proc Natl Acad Sci U S A 108, 3294-9 (2011).

118. Yang, V.S. et al. Geminin escapes degradation in $\mathrm{G} 1$ of mouse pluripotent cells and mediates the expression of Oct4, Sox2, and Nanog. Curr Biol 21, 692-9 (2011).

119. Fujii-Yamamoto, H., Kim, J.M., Arai, K. \& Masai, H. Cell cycle and developmental regulations of replication factors in mouse embryonic stem cells. J Biol Chem 280, 12976-87 (2005).

120. Kerns, S.L., Schultz, K.M., Barry, K.A., Thorne, T.M. \& McGarry, T.J. Geminin is required for zygotic gene expression at the Xenopus midblastula transition. PLoS One 7, e38009 (2012).

121. Li, V.C., Ballabeni, A. \& Kirschner, M.W. Gap 1 phase length and mouse embryonic stem cell self-renewal. Proc Natl Acad Sci U S A 109, 12550-5 (2012).

122. Uerlings, $Y$. in

( Georg-August-Universität Goettingen, 2008).

123. Caliskan, N. (Georg August University, 2009).

124. Aghazadeh-Tabrizi, G. (Georg August University, Goettingen, 2009).

125. Mikkelsen, T.S. et al. Dissecting direct reprogramming through integrative genomic analysis. Nature 454, 49-55 (2008).

126. Luo, L., Yang, X., Takihara, Y., Knoetgen, H. \& Kessel, M. The cell-cycle regulator geminin inhibits Hox function through direct and polycombmediated interactions. Nature 427, 749-53 (2004).

127. Tesar, P.J. et al. New cell lines from mouse epiblast share defining features with human embryonic stem cells. Nature 448, 196-9 (2007).

128. Brons, I.G. et al. Derivation of pluripotent epiblast stem cells from mammalian embryos. Nature 448, 191-5 (2007).

129. Kroll, K.L. Geminin in embryonic development: coordinating transcription and the cell cycle during differentiation. Frontiers in bioscience : a journal and virtual library 12, 1395-409 (2007). 
130. Morita, S., Kojima, T. \& Kitamura, T. Plat-E: an efficient and stable system for transient packaging of retroviruses. Gene Ther 7, 1063-6 (2000).

131. Schwenk, F., Baron, U. \& Rajewsky, K. A cre-transgenic mouse strain for the ubiquitous deletion of loxP-flanked gene segments including deletion in germ cells. Nucleic Acids Res 23, 5080-1 (1995).

132. Hubner, K. et al. Derivation of oocytes from mouse embryonic stem cells. Science 300, 1251-6 (2003).

133. Wiese, C., Kania, G., Rolletschek, A., Blyszczuk, P. \& Wobus, A.M. Pluripotency: capacity for in vitro differentiation of undifferentiated embryonic stem cells. Methods Mol Biol 325, 181-205 (2006).

134. Gaspard, N. et al. Generation of cortical neurons from mouse embryonic stem cells. Nature protocols 4, 1454-63 (2009).

135. Ying, Q.L., Stavridis, M., Griffiths, D., Li, M. \& Smith, A. Conversion of embryonic stem cells into neuroectodermal precursors in adherent monoculture. Nat Biotechnol 21, 183-6 (2003).

136. Schroeder, I.S., Wiese, C., Truong, T.T., Rolletschek, A. \& Wobus, A.M. Differentiation analysis of pluripotent mouse embryonic stem (ES) cells in vitro. Methods Mol Biol 530, 219-50 (2009).

137. Pfaffl, M.W. A new mathematical model for relative quantification in realtime RT-PCR. Nucleic Acids Res 29, e45 (2001). 


\section{Curriculum Vitae}

\section{Golnaz Aghazadeh Tabrizi}

Am fassberg 11

37077 Gottingen, Germany

Phone: +49 5515083293

Email: gaghaza@gwdg.de

\section{Personal info}

Date and place of birth: Apr. 12, 1985. Esfahan

Nationality: Iranian

Marital status: Married

\section{Education}

- Ph.D. Student

Developmental biology research group, department of molecular cell biology, Max Planck's institute for biophysical chemistry (2009-now)

- M.Sc. in Molecular Medicine

Faculty of medicine, University of Gottingen, Gottingen, Germany (June 2009)

- Student of M.Sc./ Ph.D. International program of Molecular Medicine

Faculty of medicine, University of Gottingen, Gottingen, Germany (2007-now)

- B.Sc. in Biotechnology

Department of Biotechnology, Faculty of Science, University of Tehran, Tehran, Iran, September 2007

\section{Honors and Awards}

- $\quad$ MPI stipend, Oct 2008-Oct 2012.

- University of Gottingen, Faculty of Medicine Stipend, Oct 2007-Sep 2008

- Iranian Ministry of Science, Research and Technology Stipend for Exceptional Talents.2005-2007

- Iranian Exceptional Talents Society Fellowship for scientific Olympiad medalists 2003-2007

- University of Tehran Fellowship for Scientific Olympiad Awardees and high ranking students in national Entrance Exam.2003-2007

- $\quad$ Silver Medal in $14^{\text {th }}$ International Biology Olympiad in Belarus, Minsk, July 2003

- $\quad$ Selected as a member of Iran national biology team, Spring 2003

- Was exempted from taking Entrance Exam and accepted to continuous PhD program in Biotechnology, university of Tehran. September, 2003

- Was a member of Exceptional Talents Society, Iran, 2002-now

- $\quad$ Gold Medal in $5^{\text {th }}$ National Biology Olympiad in Iran, Summer 2002

\section{Publication}

- $\quad$ Baharvand, H. (2008). Stem cells and their niche. In Aghazadeh Tabrizi, G. \& Baharvand, H. (Eds.). Adult Stem Cells. Iran: Khaneh Zist shenasi (in Persian) 